STATE OF OREGON

DEPARTMENT OF GEOLOGY AND MINERAL INDUSTRIES

910 State Office Building

Portland, Oregon 97201

$\mathrm{DOE} / \mathrm{ID} / 12526--\mathrm{T} 2$

OPEN-FIIE REPORT $0-86-3$

DE87 013077

\title{
INVESTIGATION OF THE THERMAL REGME AND GEOLOGIC HISTORY OF THE CASCADE VOLCANIC ARC: FIRST PHASE OF A PROGRAM FOR SCIENTIFTC DRIIING IN THE CASCADE RANGE
}

\author{
Prepared by \\ George R. Priest \\ Oregon Department of Geology and Mineral Industries
}

With contributions by:

Keith E. Bargar, U.S. Geological Survey

Gerald L. Black, Oregon Department of Geology and Mineral Industries

David' $D$. Blackwell, Southern Methodist University

Richard W. Couch, Oregon State University

Robert A. Duncan, Oregon State University

John Evans, U.S. Geological Survey

Norman Goldstein, Lawrence Berkeley Laboratory

Bezalel C. Haimson, University of Wisconsin

Scott Hughes, Oregon State University

Mahedeva Iyer, U.S. Geological furvey

IErry E.C. Kelth, U.S. Geological Survey

Michael A. Korosec, Washington Department of Natural Resources

J.C. Laul, Battelle P.N.W. Laboratory

Shaul Levy, Oregon State University

Robert H. Mariner, U.S. Geological Survey

Walter D. Mooney, U.S. Geological Survey

John Rowley, Los Alamos National Laboratory

David R. Sherrod, U.S. Geological Survey

Monty Smith, Battelle P.N.W. Laboratory

Al Waibel, Columbia Geoscience

Craig S. Weaver, U.S. Geological Survey

Neil M. Woller, Oregon Department of Geology and Mineral Industries

P. Michael Wright, University of Utah Research Institute

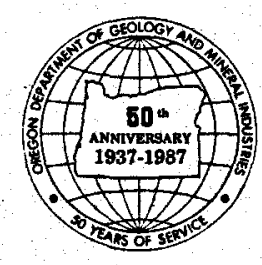

1987

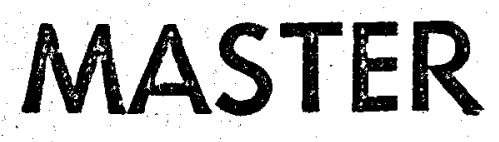

Preparation and publication of this document were supported by the Oregon

Department of Geology and Mineral Industries and Grant No. DE-FG07-84ID12526

from the U.S. Department of Energy 


\section{DISCLAIMER}

This report was prepared as an account of work sponsored by an agency of the United States Government. Neither the United States Government nor any agency Thereof, nor any of their employees, makes any warranty, express or implied, or assumes any legal liability or responsibility for the accuracy, completeness, or usefulness of any information, apparatus, product, or process disclosed, or represents that its use would not infringe privately owned rights. Reference herein to any specific commercial product, process, or service by trade name, trademark, manufacturer, or otherwise does not necessarily constitute or imply its endorsement, recommendation, or favoring by the United States Government or any agency thereof. The views and opinions of authors expressed herein do not necessarily state or reflect those of the United States Government or any agency thereof. 


\section{DISCLAIMER}

Portions of this document may be illegible in electronic image products. Images are produced from the best available original document. 


\section{NOTICE}

The Oregon Department of Geology and Mineral Industries is publishing this paper because the subject matter is consistent with the mission of the Department. To facilitate timely distribution of information, this document has not been edited to our usual standards. 


\section{DISCLAIMER}

This report was prepared as an account of work sponsored by an agency of the United States Government. Neither the United States Government nor any agency thereof, nor any of their employees, makes any warranty, express or implied, or assumes any legal liability or responsibility for the accuracy, completeness, or usefulness of any information, apparatus, product, or process disclosed, or represents that its use would not infringe privately owned rights. Reference herein to any specific commercial product, process, or service by trade name, trademark, manufacturer, or otherwise does not necessarily constitute or imply its endorsement, recommendation, or favoring by the United. States Government or any agency thereof. The views and opinions of authors expressed herein do not necessarily state or reflect those of the United States Government or any agency thereof.

\section{PREFACE}

This document is a plan for an extensive first phase of scientific drilling in the Cascade Range of Oregon, Washington, and northern California. It explains the importance of the Cascade Range as a natural laboratory for the study of large-scale earth processes that occur when major crustal plates converge. Many of these processes can be effectively studied by surface geological and geophysical surveys, but drilling will be necessary to explore the thermal and hydrothermal regime of the range. The research outlined is intended as a contribution to the U.S. Continental Scientific Drilling Program, a collaborative effort of the U.S. Department of Energy (USDOE), the U.S. Geological Survey (USGS), and National Science Foundation (NSF).

This paper has three purposes: (1) to present long-range goals for scientific drilling in the Cascade Range; (2) to provide a background and to act as a supporting document for future drilling proposals; and (3) to provide a framework of scientific goals that scientists (government, university, or industry) interested in Cascade research might find helpful in using to explain their proposed research.

Comments or suggestions regarding information in this document should be sent to:

Dr. David D. Blackwell
Geothermal Laboratory
253 Heroy Building
Southern Methodist University
Dallas, Texas 75275

or

Dr. George R. Priest

Regional Geologist

Oregon Department of Geology and Mineral Industries

910 State Office Building

Portland, Oregon 97201

\section{ACKNOWLEDGMENTS}

Preparation and publication of this document were supported by the Oregon Department of Geology and Mineral Industries (DOGAMI) and Grant Number DE-FG07-84ID12526 from the U.S. Department of Energy (USDOE). The plan was organized and modeled after a plan by the Valles Caldera Scientific Drilling Team (Goff and Nielson, 1986). Much valuable criticism and advice was offered by the following individuals : 
John D. Beaulieu, DOGAMI

Michael Fehler, Los Alamos National Laboratory

Gordon G. Goles, University of Oregon

Donald A. Hull, DOGAMI

Norman S. MacLeod, U.S. Geological Survey (USGS) (retired)

Martin W. Molloy, USDOE

L.J. Patrick Muffler, USGS

Marshall J. Reed, USDOE

Gary A. Smith, University of Arizona

Edward M. Taylor, Oregon State University (OSU)

Richard Traeger, Sandia National Laboratory

Harve Waff, University of Oregon

George W. Walker, USGS (retired)

Deep Observation and Sampling of the Earth's Continental Crust (DOSECC) allowed representatives of the ad hoc Cascade Task Force to present the Program for Scientific Drilling in the Cascades (PSDC) to DOSECC-sponsored conferences on scientific drilling. Robert Andrews of DOSECC (formerly of the National Research Council) gave valuable advice about the national Continental Scientific Drilling Program and sent many information documents. His participation in the early meetings of the ad hoc Cascade Task Force added a valuable national perspective to the proceedings.

The USGS, American Geophysical Union, and DOGAMI made their facilities available for meetings of the ad hoc Cascade Task Force.

We are particularly indebted to Sunedco Energy and Development Company for its permission to use previously confidential data on its Sunedco Well No. 58-28. Sunedco also gave us written permission to reopen the well for scientific studies. Sunedco's representative, Ed Western, was particularly helpful in providing details on the present condition of the well.

Gerald Patchen and Robert Fujimoto of the U.S. Forest Service (USFS) offered invaluable advice about legal and institutional problems that might arise in siting the holes. Their advice influenced the estimated times for the siting process.

John Doerr, a student at Portland State University, was very helpful in collating and distributing an early draft of the science plan on very short notice with a minimum of direction. Angie Karel and Sally Fowler retyped many sections from various contributors, handled distribution of review copies, and also offered valuable aid at every stage by sending out numerous mass mailings of meeting and news announcements for the program.

The editorial and cartographic staff of DOGAMI produced the final printed product. Beverly Vogt edited the manuscript and supervised all aspects of publication. Paul Staub, Mark Newhouse, Mike Kelly, and Leslie Anderson redrafted many of the figures.

Patricia Berge and Marianne Guffanti of the USGS contributed valuable lists of references on the Cascade Range. Edward M. Taylor of Oregon State University also contributed a reference list on the Santiam Pass area. 


\section{CONTRIBUTIONS OF INDIVIDUAL AUTHORS}

Keith E. Bargar, USGS: Part of the hydrothermal alteration section (Task 7).

Gerald L. Black, DOGAMI: Parts of the bibliography section, introductory sections dealing with the Cascade heat flow and hydrothermal systems, and editorial work on all sections.

David D. Blackwell, Southern Methodist University: The heat flow section (Task 9).

Robert Collier, School of Oceanography, OSU: Most of the section on hydrogeochemical studies of Blue Lake (Task 8).

Richard W. Couch, OSU: The gravity section (Task 9).

Robert A. Duncan, OSU: Part of the petrochemical studies section (Task 6).

Jack Dymond, School of Oceanography, OSU: Part of the section on hydrogeochemical studies of Blue Lake (Task 8).

John Evans, USGS : Most of the regional seismic studies section (Task 10).

Norman Goldstein, Lawrence Berkeley Laboratory: The electrical studies section (Task 9) and extensive revision of the abstract.

Bezalel C. Haimson, University of Wisconsin: Part of the in-situ stress section (Task 5 ).

Scott Hughes, OSU: Most of the petrochemical studies section (Task 6).

Mahadeva Iyer, USGS : Part of the seismic studies section (Task 9).

Terry E.C. Keith, USGS: Most of the hydrothermal alteration section (Task 7).

Michael A. Korosec, Washington Department of Natural Resources: Phase II studies in Washington.

J.C. Laul, Battelle P.N.W. Laboratory: Part of the petrochemical studies section (Task 6).

Shaul Levy, OSU: Paleomagnetic studies section (Task 11).

Robert H. Mariner, USGS : Part of the hydrogeochemical studies (Task 8).

Walter D. Mooney, USGS: Part of the seismic studies section (Task 9).

George R. Priest, DOGAMI: All introductory sections, most of the drilling and geologic tasks, organization and management sections, all summary sections, and general editing of all sections.

John Rowley, Los Alamos National Laboratory: Design of the drill holes and drilling tasks.

David R. Sherrod, USGS: Geologic summary map for the Santiam Pass area.

Monty Smith, Battelle P.N.W. Laboratory: Part of the petrochemical studies section (Task 6).

Al Waibel, Columbia Geoscience: Temperature and geologic data and preliminary interpretations from Sunedco Well No. 58-28.

Craig S. Weaver, USGS: Part of the seismic studies section (Task 9).

Neil M. Woller, DOGAMI: Part of the budget calculations and final compilation of illustrations.

P. Michael Wright, University of Utah Research Institute: References and text on hydrothermal mineralization in the Cascades that were partially utilized in the hydrothermal alteration section (Task 7). 


\section{CONTENTS}

Acknowledgments $\ldots \ldots \ldots \ldots \ldots \ldots \ldots \ldots \ldots \ldots \ldots \ldots \ldots \ldots \ldots$ iii

Contributions of individual authors $\ldots \ldots \ldots \ldots \ldots \ldots \ldots \ldots \ldots \ldots \ldots$ v

List of figures $\ldots \ldots \ldots \ldots \ldots \ldots \ldots \ldots \ldots \ldots \ldots \ldots \ldots \ldots \ldots \ldots \ldots \ldots \ldots \ldots$

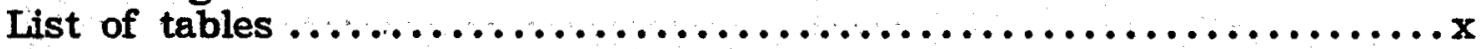

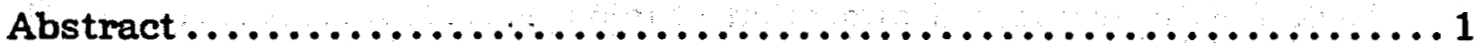

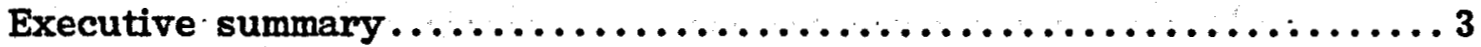

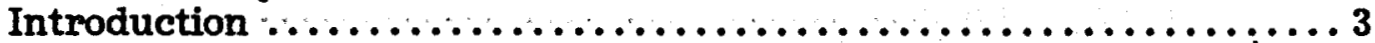

Scientific plan summary $\ldots \ldots \ldots \ldots \ldots \ldots \ldots \ldots \ldots \ldots \ldots \ldots \ldots \ldots$

Management, schedule, and cost summary $\ldots \ldots \ldots \ldots \ldots \ldots \ldots \ldots$

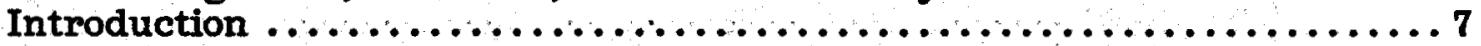

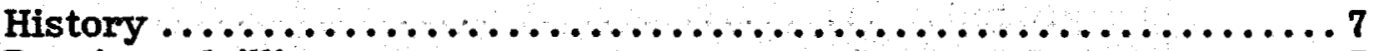

Previous drilling programs $\ldots \ldots \ldots \ldots \ldots \ldots \ldots \ldots \ldots \ldots \ldots \ldots$.

Justification for drilling $\ldots \ldots \ldots \ldots \ldots \ldots \ldots \ldots \ldots \ldots \ldots \ldots \ldots \ldots$

Site selection $\ldots \ldots \ldots \ldots \ldots \ldots \ldots \ldots \ldots \ldots \ldots \ldots \ldots \ldots \ldots \ldots \ldots \ldots \ldots$

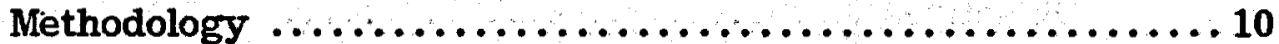

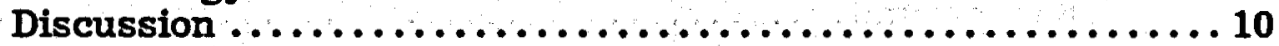

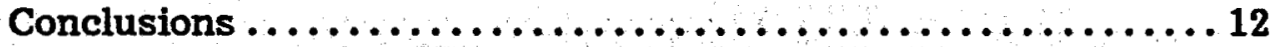

Objectives and priorities of the program $\ldots \ldots \ldots \ldots \ldots \ldots \ldots \ldots \ldots \ldots \ldots$

Introduction $\ldots \ldots \ldots \ldots \ldots \ldots \ldots \ldots \ldots \ldots \ldots \ldots \ldots \ldots \ldots \ldots \ldots \ldots \ldots \ldots \ldots$

Long-term objectives $\ldots \ldots \ldots \ldots \ldots \ldots \ldots \ldots \ldots \ldots \ldots \ldots \ldots \ldots \ldots \ldots \ldots \ldots$

Prioritized objectives of Phase $1 . \ldots \ldots \ldots \ldots \ldots \ldots \ldots \ldots \ldots \ldots$

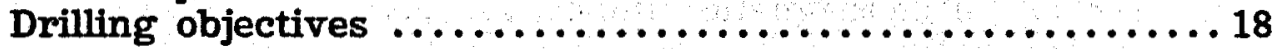

Studies that enhance the drilling program ............. 18

Prioritized objectives of Phase II ....................... 20

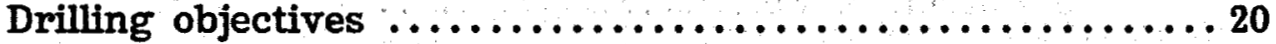

Studies that enhance the drilling program $\ldots \ldots \ldots \ldots \ldots \ldots 20$

Prioritized objectives of Phase III ...................... 20

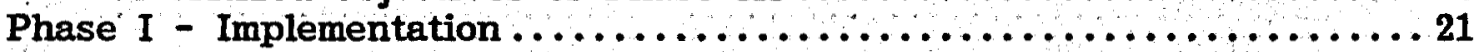

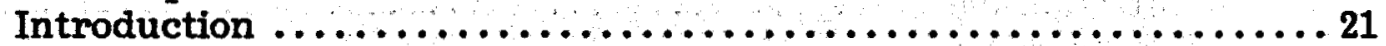

Task 1 - Drill four 1.2-km-deep holes, Santiam Pass area ...... 21 Objectives ...............................21

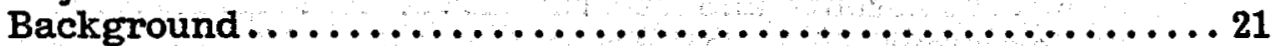

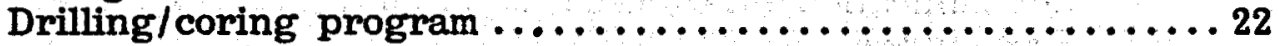

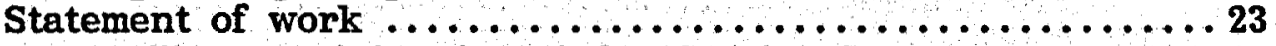

Task 2 - Drill one 2.7-km-deep hole, Santiam Pass area...... 26

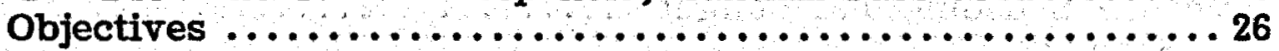

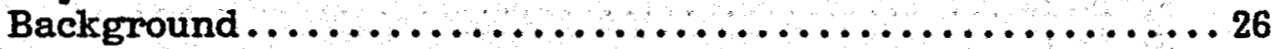

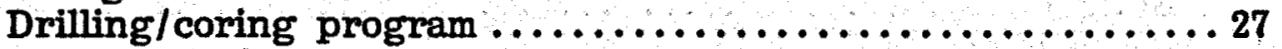

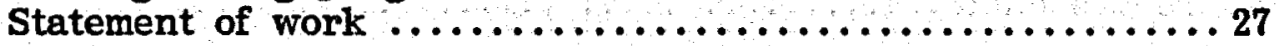

Task 3 - Drill one 2.0-km-deep hole, Breitenbush area........28

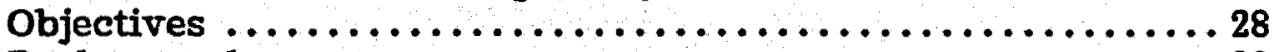

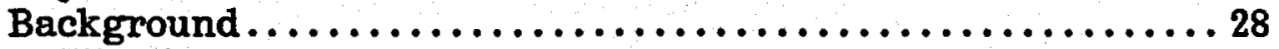

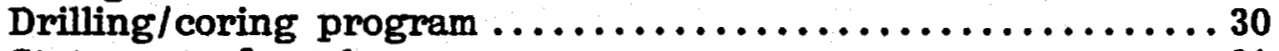

Statement of work $\ldots \ldots \ldots \ldots \ldots \ldots \ldots \ldots \ldots \ldots \ldots \ldots \ldots \ldots \ldots$ 
Task 4 - Test and deepen Sunedco Well No. 58-28 ........... 31

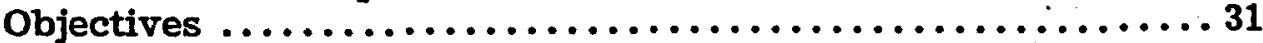

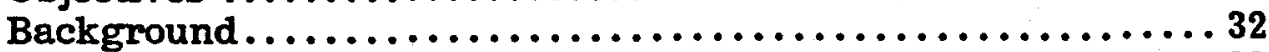

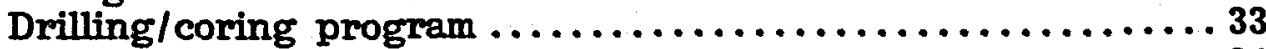

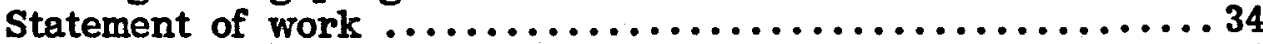

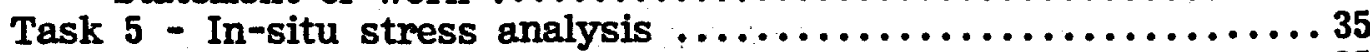

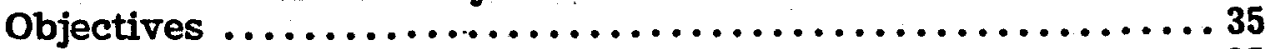

Background ....................................... 35

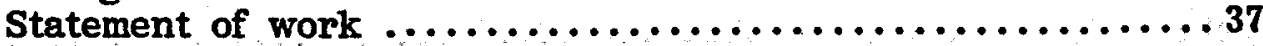

Task 6 - Geologic and petrologic studies $\ldots \ldots \ldots \ldots \ldots \ldots \ldots \ldots \ldots$

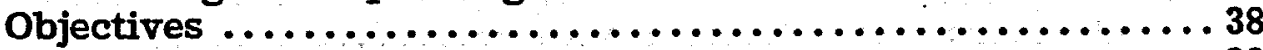

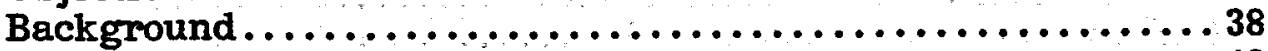

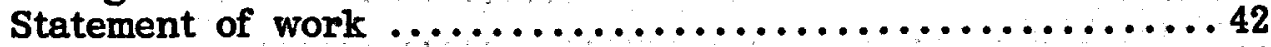

Task 7 - Hydrothermal alteration studies $\ldots \ldots \ldots \ldots \ldots \ldots \ldots \ldots 44$

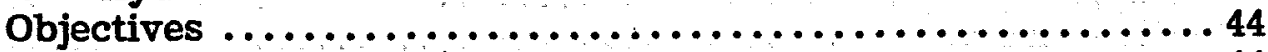

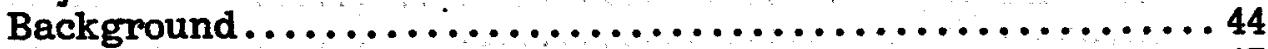

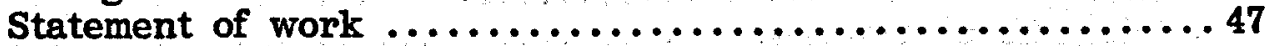

Task 8 - Gas and hydrogeochemical studies $\ldots \ldots \ldots \ldots \ldots \ldots \ldots \ldots 49$

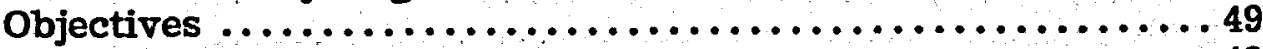

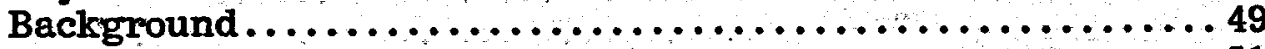

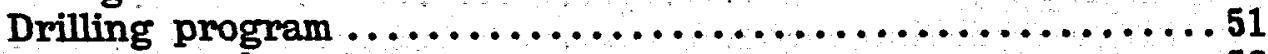

Statement of work $\ldots \ldots \ldots \ldots \ldots \ldots \ldots \ldots \ldots \ldots \ldots \ldots \ldots \ldots 52$

Task 9 - Drill-site geophysical surveys $\ldots \ldots \ldots \ldots \ldots \ldots \ldots \ldots \ldots 5$

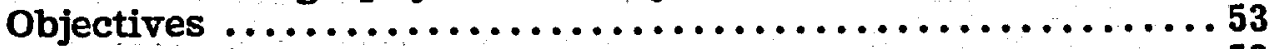

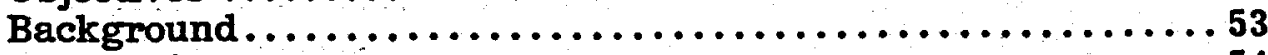

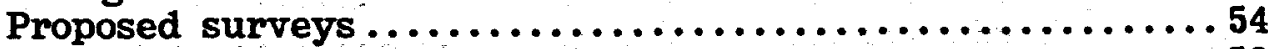

Task 10 - Regional seismic experiment $\ldots \ldots \ldots \ldots \ldots \ldots \ldots \ldots \ldots$. 58

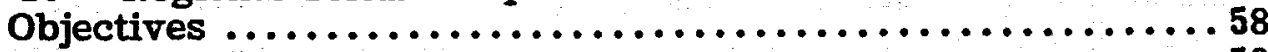

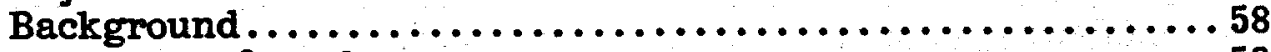

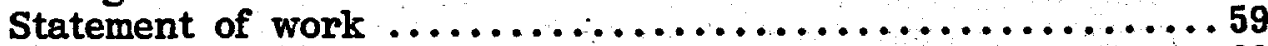

Task 11 - Paleomagnetic studies......................60

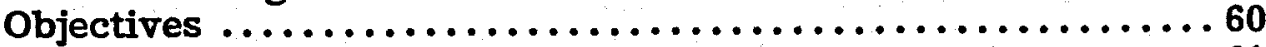

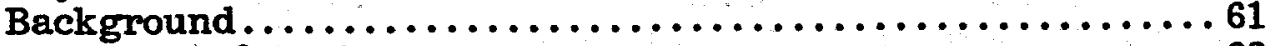

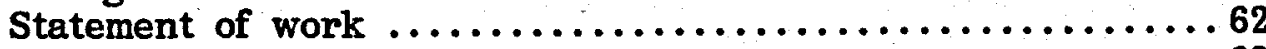

Summary $\ldots \ldots \ldots \ldots \ldots \ldots \ldots \ldots \ldots \ldots \ldots \ldots \ldots \ldots \ldots \ldots \ldots \ldots \ldots \ldots$

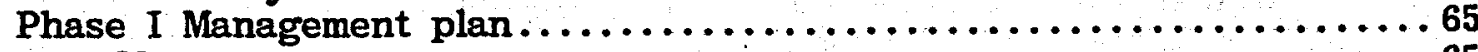

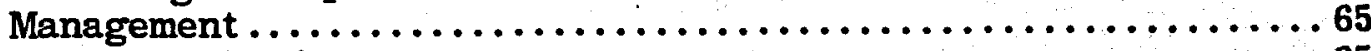

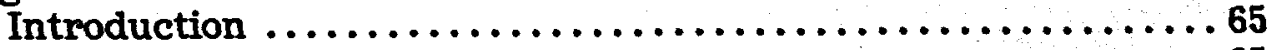

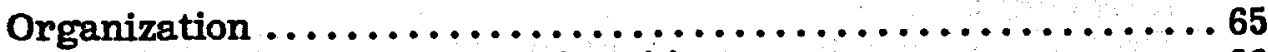

Key resposibilities and membership $\ldots \ldots \ldots \ldots \ldots \ldots \ldots 66 \ldots \ldots 6, \ldots \ldots \ldots$

Key documents and records $\ldots \ldots \ldots \ldots \ldots \ldots \ldots \ldots \ldots \ldots \ldots 68$

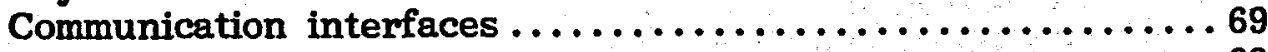

Procedures ................................69

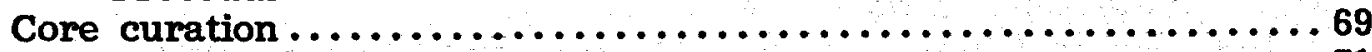

Phase I - Schedule and budget $\ldots \ldots \ldots \ldots \ldots \ldots \ldots \ldots \ldots \ldots \ldots \ldots \ldots \ldots$

Schedule ....................................

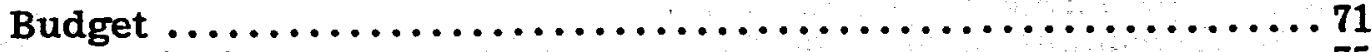

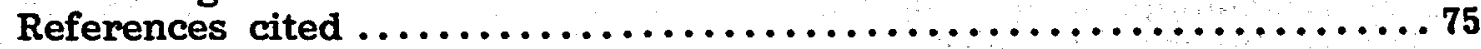




\section{IIST OF FIGURES}

Figure

Page

1. Plate tectonic map of coast of northwestern American

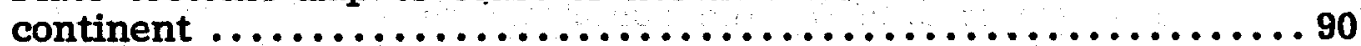

2. Map of western British Columbia, Washington, Oregon, and northern California, showing lines of constant heat flow in milliwatts per square meter in the Cascade Range $\ldots \ldots \ldots \ldots \ldots \ldots \ldots \ldots \ldots \ldots \ldots \ldots \ldots \ldots \ldots \ldots \ldots \ldots \ldots \ldots 1$

3. Map showing locations of the five proposed study areas of Phases I and II of the Program for Scientific Drilling in the Cascades

4. Schematic cross section showing the geologic environments to be sampled by the major Phase I drilling tasks (Tasks 1-4) .............................93

5. Generalized cross sections showing the changes in the gravity field, heat flow, and estimated temperatures of the crust in the northern Oregon Cascade Range ...........94

6. Schematic cross section showing the relationship of heat flow and gravity to subduction in the Cascade

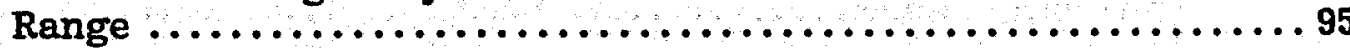

7. Geologic map and cross section of the Santiam Pass area ......................... (folded, separate sheet)

8. Temperature-depth curve from a 557-m-deep hole (13S/R7E-32DC) on the west flank of the High Cascades showing the effects of a weakly thermal aquifer $\ldots \ldots \ldots \ldots \ldots .96$

9. Illustration of drill-hole design for four $1.2-\mathrm{km}$ deep diamond core holes in the Santiam Pass area ...........97

10. Illustration of drill-hole design for a 2.7-km-deep drill hole in the Santiam Pass area ....................98

11. Geologic map of the Breitenbush River

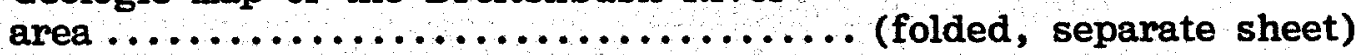

12. Temperature-depth data from Sunedco Well No. 58-28 and other moderately deep wells in the northern Oregon Cascade Range ..............................999

13. Temperature-depth curves for shallow drill holes in the Breitenbush Hot springs area ..................... 100

14. Cross section showing preliminary, speculative temperature model for the Breitenbush area 
15. Drill-hole design for a $1.8-$ to $2.0-\mathrm{km}$-deep hole southeast of Breitenbush Hot Springs ..................... 102

16. Map showing location of the Columbia embayment $\ldots \ldots \ldots \ldots \ldots 103$

17. Theoretical east-west cross section across the Oregon Cascade Range showing densities of crustal layers based on gravity, seismic, and drill-hole data............ 104

18. Present status of Sunedco Well No. 58-28 $\ldots \ldots \ldots \ldots \ldots \ldots \ldots 105$

19. Drill-hole design for deepening Sunedco Well

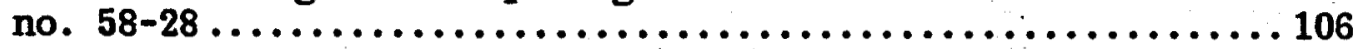

20. State of stress data for the northwestern

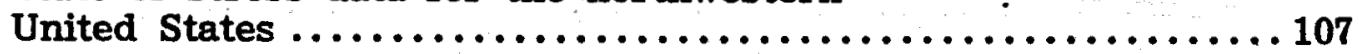

21. Pseudo-ternary Ol-P1-SiO ${ }^{2}$ plot of representative High Cascade compositions $\ldots \ldots \ldots \ldots \ldots \ldots \ldots \ldots \ldots \ldots \ldots \ldots . \ldots \ldots$

22. Representative High Cascade incompatible element and Sc compositions normalized to primordial mantle values .......................................... 109

23. Location map for magnetotelluric lines ................... 110

24. Preliminary interpretation of magnetotelluric

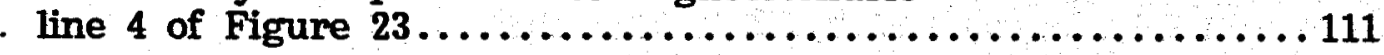

25. Map showing previous seismic lines and new seismic experiments proposed for Tasks 9 and $10 \ldots \ldots \ldots \ldots \ldots \ldots . . .112$

26. Preliminary east-west cross section through Santiam Pass ...................................... 113

27. Regional transect of western Oregon, continental

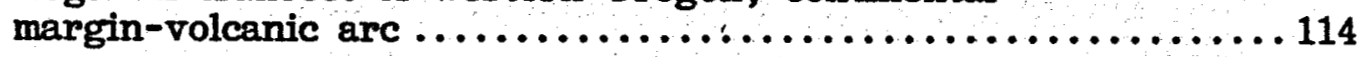

28. Generalized geotectonic map of Oregon and

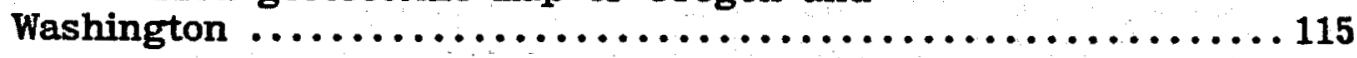

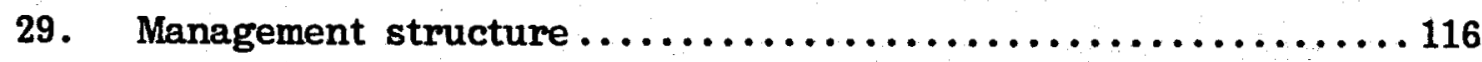

\section{LIST OF TABLES}

Table 1. Qualitative summary of the quality of the data base, access, and geothermal-resource potential at possible sites for research drilling in the Cascades.......................... 118

Table 2. Ranking of sites based on total scores

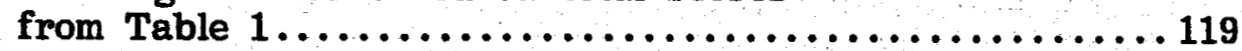

Table 3. Thermal conductivity measurements from Sunedco Well No. $58 \ldots \ldots \ldots \ldots \ldots \ldots \ldots \ldots \ldots \ldots . . \ldots, 120$ 


\begin{abstract}
A phased, multihole drilling program with associated science is proposed as a means of furthering our understanding of the thermal regime and geologic history of the Cascade Range of Washington, Oregon, and northern California. The information obtained from drilling and ancillary geological and geophysical investigations will contribute to our knowledge in the following general areas:

1. The magnitude of the regional background heat flow of parts of the Quaternary volcanic belt dominated by the most abundant volcanic rock types, basalt and basaltic andesite.

2. The nature of the heat source responsible for the regional heat-flow anomaly.

3. The characteristics of the regional hydrothermal and coldwater circulation.

4. The rates of volcanism for comparison with models for the rate and direction of plate convergence of the Cascades.

5. The history of deformation and volcanism in the volcanic arc that can be related to subduction.

6. The present-day stress regime of the volcanic arc and the relation of these stresses to plate interactions and possible large earthquakes.

7. The current geometry of the subducted oceanic plate below the Cascade Range and the relationship of the plate to the distribution of heat flow, Quaternary volcanism, and Quaternary deformation.

Phase I research will be directed toward a detailed investigation of a representative segment of the volcanic arc. The Santiam Pass segment or transect is a logical choice for several reasons. Not only are the Quaternary basalt and basaltic andesite volcanism typical of the Quaternary volcanism in the arc, but the area is accessible, and a good initial data base already exists. In concert with the Santiam Pass research, a detailed study of the nearby Breitenbush Hot Springs area is also recommended as a component of Phase 1 . The object of the Breitenbush research is to study one of the hottest known Cascade hydrothermal systems, which coincidentally also has a good geological and geophysical data base. The potential of the Breitenbush site for scientific drilling is enhanced by the existence of a $2.5-\mathrm{km}-\mathrm{deep}$ drill hole that can be re-entered for deepening and that penetrates a major hydrothermal aquifer.

A coordinated program of drilling, sampling, subsurface measurements, and surface surveys will be associated with the drilling of several holes with the primary goal of defining the thermal regime of the . study areas:
\end{abstract}


1. Drilling in the Santiam Pass area. Four 1.2-km-deep diamond core holes will be drilled in an east-west pattern across the High Cascades at the latitude of Santiam Pass, Oregon. The holes will pass through the cold ground-water regime into a region where reliable heatflow measurements can obtained and where cores and fluid samples from the pre-Quaternary volcanic rocks can be recovered. Utilizing the results of the intermediate depth drilling, scientists will select a site for a core hole to be drilled to a depth of $2.7 \mathrm{~km}$ near Santiam Pass. This hole will be aimed at sampling of deeper hydrothermal fluids and rock units.

2. Drilling in the Breitenbush Hot Springs area. Drilling at Breitenbush Hot Springs will consist of deepening the existing $2.5-\mathrm{km}-$ deep hole (Sunedco Well No. 52-28) by continuous diamond coring to a depth of $4.0 \mathrm{~km}$ and the drilling of a new $2.0-\mathrm{km}$-deep hole $6 \mathrm{~km}$ southeast of the 52-28 well. The main purposes of the Breitenbush program are to test and sample the hydrothermal aquifer intersected in the 52-28 well and the new hole, obtain reliable thermal data for the area, sample the pre-Cascade rocks, and test for deeper hydrothermal aquifers.

A number of specialized studies and surface surveys will be done in conjunction with the drilling program. In-situ stress measurements in selected drill holes in and west of the Cascade Range will help to define the stress regime of the upper crust. Geologic mapping and petrochemical analysis of rocks across a complete east-west transect through the Cascade Range at Santiam Pass will provide the data base for correlating rock units, defining magma genesis, and estimating rates of volcanism and magma supply. Compositional data from gas, fluids, and rocks in the drill holes and in outcrops will be utilized to develop an understanding of rock alteration and mineralization processes. Soilmercury surveys and a heat-flow and geochemical study of Blue Lake will be conducted in the Santiam Pass area to search for sites of current hydrothermal activity. Detailed and regional-scale geophysical surveys will be conducted, and the results will be tied into the subsurface data as a means for obtaining a three-dimensional model of the crust and upper mantle, including the extent of hydrothermal systems and the configuration of the subducted oceanic slab. Paleomagnetic measurements on core and outcrops will be utilized to correlate rock units and to determine the magnitude of crustal rotations during the last 37-40 million years.

Phase I will require financial support totaling about $\$ 11.5$ million: about $\$ 7.8$ million for essential drilling and science and about $\$ 3.7$ million for studies that will enhance the drilling program. The program will take about three to five years to complete.

In future years, studies analogous to the investigations proposed for the Santiam Pass transect should also be carried out in the Mount Shasta-Medicine Lake area, the Willamette Pass-Century Drive area, and the Mount St. Helens-Mount Adams area. In addition to these studies, a hole should be drilled to $7-10 \mathrm{~km}$ at a site that would explore the magmatic and metamorphic processes active in the source region for the regional heat-flow high that characterizes the volcanic arc.

This plan is current as of February 1987. It will be updated periodically to reflect changes in the current data base for the Cascades. 


\section{EXECUTIVE SUMMARY}

\section{INTRODUCTION}

Much of the world's explosive volcanism and many of the mineral deposits and large earthquakes occur in subduction-related volcanic arcs. The Cascade Range of Washington, Oregon, and California is the only currently active subduction-related volcanic arc in the conterminous United States. The range consists of an extinct volcanic belt of deeply eroded volcanoes and a Quaternary volcanic arc. In Oregon and northern California, the eroded volcanoes are generally referred to as the "Western Cascades" and the volcanic arc as the "High Cascades." In this paper, however, the term "Cascade Range" will refer to both the High Cascades and the Western Cascades. Currently active volcanic processes can be studied in the High Cascades. The deeply eroded Western Cascades offer an opportunity to study the development of the volcanic arc since about 40 million years $(\mathrm{m} . \mathrm{y}$.$) ago. The Cascade$ Range is thus an ideal natural laboratory for study of energy and mass-transfer processes associated with subduction-related volcanism. The geologic and plate-tectonic settings are summarized on Figure 1.

A phased program of drilling and surface surveys is proposed to advance understanding of the thermal regime, volcanic history, metamorphic processes, and tectonic setting of Cascade Range of Washington, Oregon, and northern California. Drilling and surface geological and geophysical investigations proposed here will be a first step toward achieving the following general objectives:

1. Estimation of the regional background heat flow in parts of the Quaternary volcanic belt dominated by basalt and basaltic andesite.

2. Investigation of the nature of the heat source responsible for the regional heat-flow anomaly (Figure 2 ).

3. Characterization of regional hydrothermal circulation and attendant water-rock reactions.

4. Comparison of the rate of volcanism to the rate and direction of plate convergence.

5. Comparison of the data from items 1 and 4 , above, to similar data from areas with differing rates and directions of plate convergence so that a comprehensive model can be developed.

6. Comparison of the history of deformation and magma genesis in the volcanic are to the history of subduction.

7. Determination of the stress regime of the volcanic arc to evaluate how the the arc is responding to regional tectonic forces, particularly interactions of the Juan de Fuca and North American Plates.

8. Determination of the current configuration of the subducted oceanic plate in order to understand its relationship to the distribution of heat flow, Quaternary volcanism, and Quaternary deformation. 


\section{SCIENTIFTC PLAN SUMMARY}

This plan covers the details of an extensive first phase in proposed investigation. Proposed second and third phases are discussed in general terms. Phase $I$ will require investigation of one representative segment of the volcanic arc. The Santiam Pass segment (Figure 3) is a logical choice, because it is dominated by Quaternary basalt and basaltic andesite typical of the bulk of Quaternary volcanism in the arc. It has also been well studied and is accessible. Determination of the thermal regime of the High Cascades in the Santiam Pass area is the highest initial priority of the program. It is also recommended that a similarily detailed study of the nearby Breitenbush Hot Springs area (Figure 3) be implemented as part of Phase I in order to study a typical Western Cascade hydrothermal system. The Breitenbush area has (1) a good geological and geophysical data base, (2) one of the hottest hydrothermal systems in the Cascades with the dilute $\mathrm{NaCl}$ fluids characteristic of the Cascade systems, and (3) an existing 2.5-km-deep drill hole that penetrates the hydrothermal aquifer.

Phase I can be implemented by a coordinated program of drilling and surface geological and geophysical surveys of the two study areas. Four primary drilling tasks (items 1-4, below) will be accomplished (Figure 4) and seven additional tasks (items 5-11, below) are recommended to enhance the primary tasks:

1. Drill four 1.2-km-deep diamond core holes in an east-west pattern across the High Cascades at the latitude of Santiam Pass. The primary objective of these holes is to drill through the cold ground water that masks deep heat flow. The holes will also examine the preQuaternary volcanic stratigraphy. This drilling project is the highest initial priority of the program.

2. Drill one 2.7-km-deep hole in the High Cascades near Santiam Pass to sample deep hydrothermal fluids and stratigraphic units.

3. Drill a 2.0-km-deep hole southeast of Breitenbush Hot Springs. This hole will allow direct observation of changes in the hydrothermal aquifer as it ascends to the hot springs from beneath the axis of the High Cascades.

4. Sample the hydrothermal aquifer at $760 \mathrm{~m}$ in Well No. 58-28, relog the upper part of the well, and deepen it from $2.5 \mathrm{~km}$ to $4.0 \mathrm{~km}$ by diamond coring. This task will add additional compositional data on the shallow hydrothermal system at Breitenbush Hot Springs and definitively test whether the Cascade heat-flow anomaly is produced from a deep heat source. The well may also allow sampling of pre-Cascade basement rocks.

5. Conduct in-situ stress tests utilizing hydrofracturing, wellbore breakout analysis, and triaxial strain-release measurements on selected drill holes to examine how the volcanic arc is responding to tectonic forces. Conduct similar tests on an appropriate abandoned oil exploration well west of the Cascade Range to study crustal stress outside of the regional heat-flow anomaly.

6. Complete the geologic coverage of the Western Cascades and High Cascades at the latitude of Santiam Pass by producing the following items:

a) Geologic maps (scale 1:62,500) of the Brownsville, Cascadia, and Sweet Home topographic quadrangles (Figure 3 ) to 
complete geologic mapping across the full width of the range at the latitude of Santiam Pass in order to investigate the geologic history of the arc.

b) Isotopic dates and mineralogic and chemical analyses of selected rocks from the entire Santiam Pass transect to aid in correlating rock units and deciphering the petrologic evolution of the arc.

7. Study hydrothermal alteration and mineralization in the drill holes and in outcrop in the Santiam Pass transect, the Breitenbush Hot Springs area, the Little North Santiam mining district (mesothermal mineralization) (" $L$ " in Figure 3), and the Halls diorite porphyry (epithermal mineralization) ("H" in Figure 3 ). These studies will be aimed at understanding the history of hydrothermal circulation and mineraldeposition processes in the volcanic arc.

8. Determine the configuration and evolution of current hydrothermal systems in the study areas by utilizing fluid, gas, and soil geochemical data.

9. Conduct detailed electrical, gravity, and seismic surveys in the Santiam Pass transect to delineate upper crustal structure.

10. Conduct a regional seismic experiment capable of mapping the subducted oceanic plate, gross crustal structure, and magma bodies in the crust and upper mantle.

11. Measure paleomagnetic-pole orientations in rocks from a variety of stratigraphic and geographic positions in the central part of the Cascade Range to test for rotation of major tectonic blocks by regional crustal deformation.

It is recommended that a second phase be implemented in future years. Phase II will consist of studies analogous to the work proposed for the Santiam Pass transect but conducted in geologically contrasting arc terranes of the Mount Shasta-Medicine Lake area, the Willamette Pass-Century Drive area, and the Mount St. Helens-Mount Adams area (Figure 3). Phase III of the program will consist of exploration of the magmatic and metamorphic processes active in the source region for the regional heat-flow high that characterizes the volcanic arc. This will require drilling, sampling, and testing a 7-to $10-\mathrm{km}$-deep hole at a site selected on the basis of data collected from Phases I and II.

\section{MANAGEMENT, SCHEDULE, AND COST SUMMARY}

The program will be managed by the Scientific Steering Committee (SSC). The SSC will be composed of representatives from the major participating organizations. The Interagency Coordinating Committee (ICC) will advise the SSC on policy and regulatory issues. The ICC will be composed of representatives from organizations that manage, fund, or regulate the project. Day-to-day management will be carried out by the Project Coordinator, Chief Scientist, and Chief Engineer.

Phase I will require about $\$ 11.5$ million: $\$ 7.8$ million for essential drilling (Tasks 1-4) and $\$ 3.7$ million for studies that will enhance the drilling tasks (Tasks 5-11). No accurate cost estimates are as yet available for Phases II and III. Phases I and II will take about three to five years each; Phase III will take about five years. 


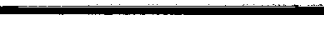




\section{INTRODUCTION}

\section{HISTORY}

The Cascade Range has been the focus of government-sponsored drilling programs for the last twenty years. Most of the activity has been supported by USDOE with the goal of assessing the geothermalresource potential of the range. During the last three years, the national Continental Scientific Drilling Program (CSDP) has come to recognize that the Cascade Range is a high-priority scientific drilling target. Opportunities for studying subduction-related volcanic processes were outlined by the ad hoc Cascade Task Force at national forums on scientific drilling sponsored by the American Geophysical Union in 1984 and the CSDP in 1985 and 1986. A workshop on the Cascade Range sponsored by the USGS in 1985 also helped to develop the major scientific issues that could be addressed by scientific drilling in the Cascade volcanic arc. Discussions among interested scientists at these forums concluded that the most important initial goal of a Cascades drilling program is to investigate the thermal regime of the range. Penetration of the so-called "rain curtain" effect that masks deep conductive and convective heat flow in the Quaternary volcanic rocks of the High Cascades was given the highest priority. Copious flows of cold ground water in the youngest volcanic rocks wash away conductive heat down to depths in the $200-$ to $750-\mathrm{m}$ range. This phenomenon prevented measurement of heat flow in the High Cascades by previous drilling programs, which focused on relatively low-cost 152-mdeep temperature-gradient holes. Discussions at the meetings concluded that the next highest priority goal was to test the heat-flow model of Blackwell and others (1978, 1982b), which predicts that much of the range is underlain at depths of $7-10 \mathrm{~km}$ by a heat source at temperatures of $600^{\circ}-800^{\circ} \mathrm{C}$. Numerous other important scientific issues were discussed, but these two problems were thought to be the most important for scientific drilling.

\section{PREVIOUS DRIIINTG PROGRAMS}

The first intensive drilling program in the Cascades was funded primarily by USDOE and was aimed at examining the structure and geothermal-resource potential of a typical Cascade stratocone. The Mount Hood area was selected and a five-year study commenced in 1976. The project resulted in drilling of 24 shallow (less than $610-\mathrm{m}$-deep) temperature-gradient holes, two 1,220-m-deep wells, and one 1,836-mdeep well. The deepest well passed completely through the Cascade rocks into what may be old accreted oceanic crust and, in addition, crossed a large fault that probably bounds the west side of the graben that encloses Mount Hood (Priest and others, 1982a). Moderately 
detailed gravity, aeromagnetic, and magnetotelluric surveys were completed, as were studies of the petrology, geology, and hydrothermalalteration patterns. Gravity results indicate that the volcano sits in a graben (Couch and Gemperle, 1979; Williams and others, 1982). Detailed gravity models of the cone revealed the presence of a probable highdensity intrusion (Williams and Finn, 1981, 1983). Access problems prevented direct investigation of the central conduit and possible small magma-hydrothermal systems directly beneath the apex of the cone. Studies in other parts of the area found no evidence for a large shallow magma body, although the magnetotelluric data and heat flow are consistent with a deep (about $10 \mathrm{~km}$ ), north- to northwest-trending zone composed of hot rock with some magma or electrically conductive fluid (Steele and others, 1982; Mozley, 1982; Mozley and others, 1985). Although hydrothermal fluid was recovered in one well on the volcano, insufficient fluid samples were available to do any detailed modeling of the hydrologic system or to evaluate the geothermal potential. The Mount Hood investigation ended with more questions than answers about heat flow and hydrology in the stratocone environment.

Much was learned about stratocone hydrothermal systems from study of the Lassen Peak geothermal system. This study took advantage of fluid samples from an existing 1.2-km-deep hole and numerous hot springs. The volcano has, at low elevations, a liquid-dominated hydrothermal system at about $240^{\circ} \mathrm{C}$, with a parasitic vapor-dominated zone developed in the higher elevations (Muffler and others, 1982; Ingebritsen and Sorey, 1985).

High Cascade volcanism in the majority of the volcanic arc consists of basalt and basaltic andesite erupted from shield volcanoes, so the stratocone investigations at the dacitic Mount Hood and Lassen Peak volcanoes are not necessarily applicable to the volcanic arc as a whole. A first step toward evaluation of the overall heat flux in the volcanic arc was accomplished by drilling of numerous shallow $(152-600 \mathrm{~m})$ holes chiefly in older rocks adjacent to the High Cascades. During this USDOE-funded program, 94 shallow temperature-gradient holes were drilled, and numerous water wells were logged throughout the Cascade Range (i.e., Schuster and others, 1978; Mase and others, 1982; Korosec and others, 1983; Black and others, 1983; Blackwell and Steele, 1983; Korosec, 1983; Barnett, 1986). Few holes were drilled in the High Cascades, because rapidly flowing shallow ground water was known to wash away the conductive heat at the shallow depths drilled. Good conductive gradients were obtained in older, more altered rocks in adjacent areas such as the Western Cascades. A regional heat-flow high, which includes the western edge of the High Cascades and the eastern part of the Western Cascades, was found along the entire length of the volcanic arc (Blackwell and others, 1978, 1982b; Blackwell and Steele, 1983). Heat-flow values west of the anomaly are 30-40 $\mathrm{mWm}^{-2}$, whereas heat flow in the anomaly is $80-100+\mathrm{mWm}^{-2}$. The transition occurs over a lateral distance of only about $20 \mathrm{~km}$ (Blackwell and others, 1978, 1982b; Blackwell and Steele, 1983). Blackwell and others $(1978,1982 \mathrm{~b})$ postulated that the anomaly in north-central Oregon is caused by a heat source at temperatures of $600^{\circ}-800^{\circ} \mathrm{C}$ at depths of 7$10 \mathrm{~km}$ beneath much of the High Cascades and the eastern part of the Western Cascades. It is also possible that geothermal aquifers at lower temperatures $\left(200^{\circ}-350{ }^{\circ} \mathrm{C}\right)$ and shallower depths $(3-5 \mathrm{~km})$ may also cause the heat-flow high. Temperatures from Sunedco Well No. 58-28 
indicate that the conductive heat-flow high in the central Western Cascade Range persists to at least $2.5 \mathrm{~km}$, so even if aquifers are the source of the anomaly, they must lie below depths of $2.5 \mathrm{~km}$ and be at temperatures in excess of about $160^{\circ} \mathrm{C}$ (A. Waibel, in preparation; Priest, 1985a,b; Blackwell and others, 1986a).

The shallow drilling accomplished in the USDOE-sponsored program thus outlined a regional heat-flow anomaly but failed to establish its amplitude in the Quaternary volcanic rocks of the High Cascades. The drilling also did not establish the location of the heat-flow transition between the High Cascades and geologic provinces to the east. Most of the data were from shallow holes, so the vertical extent of the anomaly is not known with certainty except at the Sunedco drill site near Breitenbush Hot Springs. The next step clearly is to drill deeper in both the Western Cascades and the High Cascades.

\section{JUSTIFICATION FOR DRIHING}

Much has been learned about the Cascade Range from surface surveys and shallow temperature-gradient drilling. Nevertheless, a number of major tasks remain. Among the most important of these are:

1. Mapping and characterizing hydrothermal systems in both the Western Cascades and the High Cascades.

2. Determining background conductive heat flow in the High Cascades.

3. Mapping the pre-Quaternary structure and stratigraphy of the High Cascades.

4. Accurately characterizing the source of the regional heat-flow anomaly.

The geophysical and geological surveys have failed to accomplish these tasks, primarily because most of the objectives deal with active processes that can be studied best in the active part of the volcanic arc, the High Cascades. Unfortunately, geophysical surveys have not been very successful in the High Cascades because of the difficulties presented by lack of access, high resistivity, low seismic velocity, and structural complexity of the young rolcanic rocks. Another problem is the lack of drill-hole data to constrain the many possible geophysical models. Heat-flow analysis has been particularly hindered in the High Cascades because of cold ground water, which, as previously mentioned, washes away the deep conductive heat flow to depths of $500 \mathrm{~m}$ or more. Geological surveys can examine deep parts of the geologic section only in areas of deep erosion and uplift. Because the High Cascades are generally not eroded very deeply, the pre-Quaternary structure and stratigraphy there are largely unknown. The same problem arises to a lesser extent in the Western Cascades, where most of the rocks have low dips and where erosion has not reached deeply enough in most places to expose the basal parts of the section or preCascade rocks. Reconstructing the history of the volcanic arc and examining the circulation of hydrothermal fluids into the Western Cascades will require compositional data from fluids and rocks that suface study and geophysical modeling cannot provide.

Drilling of intermediate-depth and deep drill holes is therefore crucial to further progress in understanding the mass- and energy- 
transfer processes active in the Cascade Range. Only drill holes can provide the necessary fluid and rock samples and down-hole geophysical measurements to place quantitative constraints on possible geologic and hydrologic models.

\section{SITE SETECTION}

\section{Methodology}

Given that drilling should occur in the Cascade Range, the problem then is to decide which areas have the greatest potential for accomplishing the above tasks while gaining as much scientific data on as wide a range of other problems as possible. Most of the abovementioned tasks are related to characterization of the thermal regime of parts of the volcanic arc with the highest potential heat flow, so picking sites can, to a first approximation, be accomplished by utilizing a geothermal-exploration strategy. The geothermal-exploration industry has evolved $a_{5}$ phased approach to drilling programs. Surface geologic, geochemical, and geophysical surveys are normally followed by shallow drilling of temperature-gradient holes (60-600 m deep) that, in turn, are followed by drilling of deeper. wells $(600-2,500 \mathrm{~m}$ deep) to test for high-temperature, high-pressure hydrothermal fluids. Tables 1 and 2 are qualitative ratings of the position of various parts of the Cascade Range with respect to resource potential (a measure of the likelihood of high-temperature rocks and fluids), access, and completion of successful completion of a temperature-gradient drilling program. These tables utilize only data that are available to the public. The evaluation categories in the tables could be separated into a number of subcategories corresponding to the various exploration phases, but this separation would not materially affect the final ranking of sites. The point of this exercise is that there are only a few areas that are at present both accessible and well studied enough to be targets for scientific drilling.

Discussion following:

Areas that stand out as good potential drilling sites are the

1. Newberry volcano, central Oregon, and Medicine Lake volcano, northern California.

2. The Breitenbush Hot Springs area, central Oregon.

3. Santiam Pass area, central Oregon.

4. Areas adjacent to Mount Shasta, northern California.

5. Willamette Pass-Century Drive transect, central Oregon.

7. Areas adjacent to Crater Lake, southern Oregon.

6. Areas adjacent to Mount Hood, northern Oregon.

The Newberry and Medicine Lake volcanoes, which are major volcanic centers with large data bases, scored high in the ranking. These volcanoes have a high potential for shallow, high-temperature hydrothermal systems, as shown by the USGS Newberry 2 well (Sammel, 1981). However, further drilling in these areas may not reveal much about the High Cascades to the west, particularly areas characterized 
by andesitic to basaltic volcanism. Geologists, in fact, are debating whether the Newberry and Medicine Lake volcanoes should even be included in the Cascade geologic province.

Although the Breitenbush area is in the volcanically inactive Western Cascades, it ranks very high relative to other sites (Table 2) because of its abundant geological, geophysical, and drilling data and known, potentially exploitable hydrothermal system. Sunedco Energy and Development has released much of its Breitenbush area data, including data from its 2.5-km-deep well (Well No. 58-28), the deepest well in the U.S. Cascades. This well intersected a major hydrothermal aquifer and can be reentered for deepening and additional scientific studies (Edward Western, Sunedco Energy and Development, personal communication, 1983). Data from numerous shallow temperature-gradient holes are also available for the Breitenbush area. The temperaturegradient data indicate that the aquifer in Well No. 58-28 dips to the east, where it might be intercepted at higher temperatures (A. Waibel, unpublished interpretations, 1985).

The accessibility, excellent geological coverage, and availability of regional heat-flow data in the adjacent Western Cascades and Green Ridge (Taylor, 1967; Taylor, unpublished 1:24,000-scale mapping; Black and others, 1982, 1983) make the Santiam Pass area a prime target for scientific drilling in the High Cascades. The pass is also located in a part of the arc that is dominated by basalt and basaltic andesite volcanism. This type of volcanism is typical of much of the Quaternary volcanism in the southern and central High Cascades, the part of the arc with the largest quantity of Quaternary volcanic rock (White and McBirney, 1978). Santiam Pass is also one of the few easily accessible places in the High Cascades where the axis of volcanism can be located with a great deal of confidence. It thus affords an unique opportunity to test the hypothesis that the current axis of mafic to intermediate volcanism may have high conductive heat flow and a high potential for hydrothermal resources. In addition, the area lies in a large Pliocene graben that formed after eruption of voluminous ash flows and lavas of late Miocene to early Pliocene age from the High Cascades (Taylor, $1980,1981)$. Drilling could provide quantitative constraints on the amount of displacement on this graben and the nature of the pregraben volcanic arc (now completely buried by Quaternary volcanoes). Drilling would also help to test the hypothesis that the regional residual gravity high under the Three Sisters-Mount Jefferson segment is caused by a large intrusive complex ( $R$. Couch, personal communication, 1985). Drilling in the areas adjacent to Mount Shasta would be of great value in terms of both geothermal assessment and volcanologic research. Drilling would capitalize on the detailed geophysical and geological data base that has been developed for this area by the USGS. Completing a transect eastward to Medicine Lake would also be of interest, because the transect would cross the transition zone between the shield-volcano environment of Medicine Lake and the large composite-cone environment of Mount Shasta.

The Century Drive area adjacent to South Sister is unique in that it contains the only Holocene rhyodacite volcanic centers in the High Cascade Range that are accessed by a major highway. The area, which is adjacent to a long-lived silicic highland of regional extent (Taylor, 1980,1981 ) would be an ideal place to determine if hydrothermal resources associated with silicic volcanism are present in the main High 
Cascade Range. Heat-flow and geophysical profiles across the full width of the Willamette Pass-Century Drive area would be of interest, especially in comparison with profiles at Santiam Pass, where mafic and intermediate volcanism prevails. Extending the studies to Newberry volcano would allow investigation of the relationship between the silicic highland at Century Drive and basaltic to silicic volcanism at the Newberry shield volcano.

The flanks of Mount Mazama adjacent to Crater Lake scored high in the table because of the potential public availability of data from drilling that is in progress at the writing of this document. The area is also accessible, and the geology is relatively well known (e.g., Williams, 1942, 1957; Smith and others, 1982; Bacon, 1983). Study of this large volcanic edifice will, as in the case of Mount Shasta, provide interesting information on an area with a long-lived volcanic system and with an anomalously high rate of silicic to intermediate magma production. The uniqueness of the Crater Lake area and potential environmental and institutional problems linked to its status as a national park make it a poor choice for an initial study area. Study of the Crater Lake area might be more appropriate for a later phase of scientific drilling aimed at characterizing geologically contrasting parts of the volcanic arc, although there may be better sites. For instance, the Century Drive area has much younger silicic volcanism.

Areas adjacent to Mount Hood scored well in the ranking because of the large available data base. However, extensive drilling in the area has not been successful in locating indications of major hightemperature hydrothermal systems. According to some interpretations of the geophysical surveys ( $N$. Goldstein, personal communication, 1986), the drill holes may be too shallow and not in the best locations to intercept the hydrothermal systems. In any case, the gravity data indicate that, unlike many of the large High Cascade volcanoes to the south, Mount Hood may not lie above a large, shallow intrusive complex (R. Couch, personal communication, 1985), although Williams and Finn $(1981,1983)$ concluded that a shallow, high-density intrusion could be present. South of Mount Hood, the regional background heat flow increases $70 \mathrm{mWm}^{-2}$ to in excess of $100 \mathrm{mWm}^{-2}$ (see Figure 2 and Blackwell and others, 1982b), which would be additive to any local heat flow associated with shallow intrusions. Therefore, all other things being equal, drilling in or near a stratocone such as Mount Shasta, which is one of the Cascade volcanoes that are located south of Mount Hood, would probably encounter higher temperatures for a given depth of drilling.

A transect of detailed temperature-gradient drilling and surface surveys across the southern Washington Cascades would be valuable. This information would help to improve the meager heat-flow data base in Washington and allow comparisons between this area of somewhat lower regional heat flow (Blackwell and Steele, 1983) and lower rates of Quaternary volcanism to areas with higher rates in Oregon and northern California. Therefore, this transect is important for developing a comprehensive model for the Cascades as a whole.

Conclusions

The Santiam Pass and Breitenbush areas are the best sites for the first phase of a scientific drilling program in the Cascade Range. 
The Breitenbush area has a known hydrothermal convection system, high background heat flow, and a large existing data base for siting drill holes. Sunedco Well No. 58-28, the $2.5-\mathrm{km}$-deep drill hole near Breitenbush Hot Springs, offers an unique opportunity to sample the hydrothermal system and to reach very great depths at relatively low cost. Deepening the hole could definitively test whether the regional heat-flow anomaly persists to great depth. The best site to characterize the background heat flow for much of the Quaternary volcanic arc is the Santiam Pass site. This area is accessible and has a good geologic. data base, a well-defined volcanic axis, and abundant mafic volcanism typical of the southern and central part of Quaternary volcanic arc.

In future years, scientific drilling should be accomplished in the southern Washington Cascades, the Century Drive-Willamette Pass area, and the Mount Shasta area in order to develop a comprehensive thermal and geologic model of the Cascade Range. It would also be useful to link up an east-west transect across the Cascades to a similar transect across Newberry or Medicine Lake volcano to examine the interrelationship between one of these basaltic-silicic volcanic centers and the main Cascade arc.

The first phases of drilling should lead to selection of a site for an ultradeep hole. Drilling to depths of $7-10 \mathrm{~km}$ will be necessary to investigate deep magmatic and metamorphic processes related to the regional heat-flow anomaly. 


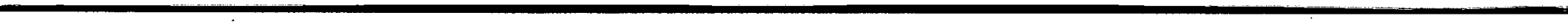




\section{OBJECTIVES AND PRIORITIES OF THE PROGRAM}

\section{INTRODUCTION}

The overall objective of the program is to characterize the mass- and energy-transfer processes in subduction-related volcanic arcs. The Cascade Range, which is the most accessible and well-studied arc of this type in the United States, is a logical place to focus a national continental scientific drilling program.

\section{LONG-TERM OBJECTIVES}

The program of scientific drilling outlined here will contribute to resolution of the following major scientific issues:

1. Estimate background heat flow in the High Cascades. As previously explained, the highest priority objective of the program is to determine the magnitude of the regional heat-flow anomaly in the High Cascades. The bulk of the Quaternary volcanic rock in the Cascade Range is basalt or basaltic andesite, but this type of volcanism is concentrated mainly in the central and southern part of the arc (White and McBirney, 1978). The highest initial priority will therefore be to establish the regional background heat flow in a part of the arc characterized by basalt and basaltic andesite.

2. Investigate the heat source for the Cascade heat-flow anomaly. A regional zone of high heat flow occurs throughout the length of the Cascade volcanic arc (Figure 2) (Blackwell and Steele, 1983). The heat-flow anomaly in the Cascades in Oregon may be caused by conduction of heat from a zone of high-temperature $\left(600^{\circ}-800^{\circ} \mathrm{C}\right)$ rock at a depth of 7-10 km (Figure 5) (Blackwell and others, 1978, 1982b). Alternatively, the heat-flow anomaly could be caused by regional fluid circulation from a heat source possibly deeper or narrower than proposed by these workers. The former hypothesis could be proven if heat flow in a deep drill hole in the anomaly remained consistently high $\left(100 \mathrm{mWm}^{-2}\right)$ down to $7-10 \mathrm{~km}$. The latter hypothesis predicts that there will be a marked decrease of the heat flow at less than 7-10 $\mathrm{km}$. The former case would be consistent with a regional zone of magma accumulation at 7-10 km (Figure 6), and the latter case would be consistent with regional circulation of high-temperature geothermal fluids at depths shallower than 7-10 $\mathrm{km}$. 
3. Characterize regional hydrothermal circulation. Most known hydrothermal systems in the Oregon part of the Cascade volcanic arc are located on the eastern edge of the Western Cascades and are not obviously related to individual High Cascade volcanic centers. This observation may imply that there is a regional hydrothermal circulation system (Blackwell and others, 1978, 1982b; Priest, 1983). PreQuaternary strata in many areas of the Western Cascades dip easterly under the High Cascades (Wells and Peck, 1961; Peck and others, 1964). Does meteoric water percolate downward in the High Cascades and rise along permeable east-dipping strata into the Western Cascades? What chemical changes occur in the ascending thermal fluid, and how rapidly does it cool? What water-rock reactions occur? These questions can be answered by sampling fluids and rocks from a series of drill holes in known hydrothermal systems in the Western Cascades and in deep $(>2 \mathrm{~km})$ holes in the High Cascades.

4. Determine the relationship between the rate and direction of plate convergence and the rate of volcanism. Volumes of radiometrically dated volcanic rocks found by drilling, mapping, and geophysical sounding will give estimates of volcanic rate. These rate data can be compared to the history of subduction of the Juan de Fuca Plate to develop a quantitative relationship. The rate of volcanism can best be measured by detailed study of an arc segment that is (1) accessible; (2) lithologically representative; (3) not dominated by one or two anomalously large, long-lived volcanoes; and (4) shoreward from the part of the Juan de Fuca Plate with the best-known, least-complex history of subduction.

5. Develop a comprehensive model of the relationship between plate convergence rate and rate of volcanism and heat flow. This objective can be achieved only by comparing rates of heat flow and rolcanism between areas having widely differing rates and directions of plate convergence. Where the angle of the plate-convergence vector relative to the plate boundary is the same, is there a linear relationship between the rate of convergence and the rate of volcanism and heat flow? The rate of convergence has decreased over the last $40 \mathrm{~m} . \mathrm{y}$. (Riddihough, 1977, 1984; Engebretson, 1982), and the overall rate of volcanic activity in the Cascades also appears to have decreased with time (Verplanck and Duncan, 1984). How does varying the angle of convergence at constant convergence rate affect magma production? For example, the direction of movement of the Juan de Fuca Plate in Washington is nearly perpendicular to the continental margin, whereas oblique convergence occurs at a very similar rate in Oregon (Figure 1) (Riddihough, 1984). The rather modest rate of Quaternary volcanism and heat flow in the Washington Cascades compared to the Cascades in central Oregon (White and McBirney, 1978; Blackwell and Steele, 1983) suggests that the angle of convergence is an important factor (Muffler and others, 1982a; Rogers, 1985; Weaver and Michaelson, 1985). 
6. Determine if there is a causal relationship between the histories of magma genesis, deformation, and subduction. Changes in the configuration and convergence rate of the plates may be reflected in changes of stress and strain transmitted to the volcanic arc. Sharp decreases in the rate of convergence of the plates will probably cause relaxation of compressional stress in the overriding continental plate. Easier egress of magma to the surface may result in less differentiation and thus more basaltic volcanism perhaps associated with episodes of normal faulting. If it could be demonstrated that decreases in convergence rate correlate with major episodes of normal faulting and basaltic volcanism, this hypothesis would be supported. Reconstructions of the history of plate interactions between the Juan de Fuca and North American Plates support the occurrence of sharp decreases in the rate of plate convergence (Riddihough, 1977, 1984; Engebretson, 1982). Regional episodes of basaltic volcanism that are roughly contemporaneous with these decreases in convergence rate have also been reported (e.g. Waters, 1962; Peck and others, 1964; White and McBirney, 1978; Priest and others, 1982b, 1983c; Wells and others, 1984). The overall rate of volcanism appears to have decreased contemporaneously with the decrease in rate of plate convergence (Verplanck and Duncan, 1987) However, much more work needs to be done on the stratigraphy of the Cascade Range and the Juan de Fuca Plate before these correlations can be demonstrated conclusively.

7. Determine the stress regime of the volcanic arc. How is the anomalously hot crust of the arc responding to regional tectonic forces? What can the stress regime tell us about the transfer of stress between the plates? The higher seismic activity associated with the northern part of the Cascade Range compared to areas farther south (Dehlinger and others, 1970) has allowed partial determination of the crustal-stress regime in the Mount St. Helens and Mount Hood areas from focalmechanism studies (e.g., Weaver and others, 1982; Grant and others, 1984). Phase I studies should focus on filling in the picture in the Cascade Range farther south with in-situ stress measurements. At present there are essentially no high-quality measurements of stress direction in the central and southern Cascade Range, although volcanic vent alignments suggest a north-south orientation for the maximum compressive stress axis (Zoback and Zoback, in preparation).

It is not now known how the Cascade arc responds to regional tectonic stresses generated at the plate boundaries. The southern part of the arc bounds the normal-faulted terrain of the Basin and Range Province. How does the stress regime vary across the Cascades? Does the direction of maximum compressive stress change direction? Is weakening of the crust by magmatic heating a factor? Measurement of in-situ stress both within and outside of the Cascade heat-flow anomaly will help to answer these questions. 
8. Determine the current configuration of the subducted oceanic plate. The subducted oceanic plate may affect the distribution of heat flow, Quaternary volcanism, and Quaternary deformation. If the configuration of the subducted plate can be defined, then systematic geometric relationships between the plate and these phenomena can be sought. For example, the western limit of the active High Cascade volcanic belt ends abruptly on a north-northeast-trending line. How deep is the subducted plate at this line? What is the significance of this depth in terms of magma generation and mantle dynamics? What is the dip on the subducted plate beneath the central Cascades? Is there, as postulated by Weaver and Michaelson (1985), a tear or wrinkle in the subducted slab between a low-dipping slab in Washington and a more steeply dipping slab in central Oregon? Is the slab fragmented under central Oregon (Weaver and Michaelson, 1985)? Can these factors account for the fact that the rates of volcanism and regional heat flow in the Cascade Range of Oregon are higher than those in Washington? Geophysical surveys may help to resolve these questions by locating the subducted slab and examining the velocity structure in the crust and upper mantle. Active techniques such as seismic refraction will be necessary, because much of the Cascade Range is essentially aseismic.

\section{PRIORITIZED OBJECTIVES OF PHASE I}

\section{Drilling objectives}

The principal drilling objective of Phase $I$ is to determine the thermal regime of a part of the Cascade Range characterized by mafic Quaternary volcanism typical of the southern and central part of the volcanic arc. The most important objective is to penetrate below the so-called "rain curtain" effect in order to determine the regional background heat flow in the High Cascades. The next most important objective is to test the depth behavior of high-temperature gradients associated with the regional heat-flow anomaly. The third-priority objective is to sample and characterize hydrothermal fluids and associated water-rock reactions in both the Western Cascades and High Cascades. The fourth-priority objective is to integrate the drill-hole data with geological and geophysical surveys in order to develop a threedimensional model of crust and upper mantle, including the state of crustal stress.

\section{Studies that enhance the drilling program}

In-situ stress measurements. The principal objective of the insitu stress measurements is to obtain an east-west profile of the state of crustal stress from the coast to the volcanic arc to see how the arc is responding to regional tectonic forces. The second-priority objective is to establish the hydrofracturing characteristics of Cascade volcanic rocks for possible hot dry rock applications.

Geologic and petrologic studies.

1. Geologic mapping. The principal objective of the geologic mapping is to complete $1: 62,500$-scale geologic mapping 
across an east-west transect of the Cascade Range in order to reconstruct the geologic history of the central part of the volcanic arc.

2. Petrochemical studies. The most important goal of the petrochemical studies to define magma sources and magma evolution. The studies will also support the geologic mapping by providing chemical and isotopic data for correlations and age estimates. Magma supply rate and rates of eruption will be estimated from the mapped volume of radiometrically dated volcanic units.

Hydrothermal-alteration studies. The most important objective of this task is to determine the history of metamorphism, especially episodes of hydrothermal alteration, in the drill holes and outcrops in the study areas. The secondary goal is to investigate mineralization processes under epizonal and mesozonal conditions.

Gas and hydrogeochemical surveys. The chief goal of these surveys is to develop quantitative reaction-path models for the evolution of hydrothermal fluids and gases in the study areas. The secondary goal is to estimate the ages of hydrothermal fluids and gases. The thirdpriority goal is to utilize chemical analysis of soils, springs, and lakes in the study areas to explore for areas with currently active hydrothermal systems.

Drill-site geophysical surveys. The principal objective of local geophysical surveys near drill sites is to utilize geophysical models calibrated to physical measurements in the drill holes to determine upper crustal structure and the possible thickness and lateral continuity of various units, including hydrothermal aquifers. The secondary goal of the geophysical surveys is to determine if the anomalously high chloride content of Blue Lake is caused by an active hydrothermal system (Johnson and others, 1985). This will require a heat-flow survey of the lake bottom.

Regional seismic experiment. The principal objective of the regional seismic survey is to locate the subducted oceanic plate in the central Oregon Cascade Range. Geometric relationships between the subducted plate and the pattern of heat flow, crustal deformation, and volcanism can then be determined. The second-priority objective is to test for zones of partially or totally molten rock in the crust and upper mantle.

Paleomagnetic study. The principal objective of the paleomagnetic study is to establish how much rotation of major crustal blocks has occurred in the Oregon Cascade Range through time. Comparison of these data to data on the timing and magnitude of major extensional events such as Basin and Range extension and formation of arc-parallel -grabens in the Cascade Range will test causal relationships. The second-priority objective is to utilize paleomagnetic stratigraphy to aid in correlation and dating of rock units. 


\section{PRIORITIZED OBJECTIVES OF PHASE II}

\section{Drilling objectives}

The principal drilling objective is to determine how the thermal regime in the Cascades varies along the length of the volcanic arc and how this thermal regime correlates to variations in the geology. The next most important objective is to characterize hydrothermal fluids and alteration in the High Cascades. The third-priority objective is to integrate the drill-hole data with additional studies on in-situ stress, geophysics, and geologic mapping.

\section{Studies that enhance the drilling program}

In-situ stress. The principal objective of the in-situ stress measurements is to establish how the state of crustal stress varies along the length of the volcanic arc to see how the arc is responding to regional tectonic forces. The second-priority objective is to examine the hydrofracturing properties of volcanic rocks for hot dry rock applications.

Geologic mapping. The principal objective of the geologic mapping is to complete enough $1: 62,500$-scale geologic maps to reconstruct the geologic history of the volcanic arc as a whole.

Local geophysical surveys. The principal objective of local geophysical surveys near drill sites is to determine the shallow crustal structure from geophysical models calibrated to physical measurements in the drill holes. This will allow stratigraphic units identified in the holes to be extrapolated laterally to structural discontinuities such as faults or unconformities. In some areas, such as the Century Drive area near South Sister, it may also be possible to test for the presence of shallow silicic magma bodies.

\section{PRIORITIZED OBJECTIVES OF PHASE III}

The principal objective is to directly sample rocks and fluids from depths of 7-10 $\mathrm{km}$ in order to characterize magmatic and metamorphic processes active there. According to the preferred heat-flow model of Blackwell and others (1982b) and to Curie-point isotherm studies (Connard, 1980; McLain, 1981; Connard and others, 1983; Foote, 1986), temperatures of $600^{\circ}-800{ }^{\circ} \mathrm{C}$ should be present at these depths under the main part of the Cascade heat-flow anomaly in Oregon. This temperature is high enough to initiate granulite-facies metamorphic processes and partial melting in hydrous silicic rocks. Determination of the composition of deep metamorphic fluids should be possible by downhole sampling. If experiments can be designed, this hole may offer an opportunity to observe the mode of formation of partial melts. These experiments might determine whether magma at high pressures and low percentages of melting forms a thin interlocking film of liquid throughout the melt zone or tends to congregate into discrete masses. Solution of this problem will help to characterize the dynamics of partial melting and magmatic intrusion. 
PHASE I - IMPLEMENTATION.

\section{INTRODUCTION}

Phase I will be implemented by drilling and surface geological and geophysical surveys in the central Cascade Range, Oregon. The studies will be focused on the Breitenbush Hot Springs area and on an east-west transect across the Cascade Range at the latitude of Santiam Pass.

TASK 1 - DRII FOUR 1.2-KM-DEEP HOLES, SANTIAM PASS AREA

\section{Objectives}

Four 1.2-km-deep diamond core holes will be drilled primarily to establish the magnitude of the background heat flow in the High Cascades at Santiam Pass. When combined with geologic map data, the results will allow comparison of the background heat flow with the amount and type of surface volcanism. Lithologic analysis of the drill core and geophysical measurements in the holes will allow characterization of major stratigraphic units, which will help in mapping the structure of the area. If stratigraphic units that have distinctive geophysical signatures can be identified, then surface surveys might be used to map the subsurface extent of these units so that faults and unconformities can be identified.

\section{Background}

Santiam Pass is an area of abundant Pleistocene to Holocene volcanism in the High Cascades of Oregon (Figures 3 and 7 , folded, separate sheet). The area is dominated by basalt and basaltic andesite volcanism, although local andesitic vents are also present (Figure 7, folded, separate sheet). The youngest units are basalt and basaltic andesite flows and pyroclastic rocks that were vented between about 2,000 and 3,500 years ago (Taylor, 1980, 1981). Holocene vents are located on the east flank of the High Cascades at Blue Lake and on the west flank of the range in the Sand Mountain area (Figure 7). Mafic Holocene vents on the west flank of the range are aligned north-south and northwest-southeast (Figure 7).

The High Cascades at this latitude lie in a north-south-trending graben bounded on the east by the Green Ridge faults (Hales, 1975; Taylor, 1980, 1981; Conrey, 1985) and on the west by faults bounding the eastern margin of the Western Cascades (Figure 7) (Avramenko, 1981; Black and others, 1987). These faults probably formed between 
about 3 and 5 million years before the present (Ma) (Taylor, 1980, 1981; Black and others, 1987). Only the outermost faults of the graben are exposed. The north-south-trending Holocene vent alignments suggest that additional faults probably occur in the interior of the graben (Taylor, 1980, 1981). The fact that Holocene eruptions with significantly different ages have occurred on the same vent alignments supports the concept that the vents are controlled by buried faults rather than fissure systems aligned parallel to the maximum compressive stress axis (Taylor, personal communication, 1985). Correlation of units from drill holes to units in the bounding blocks at Green Ridge and in the Western Cascades will constrain the amount of offset on the grabenbounding faults.

Shallow heat-flow measurements in the Sand Mountain area and at Green Ridge were not very successful in outlining the regional background heat flow. Only one hole at Green Ridge had a reasonably linear, conductive gradient. The heat flow for this 152-m-deep hole (101 $\mathrm{mWm}^{-2}$, Black and others, 1983) may not be a good indication of the regional background heat flow in this area, because the hole is located on a fault scarp, an area that may have extensive fluid convection. Convective effects of a slightly thermal $\left(25^{\circ} \mathrm{C}\right.$ ) aquifer in a 557-m-deep hole (13S/7E-32D) in the Sand Mountain area are clearly evident in the temperature-depth curve (Figure 8) (Youngquist, 1980; Blackwell and others, 1981). The upper part of the hole has a heat flow of about 103 $\mathrm{mWm}^{-2}$, whereas the lower part has an anomalously low gradient and heat flow compared to conductive values for the region (Figure 8) (Black and others, 1982, 1983). Measurements in deeper holes are clearly necessary in both areas to determine the background conductive heat flow. Likewise, there are no data between these two holes in the main area of Quaternary volcanism. Drilling in the High Cascades to the north and at Newberry volcano indicates that relatively conductive temperature gradients can normally be expected in Quatemary volcanic rocks below about 150 and $1,000 \mathrm{~m}$, respectively $(\mathrm{e} . \mathrm{g} .$, hole EWEB-SB of Black and others, 1982, 1983; and hole $\mathrm{N}-1$ of Woller and others, 1986). Therefore, drilling to depths of about $1,000-1,200 \mathrm{~m}$ will be necessary to be sure of getting through the "rain curtain" effect in the High Cascades.

There is little information on hydrothermal fluids in the Santiam Pass area. Hydrothermal fluids are present there, however. The previously mentioned hole (13S/7E-32D) encountered an aquifer containing low-temperature thermal fluids. Blue Lake, a Holocene explosion crater, has an anomalously high chloride content relative to other High Cascade lakes in Oregon (Johnson and others, 1985). Therefore, holes in either area have a chance of encountering thermal fluids that might be sampled.

\section{Drilling/coring program}

In order to achieve the primary objective of measuring the regional background heat flow across the High Cascades, it will be necessary to drill at least four $1.2-\mathrm{km}$-deep holes in an east-west pattern, with one hole on the west side of the volcanic axis (here taken to be coincident with the drainage divide), one hole at or near the volcanic axis, and two holes on the east flank. Previous experience in drilling the Quaternary volcanic rocks in this region indicates that 
diamond coring is the most cost-effective technique for temperaturegradient holes in this depth range. Diamond coring is less hampered than conventional rotary drilling by lost circulation zones, which are common in these rocks. Diamond cores will also yield superior lithologic and structural data that are important for the secondary objectives of the study. In addition, core holes offer optimum borehole wall quality for in-situ stress determinations by hydraulic fracturing techniques, should these be conducted.

A site survey will be initiated during the first field season to locate drill sites that strike the best balance between environmentallogistical concerns and scientlfic suitability. Sites will be picked with the help and cooperation of federal, state, and county regulatory agencies. About one year of site selection and permitting is anticipated before drilling can begin. The coring program will be conducted for all four holes in the following manner (see Figure 9):

1. Prepare site with $1.2-$ by $1.8-\mathrm{m}$ cellar with cement floor.

2. Excavate sump and prepare water-supply system.

3. Mobilize rig and rig up.

4. Drill a $20-\mathrm{cm}$ hole to $30.5 \mathrm{~m}$ and set $16.8-\mathrm{cm}$ conductor casing.

5. Drill $P Q(11.7 \mathrm{~cm})$ to $122-152 \mathrm{~m}$.

6. Ream to $15.2 \mathrm{~cm}$ and set $11.4-\mathrm{cm}$ casing.

7. Drill $\mathrm{HQ}$ to $1.2 \mathrm{~km}$.

8. Run full suite of logs.

9. Air lift any deep aquifers and take downhole-fluid samples of aquifers.

10. Run vertical seismic profile survey.

11. Set 5.1-cm pipe (water-filled, capped, and surrounded by heary mud).

12. Demobilize rig.

13. Monitor temperatures over the following year.

14. Pull pipe and abandon; cement any aquifers and put in $15-\mathrm{m}-$ long surface plug.

15. Restore site.

Statement of work

Planning and coordination. The drilling program will be planned and executed by close coordination between the Interagency Coordinating Committee, Steering Committee, Project Coordinator, Chief Engineer, and participating investigators. Several planning and coordination meetings will be held during the period between funding and the initiation of drilling. These meetings will serve to review progress reports on the various work components and to assign new work. Additional details on the management structure for the program are given in the section on project management.

Site-selection studies. As a minimum, site selection will include the following studies of the High Cascades at the latitude of Santiam Pass:

1. Review of all published and unpublished geological, geophysical, geochemical, and hydrological data.

2. Isotopic dating of rock units as necessary. 
3. Publication of geologic maps of the Three-Fingered Jack and Sisters $15^{\prime}$ topographic quadrangles at a scale of $1: 62,500$. These maps will be compiled from existing unpublished field data of Edward $M$. Taylor, OSU.

The following optional studies should be done in advance of drilling to maximize the potential for meeting the secondary geologic and hydrologic objectives:

1. Heat-flow and geochemical surveys of Blue Lake (see relevant parts of Tasks 8 and 9 , below).

2. Detailed gravity, resistivity, seismic, and soil geochemical surveys (see relevant parts of Tasks 8 and 9 , below).

3. Drilling of a shallow hole to intersect and sample the thermal aquifer known to exist at the site of hole 13S/7E-32D (Figure 8; also relevant part of Task 8 ).

Permits. The necessary permits and land-access agreements for drilling of the holes will be completed. This task includes establishing safety requirements, preparing environmental impact statements, and securing permits from designated state and federal agencies.

Contracting. Specifications for the drilling operation will be established, and requests for bids will be prepared and released to the public. Responses to procurements will be reviewed by the contracting agency. A contract will be negotiated and signed with the successful bidder.

Drilling. Four diamond core holes will be drilled as described in the coring program above. During drilling, the Chief Engineer will maintain a staff on the rig. In addition, a team of scientists will be present to monitor collection of samples and to ensure proper documentation of the samples.

Preliminary examination. A specific set of scientific needs is required during and soon after the coring program. These needs include lithologic and geophysical logging, hydrothermal-alteration studies, and fluid and gas sampling. These tasks are considered the minimum necessary to obtain essential data from the holes. This information is critical for investigators wishing to do more exhaustive, detailed studies at a later time:

1. Lithologic logging. Lithologic logging by knowledgeable geologists at the site is required for basic documentation and characterization. This descriptive process is needed to provide (1) background for studies associated with the drilling process, such as geophysical logging and fluid sampling, and (2) documentation required for the curation process. The lithologic log is the most basic piece of data and will be widely circulated.

2. Geophysical logging. A full suite of geophysical logs will be run on the holes. The following logs are proposed: tions).

a. Caliper (measure borehole size for condition and log correc-

b. Natural gamma ray (lithology determination).

c. Spectral gamma ray (identification of fluid movement and zones of anomalous concentrations of radioactive elements; lithology determination).

d. Thermal and epithermal neutron (identification of zones of 
bound water and porosity).

e. Density (lithology determination, calibration of surface gravity and seismic surveys).

f. Temperature (temperature gradient necessary for heat-flow calculations).

g. Spinner (utilized only in case of evidence of major thermal

fluid entries to locate and evaluate flowing aquifers).

h. Directional survey (well orientation).

i. Sonic travel time and wave form (sonic velocity of wall rocks for seismic modeling, location of fractures, and calibration of surface seismic and gravity surveys).

j. Vertical seismic profile (seismic velocities and reflection characteristics of the crust in and below the drill hole).

k. Resistance (calibrate surface surveys for in-situ resistance).

All logs will be acquired in analog and digital form. All will be calibrated immediately before and after logging, and a 60-m repeat run will be acquired. Copies of all logs will be filed with Petroleum Information Service, Denver, Colorado, where interested researchers may obtain them for reproduction costs only.

3. Hydrothermal alteration studies. Following the lithologic logging, selected samples will be analyzed by $X$-ray diffraction and petrographic techniques in order to characterize the hydrothermal alteration assemblages. This initial study will not be exhaustive but will provide needed background for the interpretation of geophysical logs and the design of fluid-sampling programs. In addition, the results will provide information that can be distributed to other researchers to allow them to develop research proposals for more detailed work.

4. Fluid and gas sampling. It is unlikely that these holes will penetrate high-temperature $\left(>150^{\circ} \mathrm{C}\right)$ artesian fluids, so fluid and gas samples will probably be obtained by downhole sampling and air lifting. Gas samples will be collected with both flow-through and caustic-sodatype gas bottles. This task will be done only if there is evidence that significant thermal fluid entries have been encountered. The thermalfluid zones will be isolated for sampling using packers as necessary.

All water samples will be analyzed for major-, minor-, and traceelement chemistry, stable isotopes of oxygen and hydrogen, $13 \mathrm{C},{ }^{34} \mathrm{~s}$ isotopes, and tritium. All gas samples will be analyzed for bulk composition; gas/steam ratio; and ${ }^{36} \mathrm{Cl},{ }^{13} \mathrm{C},{ }^{18} \mathrm{O}$, and ${ }^{2} \mathrm{H}$ isotopes of appropriate gas species. Samples for more specialized analytical work will be provided to interested investigators.

5. Heat-flow analysis. Thermal conductivities will be measured on all lithologic units. Temperature-depth data will be corrected for terrain effects. Heat flow as a function of depth will be calculated from the temperature and conductivity data for each hole.

6. Information dissemination. The data will be made available to the scientific community as rapidly as possible to encourage widespread use of the data and to stimulate submission of proposals for work on the holes. The data will be disseminated by oral presentations at appropriate public meetings and as reports through DOGAMI, the USGS, and participating national laboratories. The Chief Scientist will be responsible for ensuring that information is disseminated promptly (see the Management Plan chapter).

7. Curation. Curation will be accomplished utilizing standard 
methods established by USDOE (Goff, 1986). Curation will be the responsibility of the Project Curator (see description of the responsibilities of the Sample Curator in the Management Plan). Core and fluid samples collected during this program will be temporarily curated at a facility conveniently close to the drill sites. Initial sample dissemination, core photography, and measurements of density and electrical resistance of all rock units will occur at this site. Permanent storage of core will be at an appropriate USDOE repository.

\section{TASK 2 - DRII ONE 2.7-KM-DEEP HOLE, SANTIAM PASS AREA}

\section{Objectives}

The chief objective of this hole is to sample deep thermal fluids and rocks from the High Cascades. Temperature-gradient data from the 2.7-km-deep hole will also serve to evaluate the quality of the data from the 1.2-km-deep holes with respect to regional heat-flow measurement and temperature gradient at depth. For instance, if the temperature gradient in one of the $1.2-\mathrm{km}$-deep holes is being raised by upwardconvecting hydrothermal fluids at 1.2 to $2.7 \mathrm{~km}$, the temperature $\log$ of the 2.7-km-deep hole will reflect this upflow. If one of the $1.2-\mathrm{km}-$ deep holes has anomalously high heat flow relative to the other three holes, the deeper hole will be sited nearby.

The secondary objective of this hole is to sample rock units that can be used for stratigraphic correlation. This hole may go through a significant part of the pre-Quaternary volcanic pile (see cross section of Figure 7, folded, separate sheet). Information on deep lithology will increase the likelihood of correlations to pre-Quaternary rocks in uplifted fault blocks on both sides of the High Cascades graben (see background section of Task 1 ).

\section{Background}

There are no moderately deep drill holes in the High Cascades that are not in composite cones of andesitic or dacitic composition. No deep hydrothermal fluids have been sampled from the vast areas of basalt to basaltic andesite shield volcanoes that lie between the isolated composite cones in the central and southern High Cascades. The proposed hole will be the first opportunity to penetrate one of these areas deeply enough to be sure of sampling relatively hot fluids and gases. Core from the hole will allow evaluation of potential reservoir rocks for hydrothermal resources. The hole will therefore be the first definitive test of the geothermal potential of the High Cascade mafic rolcanic fields.

As previously mentioned (Task 1), the holes in the Santiam Pass area will be able to penetrate a major graben that has displaced pre-3m.y.-old rocks downward to an unknown depth. If the displacement on the graben is to be determined, rocks older than the the graben must be penetrated to establish correlations to upthrown blocks to the west and east. If there is relatively little downward displacement on interior faults within the graben, then the 1.2-km-deep holes may penetrate deeply into pre-graben rocks (see cross section, Figure 7 , folded, separate sheet). If there are large displacements in the interior of the 
graben, then only the 2.7-km-deep hole may reach into pre-graben rocks.

\section{Drilling/coring program}

Core drilling is not necessary in the upper part of this well, because lithologic data will be available from an adjacent $1.2-\mathrm{km}$-deep hole of Task 1. The upper $1.2 \mathrm{~km}$ of the hole can therefore be rotary drilled. This technique will ensure a large-diameter hole in the upper, least-stable part of the hole, so that coring can begin at the H-size at a depth of $1.2 \mathrm{~km}$. The hole will then be continuously cored to from 1.2 to $2.7 \mathrm{~km}$. Because the top section of the hole is to be rotary drilled, two alternate strategies are possible:

1. Use a small rotary rig to drill to $1.2 \mathrm{~km}$, demobilize, and use a large-core rig to do the $1.8 \mathrm{~km}$ of coring in the lower part of the hole.

2. Select a large-core rig that has rotary capability for the upper $1.2 \mathrm{~km}$ and coring capability for the lower $1.8 \mathrm{~km}$.

A detailed technical (and cost) trade-off analysis is necessary to select from these two options. Therefore, only a selection sequence outline is provided here for option 2 above (see also Figure 10):

1. Establish water supply at site.

2. Prepare site with sump and cellar.

3. Mobilize rig and rig up.

4. Set $30.7-\mathrm{cm}$ surface conductor to $30.5 \mathrm{~m}$ in a $31.1-\mathrm{cm}$ hole.

5. Drill a $20-\mathrm{cm}$ hole to $1.2 \mathrm{~km}$.

6. Set $11.4-\mathrm{cm}$ protective casing to $1.2 \mathrm{~km}$.

7. Clean hole and switch over to core drilling.

8. Diamond core $\mathrm{H}$-size to $2.7 \mathrm{~km}$. Be prepared to conduct drill-stem testing, air lifting, or swabbing should major thermal aquifers be encountered.

9. Run full suite of logs.

10. Air lift the hole and take fluid samples.

11. Run vertical seismic profile survey,

12. Set $5.1-\mathrm{cm}$ pipe, capped, filled with water, and surrounded with heavy mud.

13. Rig down and demobilize rig.

14. Conduct sequential temperature logs for the following year.

15. Plug and abandon, pulling pipe, cementing major aquifers, and setting a 15-m-deep surface plug.

16. Restore site.

\section{Statement of work}

Planning and Coordination. Planning and coordination will be accomplished as in Task 1 .

Permits. Permits from the appropriate state, county, and federal agencies will be obtained. The need for extensive fluid sampling at the site and the need for a water source will require a large holding pond and possible temporary water rights for a water well or surface water source. The greater degree of site disturbance necessitated by this drilling operation relative to that of Task 1 may require additional 
environmental-impact analysis.

Contracting. Contracting will be accomplished as in Task 1.

Drilling. A 2.7-km-deep hole will be drilled, as described in the drilling/coring program above. During drilling, the Chief Engineer will maintain a staff on the rig. In addition, a team of scientists will be present to monitor collection of samples and to ensure proper documentation of the samples.

Preliminary examination. As described in the Statement of Work in Task 1, the preliminary examination will include lithologic and geophysical logging, hydrothermal alteration studies, fluid and gas sampling, paleomagnetic measurements, and state-of-stress measurements.

Information dissemination. Data from the well will be made available to the public as quickly as possible through oral presentations and published reports.

Curation. Sample curation will be handled as in Task 1.

TASK 3 - DRTL ONE 2.0-KM-DEEP HOLE, BREITENBUSH AREA

\section{Objectives}

The major objective of this hole is to test a theoretical model of the hydrothermal system at Breitenbush Hot Springs in the Western Cascades of Oregon. The model predicts that the hydrothermal aquifer ascends in a discrete stratigraphic unit from source areas in the High Cascades southeast of the hot springs. It is assumed that the hydrothermal fluid cools and changes chemical composition as it ascends to the surface, although there are insufficient constraints on the proposed model to predict the magnitude of these changes. Penetrating the aquifer at a predicted depth of $1.8 \mathrm{~km}$ will test the validity of the model. Determination of the temperature and composition of the fluid will put constraints on the physiochemical changes that occur as the aquifer ascends to the hot springs. If, as predicted by the model, the same aquifer occurs at a depth of about $789 \mathrm{~m}$ in Sunedco Well No. 58-28, then fluid samples and temperatures from that well can be used to further constrain the physical and chemical dynamics of the hydrothermal system (see Task 4).

The secondary objective is to evaluate the structural model for the area. The model predicts a $10^{\circ}$ southeasterly dip for the stratigraphic sequence.

\section{Background}

The Breitenbush Hot Springs area lies on the eastern edge of the Western Cascades (Figure 3). The area has been the focus of extensive research by government and industry. Several geologic maps of the area are available (Thayer, 1936; Clayton, 1976; White, 1980a,b; Hammond and others, 1982), and a detailed map of the area is in the final stages of completion by DOGAMI (Priest and others, 1987). A generalized version of this latter map is presented in Figure 11 (folded, 
separate sheet)., Several detailed geophysical surveys have been completed, including gravity (Couch and others, 1981; Couch and others, 1982b), aeromagnetics (Couch and others, 1985), and magnetotellurics (Sunedco Energy and Development Company, unpublished data, 1981). A number of temperature-gradient holes have also been drilled by Sunedco and DOGAMI (Figures 11, 12, and 13). In addition, the hydrothermal system has been penetrated by a $2.5-\mathrm{km}-$ deep geothermal test well drilled by Sunedco in 1981.

The Breitenbush hydrothermal system is, because of the extensive data base, better understood than any other such system in the Western Cascades. The hot springs issue from fractured tholeiitic basalt near the contact with an underlying ash-flow tuff sequence (units Ts and Tbq, respectively, shown in Figure 11). The sequence strikes about N. $20^{\circ}$ E. and dips about $10^{\circ}$ to the southeast (Figure 11) (Priest and others, 1987). Geochemical reservoir temperature estimates for the hot-spring fluid range from about $148^{\circ} \mathrm{C}$ to $190^{\circ} \mathrm{C}$ (Mariner, 1985). Reservoir temperatures estimated by the sulfate-water, anhydrite, and albite-anorthite geothermometers are $176^{\circ} \mathrm{C}, 174{ }^{\circ} \mathrm{C}$, and $190{ }^{\circ} \mathrm{C}$, respectively (Mariner, 1985). Sunedco Well No. 58-28, a 2.5$\mathrm{km}$-deep geothermal well drilled about $3 \mathrm{~km}$ southeast of the hot springs (Figure 11), crossed a hydrothermal aquifer at about $750-790 \mathrm{~m}$ in fractured welded tuff (unpublished $\log$ of $\mathrm{A}$. Waibel, 1980) just below the same tholeiitic lava unit (unit Ts, Figure 11) that occurs at the hot springs. A maximum temperature of about $115^{\circ} \mathrm{C}$ at about $789 \mathrm{~m}$ in the aquifer was measured eight months after drilling (Figure 12) (Blackwell and others, 1986a), but a maximum-reading thermometer (MRT) recorded a temperature of about $136^{\circ} \mathrm{C}$ during drilling (Al Waibel, unpublished data, 1981). It is possible that either the temperature log was low because injected cement caused the thermal fluids to go around the hole at a significant distance or the MRT data were high because of pressure effects (i.e., a leaky pressure vessel) or inaccuracies in the MRT itself. No water sample was taken, so it is not known if this zone represents the same aquifer that issues from the hot springs. However, the similarity of the stratigraphic position of the aquifer in the hole and at the hot springs is permissive evidence.

A temperature-gradient survey recorded (1) high gradients near Sunedco Well No. 58-28, where the aquifer is shallow; (2) relatively low gradients immediately west of the well; (3) and progressively decreasing gradients eastward from the well (Figures 11 and 13). This pattern is typical of a heat source that dips to the east. $A$ line between the aquifer in Well No. 58-28 to the surface expression of the hot springs dips about $10^{\circ}$ to the southeast, subparallel to the predicted dip for the ash-flow tuff sequence. These data are consistent with a stratigraphically controlled hydrothermal system that flows up a brittle, fractured welded tuff from heat sources to the east in the High Cascades. A crude preliminary model of the expected thermal regime is summarized in the cross section of Figure 14. The model is based on downward extrapolation of the temperature-gradient data without terrain corrections, so it is only approximate. Unpublished thermal conductivity data of Blackwell (1986) from Well No. 58-28 were used to constrain the temperature gradients at various stratigraphic levels. The model predicts that the hottest part of the aquifer will be at a depth of about $1.8 \mathrm{~km}$ and will have a temperature of almost $150^{\circ} \mathrm{C}$ at the proposed drill site southeast of Well No. 58-28. The gradient in the upper $150 \mathrm{~m}$ 
of Well No. $58-28$ was about $100{ }^{\circ} \mathrm{C} / \mathrm{km}$ on the thermistor $\log$, yet the gradient increased to about $151^{\circ} \mathrm{C} / \mathrm{km}$ below about $200 \mathrm{~m}$ (Figure 12). If similar increases occur at depth at the sites of the shallow. temperature-gradient holes, then the projected gradients and temperatures shown in Figure 14 may be too low. Also, the $136^{\circ} \mathrm{C}$ temperature obtained in the aquifer during drilling at Well No. 58-28 may be the actual temperature. In this case, higher temperatures than those predicted by downward extrapolation of the shallow temperature data to the projected aquifer might exist.

The best way of testing the proposed model is to drill into the aquifer as far southeast of the hot springs as possible. The site tentatively selected is at sec. 36, T. 9 S., R. 7 E. This site is on a wellmaintained USFS road as far southeast as possible without entering lands classified as wilderness. The site is close to a river for a source of water; it lies in a deeply incised valley, so the target stratigraphic horizon is closer to the surface than elsewhere along the stratigraphic strike; and most of the geologic section in this area is known to be relatively easy to drill. As a result, relatively cheap rotary-drilling methods can be used to reach the aquifer.

\section{Drilling/coring sprogram}

The hole will be drilled with standard air-mud rotary techniques to the projected depth of $1.8-2.0 \mathrm{~km}$ or until there is evidence of a thermal fluid entry in excess of $115{ }^{\circ} \mathrm{C}$ (the temperature of the aquifer in Sunedco Well No. 58-28). A 9-m-long diamond core will then be taken in the aquifer, after which fluids and gases in the aquifer will be sampled. The hole will then be drilled with air-mud rotary techniques to a total depth of about $2.0 \mathrm{~km}$ in order to examine the temperature profile and lithology below the aquifer. Any other aquifers encountered will be cored and sampled as well. The hole will be sequentially logged for temperature over the following year. The drilling program will proceed as follows (see Figure 15):

1. Prepare site with cellar and sump.

2. Mobilize rig and rig up.

3. Set $50.8-\mathrm{cm}$ conductor casing to $30.5 \mathrm{~m}$ in a $56-\mathrm{cm}$ hole.

4. Drill at $31.1 \mathrm{~cm}$ to $183-213 \mathrm{~m}$.

5. Set 21.6- $\mathrm{cm}$ casing.

6. Air rotary drill at $20 \mathrm{~cm}$ to the aquifer at about $1.2-1.5 \mathrm{~km}$.

7. Core the aquifer for $9 \mathrm{~m}$.

8. Air lift and swab a fluid sample. Take downhole sample of fluid and gas.

9. Rotary drill at $20 \mathrm{~cm}$ to $1.8-2.0 \mathrm{~km}$, being prepared to sample and core any major aquifers.

10. Run full suite of geophysical logs.

11. Clean hole.

12. Run vertical seismic profile.

14. Set 5.1-cm pipe, capped, filled with water, and surrounded by heavy mud; monitor temperature over the next year.

15. Plug and abandon after pulling pipe. Cement aquifers and put in 15-m-long surface plug.

16. Restore site. 


\section{Statement of work}

Planning and coordination. Planning and coordination will be accomplished as in Task 1.

Permits. Permits from the appropriate state, county, and federal agencies will be obtained. The need for extensive fluid sampling at the site and the need for a water source will require a large holding pond and possible temporary water rights for a surface water source. The greater degree of site disturbance necessitated by this drilling operation relative to that of Task 1 may require additional environmentalimpact analysis.

Contracting. Contracting will be accomplished as in Task 1 .

Drilling. A 2.0-km-deep hole will be drilled as described in the drilling/coring program above. During drilling, the Chief Engineer will maintain a staff on the rig. In addition, a team of scientists will be present to monitor collection of samples and to ensure proper documentation of the samples.

Preliminary examination. The preliminary examination will include lithologic and geophysical logging, hydrothermal-alteration studies, fluid and gas sampling, and state-of-stress measurements. These tasks will be performed as described in the Statement of Work in Task 1.

Heat-flow analysis. Temperature and thermal conductivity data from all available sources in the area will be utilized to develop a threedimensional heat-flow model of the Breitenbush hydrothermal system.

Information dissemination. Data from the well will be made available to the public as quickly as possible through oral presentations and published reports.

Curation. Sample curation will be handled as in Task 1 .

TASK 4 - TEST AND DEEPEN SUNEDCO WEIL NO. 58-28

Objectives

The principal objective of this task is to determine the vertical extent of high temperature gradients associated with the Cascade heatflow anomaly. If the anomaly is caused by a relatively shallow hydrothermal heat source, the temperature profile of the proposed $4.0-\mathrm{km}$ deep hole should become isothermal or even colder at depth in the upper part of the hole. If the anomaly is caused by a deep-seated heat source, then a relatively linear (allowing for thermal conductivity changes) conductive temperature gradient with uniform heat flow equal to or greater than $100 \mathrm{mWm}^{-2}$ will be observed. A depth of $4.0 \mathrm{~km}$ was chosen in order to stay within the depth limitations of current coredrilling technology. Therefore, this depth may be modified at the actual time of planning the drill hole.

The hole has several secondary objectives. The shallow hydrothermal system penetrated at 780-790 $\mathrm{m}$ in Well No. 58-28 will be sampled, providing data on the nature of the Breitenbush hydrothermal 
system complementary to Task 3 . If deep hydrothermal fluids are encountered, these will be sampled, providing important information on water-rock reactions and fluid circulation at great depths. Rocks from the lower part of the hole may reach pre-Cascade crust. If so, it may be possible to test the hypothesis that the Cascade Range in northern Oregon is built on a relatively young crust relative to areas to the north and south (Hamilton and Myers, 1966; Church and others, 1986). Paleomagnetic measurements on oriented cores from the hole could provide important information on major crustal rotations that have occurred both during and prior to Cascade volcanism. For example, if the deepest stratigraphic units are slices of accreted oceanic crust, the rocks should show large deviations in the direction of remanent magnetic poles from the current pole direction. The hole will also provide a vertical profile of rock stress measurements that will be invaluable for comparison and interpretation of shallower stress measurements in the preceding studies. In addition, hydrofracture data from 3-4 $\mathrm{km}$ depth are critical for evaluation of the hot dry rock resource potential of the volcanic arc. Finally, the $4.0-\mathrm{km}$ profile of physical properties such as electrical conductivity, seismic velocity, and density will help to constrain possible geophysical models of the area.

\section{Background}

The available data base and general geologic-hydrologic setting of the Breitenbush area, particularly the hydrothermal regime, are covered in the background section of Task 3. Sunedco Well No. 58-28 offers an unprecedented opportunity to reach relatively deep crustal levels in the Cascade Range at minimal cost. This well is the deepest drill hole in the Cascade Range in the United States and is located in a particularly good area for scientific drilling aimed at investigating the thermal regime of the Western Cascades. The hole is in the western part of the Cascade heat-flow anomaly in an area where the anomaly is relatively well defined (Figure 2) (Black and others, 1982, 1983). Continuing debate on the significance of this anomaly is centered on whether it is the product of relatively shallow hydrothermal circulation or whether the heat flow originates from a general zone of hot $\left(600^{\circ}-800{ }^{\circ} \mathrm{C}\right)$, magmatically heated crust at depths of 7-10 km (preferred model of Blackwell and others, $1978 ; 1982 b)$. Temperature data from Well No. 58-28 indicate that the anomalous temperature gradient typical of the Cascade heat-flow anomaly continues to depths of at least $2.5 \mathrm{~km}$ (Figure 12) (Priest, 1985a,b). An estimated heat flow can be calculated from the thermal-conductivity (Table 3 ) and temperature data. The minimum conductive gradient, free of the effects of the warm aquifer at $750-780 \mathrm{~m}$, can be estimated from the ambient surface temperature of about $2.5^{\circ} \mathrm{C}$ and the last-recorded (minimum) bottom-hole temperature of $141^{\circ} \mathrm{C}$ (unpublished Pruett Kuster tool data, A. Waibel, written communication, 1985). The resulting gradient is $56.2^{\circ} \mathrm{C} / \mathrm{km}$, giving an estimated heat flow of $126 \mathrm{mWm}^{-2}$ from an estimated average thermal conductivity of about $2.25 \mathrm{Wm}^{-1} \mathrm{~K}^{\circ-1}$. This value is typical of the Cascade heat-flow anomaly (Figure 5). Deepening the hole to $4.0 \mathrm{~km}$ will explore the temperature-gradient anomaly at greater depth. Characteristics of the gradient at depth will be important in constraining various models (see previous section).

Little is known about the deep hydrothermal fluids in the Cascade 
Range. If these fluids reach the surface at all, it is only at the few hot springs along the Western Cascade boundary, where they will have reequilibrated extensively during transport. Aside from the possible geothermal potential, studying the fluid composition and water-rock reactions may shed light on metamorphic processes such as hydrothermal ore deposition that operate in volcanic arcs.

The geologic setting of Well No. 58-28 is also excellent for scientific drilling. The well is in the middle of what has been termed variously the Columbia embayment (Carey, 1958) and the Oregon embayment (Church and others, 1986). This area (Figure 16) is thought to be underlain by young crust relative to areas to the north and south, where Mesozoic and older rocks crop out (Cantwell and others, 1965; Cantwell and Orange, 1965; Hamilton and Myers, 1966). This hypothesis is supported by geophysical data (Cantwell and others, 1965; Cantwell and Orange, 1965), the distribution of outcrops of Mesozoic and older rocks (Hamilton and Myers, 1966), the mafic composition and low incompatible-trace-element content of Cascade volcanic rocks in the embayment (White and McBirney, 1978); and the low ${ }^{206} \mathrm{~Pb} /{ }^{204} \mathrm{~Pb}$ values of galena taken from Cascade mineral deposits in the embayment

(Church and others, 1986). Thus far, the nature of this young crust has remained an enigma, although some of it may have been sampled in the OMF-7A drill hole near Mount Hood (e.g., the Eocene(?) greenstone of Priest and others, 1982a). A calculated density model about $30 \mathrm{~km}$ south of Well No. 58-28 suggests that a 4.0-km-deep drill hole may reach into crustal layers with significantly higher density than the Cascade volcanic pile (Figure 17) (unpublished density model and interpretations of R.W. Couch).

Measurement of the composition and paleomagnetic properties of the pre-Cascade basement rocks may shed light on the growth of the continental margin in the Oregon embayment, as discussed above. If the crust is accreted oceanic basalt, it will have a characteristic lightrare-earth-depleted trace-element pattern and low initial ${ }^{87} \mathrm{Sr} /{ }^{86} \mathrm{Sr}$. Radiometric dates on various mineral phases will yield minimum ages, depending on the sensitivity to post-eruptive metamorphism of the specific isotopic system employed. $\mathrm{K}-\mathrm{Ar},{ }^{40} \mathrm{Ar} /{ }^{38} \mathrm{Ar}, \mathrm{Rb}-\mathrm{Sr}, \mathrm{U}-\mathrm{Pb}$, and fission-track techniques will be utilized as appropriate.

\section{Drilling/coring program}

The drilling program will involve two phases. The first phase will be aimed at reopening Well No. 58-28 and obtaining as much scientific data as possible from the well. This task will entail utilization of a workover rig that can drill out the cement plugs, clean out the well bore, and fish out a temperature probe that was lost in the well in the original operation. The most demanding part of this first phase will be to sample the cased, cemented aquifer at about the 770-m depth. This sampling will require perforation of the casing and acidization of the well bore to remove the cement from the aquifer. A cable-tool rig can then bail the hole until it is clear of all contaminants. The aquifer will then be sampled by air lifting and utilizing a downhole sampling device. The perforated zone will then be recemented. The well will then be prepared for a deep coring rig by setting $11.4-\mathrm{cm}$ casing.

A large-size slim-hole diamond coring rig will then move on site and drill continuous core to $4.0 \mathrm{~km}$. The hole will then be logged and 
cleaned out in order to obtain downhole fluid samples:

The following is a summary of the initial drilling phase (see

Figure 18 for current hole conditions and Figure 19 for proposed work):

1. Relocate wellhead.

2. Clear back fill.

3. Remove cover plate and weld new casing head in place.

4. Excavate and line sump/reserve pit.

5. Mobilize workover rig.

6. Install blow-out preventer.

7. Clean out wellbore plugs (at 0-15.2 $\mathrm{m}$ and 769-845 m).

8. Fish thermistor probe.

9. Run full suite of geophysical logs.

10. Conduct vertical seismic profiling survey.

11. Take sidewall cores of major stratigraphic units (12 from one run of the Gearhart Hard Rock Coring Tool).

12. Bail and air lift hole; get samples of fluid from open-hole areas at $1,227 \mathrm{~m}, 1,731 \mathrm{~m}$, and $2,233 \mathrm{~m}$.

13. Set packer near the end of casing at about $792 \mathrm{~m}$ and perforate, acidize, and bail (utilizing a cable tool rig) the cemented and cased aquifer at $762-774 \mathrm{~m}$.

14. Take downhole fluid sample at the thermal aquifer.

15. Recement the aquifer and clean the hole.

16. Set 11.4-cm casing to $2.5 \mathrm{~km}$ and cement bottom $61 \mathrm{~m}$.

17. Demobilize drill rig.

The second stage of the operation will proceed as follows:

1. Change out wellhead and blowout preventer; clean sump.

2. Mobilize large-size diamond core rig.

3. Continuous core at $\mathrm{H}-\mathrm{size}(9.6 \mathrm{~cm})$ from 2.5 to about $3.2 \mathrm{~km}$.

4. Take $3 \mathrm{~m}$ of oriented core.

5. Continuous core at $\mathrm{H}$-size $(9.6 \mathrm{~cm})$ to about $4.0 \mathrm{~km}$ and take a 3-m-long oriented core.

6. Run full suite of geophysical logs.

7. Bail or lift hole until uncontaminated fluid samples can be taken with a downhole sampler.

8. Conduct vertical seismic profiling survey.

9. Set 5-cm-diameter pipe with bottom cap that is filled with water and surrounded by heavy mud.

10. Demobilize rig.

11. Take temperature logs during the next year.

12. Pull 5-cm pipe.

13. Plug aquifers and put in a 15-m-deep surface plug.

14. Cut off well head, weld cover plate, backfill, and restore site.

\section{Statement of work}

Planning and Coordination. Planning and coordination will be accomplished as in Task 1.

Permits. Permits from the appropriate state, county, and federal agencies will be obtained. The need for extensive fluid sampling at the site and the need for a water source will require a large holding pond 
and possible temporary water rights for a surface water source. The greater degree of site disturbance necessitated by this drilling operation relative to that of Task 1 may require additional environmental impact analysis. The fact that the site has been occupied by a similar drilling operation in the past will greatly facilitate the permitting process.

Contracting. Contracting will be accomplished as in Task 1.

Drilling. Sunedco Well No. 58-28 will be reopened, tested, and diamond cored to a depth of $4.0 \mathrm{~km}$. The hole will be drilled as described in the drilling/coring program above. During drilling, the Chief Engineer will maintain a staff on the rig. In addition, a team of scientists will be present to monitor collection of samples and to ensure proper documentation of the samples.

Preliminary examination. The preliminary examination will include lithologic and geophysical logging, hydrothermal-alteration studies, fluid and gas sampling, and state-of-stress measurements. These tasks will be performed as described in the Statement of Work in Task 1.

Information dissemination. Data from the well will be made available to the public as quickly as possible through oral presentations and published reports.

Curation. Sample curation will be handled as in Task 1.

\section{TASK 5 - IN-SITU STRESS ANALYSIS}

\section{Objectives}

The principal objective of in-situ stress analysis is to determine the stress regime of the central Cascade Range and, for comparison, the stress regime of areas outside of the Cascade heat-flow anomaly to the west. These data will contribute to our knowledge of the regional stress pattern and its relation to plate interactions.

The secondary goal of the in-situ stress measurements is to evaluate the hydrofracturing characteristics of the volcanic rocks in the Cascade Range. This information can be used with data on temperature to assess the area for hot dry rock geothermal resources.

\section{Background}

The state of crustal stress in the central Cascade Range and adjacent areas of western Oregon is unknown. Alignments of volcanic vents in the High Cascades indicate a probable north-south to northnorthwest direction for the maximum compressive stress (Zoback and Zoback, 1980, in preparation). However, these alignments can also be affected by pre-existing structures. The aseismic nature of the central and southern Cascade region precludes assessment of stress direction by focal-mechanism studies, although more seismicly active areas to the north at Mount Hood and Mount St. Helens and to the northeast at Warner Valley and in the Deschutes Basin have yielded state-of-stress data. In the Cascade Range of southwest Washington, the maximum 
compressive stress direction appears to be oriented in a northeast direction, subparallel to the direction of convergence between the Juan de Fuca and North American Plates (Weaver and Smith, 1983; Grant and others, 1984). Couch and Lowell (1971) concluded that most of the focal-mechanism data for Oregon indicated minimum compressive stress axes oriented east-west, indicative of east-west extension. The focalmechanism studies in the Warner Valley and Deschutes River valley of Oregon give major compressional stress axes oriented mainly N. $15^{\circ} \mathrm{E}$. and N. $18^{\circ}$ E., respectively (Couch and others, 1976; Patton, 1976). In-situ measurements in a drill hole on the Columbia Plateau in Washington showed a maximum compressive stress axis oriented north-south (Haimson and Kim, 1982; Kim and others, 1986). Smith (1982) concludes that the north-south orientation of maximum compressional stress observed everywhere in the Pacific Northwest except western Washington and northernmost Oregon is controlled chiefly by transform motion between the Pacific and North American Plates. All of the available state-of-stress determinations for the northwest are summarized in Figure 20.

In-situ stress measurement in drill holes is an effective way to begin to assess the state of crustal stress in this part of the continent. Measurements within and outside of the Cascade heat-flow anomaly will show how crustal heating in the volcanic arc affects the stress regime of the continental lithosphere. A measurement near the Juan de FucaNorth American Plate boundary (i.e., near the Oregon Coast) will help to determine whether crustal stress in western Oregon is more a function of interactions of the North American Plate with the Pacific plate or with the Juan de Fuca Plate (i.e., test the hypothesis of Zoback and Zoback, in preparation).

In-situ stress measurements from the proposed 4.0-km-deep hole (Task 4) will determine how applicable the shallower stress measurements are to deep crustal stress. Comparison of deep and shallow measurements is particularly critical for the strain-release method of measurement, which is heavily dependent on the assumption that there are no open fractures prior to release of the confining pressure. Clearly, open fractures may occur more easily at shallow depths, casting doubt on the validity of shallow state-of-stress measurements by the strainrelease method.

In-situ stress measurements by hydrofracturing in the $4.0-\mathrm{km}$ deep hole will also provide important baseline data on the hot dry rock resources in the Cascade Range. Given that temperature gradients average $61.3 \pm 3.4^{\circ} \mathrm{C} / \mathrm{km}$ within the the Western Cascade-High Cascade boundary zone in Oregon (Blackwell and others, 1978), and that temperatures of about $200^{\circ} \mathrm{C}$ are required for hot dry rock technology (Goff and Decker, 1983), then hydrofracturing data from depths of at least 3-4 km will be needed. The reservoir of this hot rock in the Cascade heat-flow anomaly is enormous. For example, in the Oregon Cascades, the volume of rock in the upper $3 \mathrm{~km}$ of the crust with a mean temperature of $190{ }^{\circ} \mathrm{C}$ is about $35,948 \mathrm{~km}^{3}$ (Black and others, 1983). If hydrothermal fluids existed throughout this reservoir, the fluids could generate about 401,760 MWe for 30 years (Black and others, 1983). Even when large areas with restricted access such as wilderness are excluded from consideration, the amount of potential. electrical energy in the region is of this same order of magnitude (Black and others, 1983). 


\section{Statement of work}

State-of-stress measurements will be made in three holes: the 2.7$\mathrm{km}$-deep hole in the Santiam Pass transect (Task 2), the 4.0-km-deep hole in the Breitenbush Hot Springs area (Task 4), and an appropriate oil and gas well outside of the Cascade heat-flow anomaly. A siteselection study of oil and gas wells in west-central Oregon will be accomplished to pick an appropriate well for the latter experiment. Stress measurements utilizing a number of techniques including hydrofracturing, strain-relief measurement on cores, and borehole breakout analysis will be made. Hydrofracturing will be accomplished by pressurizing the deepest, least-fractured part of each hole utilizing packers. Downhole televiewer logs before and after the hydrofracturing experiment will identify induced fractures. The televiewer $\log$ will also identify borehole breakouts, which provide reliable information on the horizontal principal stress direction. An oriented core will be taken in an appropriate competent rock unit near the bottom of each hole to measure triaxial strain relief. The following tasks will be accomplished on the three holes:

1. 2.7-km-deep hole at Santiam Pass:

a. An oriented 3-m-long core will be taken at or near the bottom of the hole in an appropriate competent rock unit to conduct strainrelease stress tests.

b. A down-hole televiewer log will be run.

c. A hydrofracturing experiment will measure the principal stress directions, followed by another televiewer $\log$.

2. 4.0-km-deep hole near Breitenbush Hot Springs

a. Oriented 3-m-long cores will be taken at depths of $2.7 \mathrm{~km}$ and near $4.0 \mathrm{~km}$ in competent rock units to conduct strain-release tests.

b. A down-hole televiewer $\log$ will be run.

c. Hydrofracturing experiments at about $2.7 \mathrm{~km}$ and about 4.0 $\mathrm{km}$ will measure the principal stress directions, followed by another televiewer log.

3. Abandoned oil and gas well:

a. A site-selection survey will review available abandoned oil and gas wells for an appropriate site for in-situ stress experiments. Important evaluation factors are the following:

1. Depth: The well must be at least $1 \mathrm{~km}$ deep and preferably about $2.6 \mathrm{~km}$ deep.

2. Hole condition: The hole should be in competent rocks

with no evidence of hole instability.

3. Access: The well should be accessible with minimal

legal or institutional barriers to the proposed work.

4. Location: $A$ well should be located at or near the coast approximately due west of Santiam Pass.

b. The well will be reentered and cleaned out to total depth, drilling out in the process any cement plugs.

c. About $100 \mathrm{~m}$ of $\mathrm{H}$-size core will be taken from the bottom of the hole, and the last $3 \mathrm{~m}$ will be oriented for strain-release measurements.

d. A down-hole televiewer $\log$ will be run. 
e. A hydrofracturing experiment followed by another televiewer log will measure the principal stress directions.

\section{TASK 6 - GEOLOGIC AND PETROLOGIC STUDIES}

\section{Objectives}

The principal objective of the geologic and petrologic studies is to characterize the geologic history of the central part of the the volcanic arc. This characterization will be accomplished by investigation of the age, lithology, and geochemical composition of volcanic rocks in an eastwest transect at the latitude of Santiam Pass.

Petrochemical studies of core and appropriate surface samples are designed to accomplish the following major objectives:

1. Determine downhole and surface compositional and mineralogic variations with regard to (a) mapped outcrops, (b) definition of distinct magma sources (i.e., chambers) and their evolution, (c) character and proportions of mafic and silicic products, (d) estimates of magma supply rate, and (e) the composition and percentage of rocks that were melted to produce the magma.

2. Determine the time scale for lithologic units and magmatic processes to (a) measure the timing and duration of the volcanism represented in the core stratigraphy, (b) identify any major hiatuses and pulses of activity, (c) estimate rates of eruption, and (d) estimate times for magmatic processes defined in objective 1.

3. Establish correlations between rock units to support the geologic mapping.

Geologic mapping across the full width of the Cascades at the latitude of Santiam Pass will accomplish three objectives:

1. The maps will provide the stratigraphic and structural framework for the petrochemical studies. Most importantly, the volumes and distribution of major volcanic units will be determined. These parameters are necessary for calculation of eruption rate and for evaluation of hiatuses in volcanic activity.

2. Major episodes of crustal deformation will be defined.

3. Evidence for correlation between episodes of deformation and changes in the composition of volcanic rocks will be sought.

The proposed investigation will contribute to the overall objective of correlating major episodes of continental volcanism and deformation to the history of subduction of the Juan de Fuca Plate. If strong correlations can be found, then causal relationships between subduction and continental volcanic-tectonic processes can be inferred. This experiment could shed light on fundamental processes such as magma genesis in the subduction zone and transmission of stress between the major lithospheric plates.

\section{Background}

Geology. The Santiam Pass transect (Figure 3 ) as defined here includes the rectangular area bounded by long $121^{\circ} \mathrm{W} .$, long $123^{\circ} \mathrm{W}$., 
lat $44^{\circ} 15^{\prime} \mathrm{N}$., and lat $44^{\circ} 30^{\prime}$ N. (Figure 3). Reconnaissance-level geoogic mapping is available for the entire area (e.g., Wells and Peck, 1961; Peck and others, 1964; G.W. Walker, unpublished mapping, 1985), but detailed maps at scales of 1:62,500 or larger are available only for the areas east of long $122^{\circ} 15^{\prime} \mathrm{W}$. (Taylor, 1967, 1980, 1981, unpublished mapping; Stensland, 1970; Hales, 1975; Peterson and others, 1976; Davie, 1980; Avramenko, 1981; Conrey, 1985; Yogodzinski, 1986; Smith, 1986; Black and others, 1987). These maps delineate the stratigraphic and structural setting of the High Cascades, the High Cascade-Western Cascade transition zone, and the Deschutes Basin. The east slope of the High Cascades and the adjoining Deschutes Basin has yielded a relatively well-exposed and well-preserved record of the last $8 \mathrm{~m} . \mathrm{y}$. of rolcanism in the High Cascades (e.g., Taylor, 1973; Smith, 1986). Mapping in Western Cascade-High Cascade transition zone has revealed a fragmentary record of volcanism during about the last 24 m.y. (Avramenko, 1981; Black and others, 1987; G.W. Walker, unpublished mapping, 1985). A generalized compilation map based on much of this mapping is presented in Figure 7 (folded, separate sheet). Most of the geologic mapping is aimed at exploring the geologic history of the Western Cascades. Testing for correlation between episodes of deformation and changes in the rates and compositions of volcanism during the last $37-40 \mathrm{~m} . \mathrm{y}$. can be accomplished only by detailed mapping in this province. This part of the volcanic arc is the only place where rocks of the appropriate age crop out. As previously mentioned, with the exception of the easternmost edge of the Western Cascades, previous work in this part of the Santiam Pass transect is reconnaissance in nature and is thus inadequate for documentation of details of the structure and stratigraphy. Geologic mapping in analogous areas to the north and south of the transect has revealed a complex geologic history punctuated by periods of uplift and faulting. Between about 40 and about $19 \mathrm{Ma}$, volcanism was dominated by eruptions of silicic pyroclastic flows, with local centers of rhyodacite, dacite, andesite and iron-rich andesite to basaltic andesite (Priest and others, 1982b, 1983c). Eruptions of andesite and basaltic andesite lavas predominated from about 18 to about 9 Ma (Priest and others, 1982b, 1983c; Sherrod, 1986). After 9 Ma, most of the volcanism was centered in the High Cascades and the easternmost edge of the Western Cascades, although a few widely scattered volcanic centers were locally active farther west (e.g., Snow Peak, Battle Ax Mountain, and the Armet Creek flow near Oakridge) (Thayer, 1936; White, 1980a, b; Woller and Priest, 1982, 1983; G.W. Walker, unpublished mapping, 1985). Volcanic rocks erupted after about $9 \mathrm{Ma}$ in the Santiam Pass area are predominantly basalts and basaltic andesite.

Numerous northwest-trending faults, dikes, and lineaments cut Western Cascade rocks (Callaghan and Buddington, 1938; Avramenko, 1981 ; Sherrod, 1986). Displacement on the faults is not well constrained in most cases, owing to lack of detailed geologic mapping. Local northeast-trending folds also occur (e.g., Thayer, 1936), although the nature of these folds and their relationship to the faults is not always easy to interpret (e.g., Priest and others, 1987). The northwest-trending dikes and northeast-trending folds have led to speculation that the main compressive stress axis during the Miocene was horizontal and oriented northwest (e.g., Avramenko, 1981; Sherrod, 1986). The entire Western Cascades was probably uplifted between 
about 4-5 Ma (Sherrod, 1986) at about the same time that a graben formed in the High Cascades at the latitude of Santiam Pass (Taylor, 1980, 1981). The north-striking trend of Pliocene and younger dikes, volcanic vent alignments, and faults in the High Cascades indicate that the minimum compressive stress axis was oriented east-west and horizontal after the uplift event. The majority of focal-mechanism studies of earthquakes in Oregon near the Cascade Range indicate that the minimum compressive stress axes are oriented roughly east-west (e.g., Couch and Lowell, 1971).

Much of the correlation work on the drill holes in the High Cascades will be aimed at measuring the displacement of the High Cascades graben at Santiam Pass. The graben is delineated by faults along the Green Ridge escarpment and the easternmost edge of the Western Cascades (Figure 7, folded, separate sheet). In both areas, upper Pliocene and younger volcanic rocks are banked against the fault line scarps of the graben. This structure was first inferred from geomorphic evidence by Allen (1966) and has since been confirmed by geologic data of Hales (1975), Taylor (1980, 1981), Avramenko (1981), and Black and others (1987). The graben formed about 3-5 Ma, causing the late Miocene to Pliocene volcanic arc to subside an unknown distance (Taylor, 1980, 1981). The intragraben rocks, which are $5 \mathrm{~m} . \mathrm{y}$. old and older, are now entirely buried by Quaternary volcanic rocks (Taylor, $1980,1981)$. If the pre-5-Ma volcanic arc contained any of the large composite volcanic cones present there now, then displacements must have been very large in order for the Quaternary volcanic rocks to completely obscure the older rocks (Taylor, 1980, 1981).

Establishing correlations between drilled intragraben units and units in the structurally high blocks to the east and west will provide a measure of the displacement on the High Cascades graben. The drillhole lithologic work will also offer the first opportunity to directly sample the pregraben volcanic rocks near their sources. Much of the pre-Quaternary ejecta preserved in the Deschutes Basin to the east is volcaniclastic rock derived from explosive volcanism in the pregraben volcanic arc (Taylor, 1980, 1981; Smith, 1986). Study of the source areas for these rocks will help to characterize lithologic changes that occurred as the ash flows, volcanic mudflows, and hyperconcentrated flood deposits flowed outward from the volcanic centers.

Major and trace-element geochemistry. Multielement analyses of representative central High Cascades volcanic rocks (e.g., Taylor, 1978; Hughes, 1983; Hughes and Taylor, 1986) have shown that the preponderance of basalt, basaltic andesite, dacite, and rhyodacite greatly overshadows a minor representation by andesite. This apparent bimodality has been attributed to the separate evolution of near-primary basalt ( $<53$ weight percent $\mathrm{SiO}_{2}$ ) and basaltic andesite magmas (53-58 weight percent $\mathrm{SiO}_{2}$ ), the latter of which may become trapped in crustal regimes and evolve to dacite-rhyodacite magmas ( $>62$ weight percent $\mathrm{SiO}_{2}$ ). Andesitic compositions (58-62 weight percent $\mathrm{SiO}_{2}$ ) are actually represented by high-silica basaltic andesites (Hughes and Taylor, 1986) that have primitive (olivine + plagioclase) mineralogies.

The transition from high-silica basaltic andesite to dacite involves very little change in $\mathrm{SiO}_{2}$ content but rather significant changes in mineralogy to plagioclase + orthopyroxene + augite magnetite (POAM) and in remaining bulk and trace-element chemistries. A pseudo-ternary 
$\mathrm{SiO}_{2}$-O1-P1 diagram (Figure 21) illustrates a shift in chemical trends between mafic and silicic magmas due to crustal evolution. Basaltic andesite magmas that are trapped at intermediate levels in the crust fractionate POAM mineralogy (Gill, 1981) extensively to yield silicic compositions (Hughes, 1983). Alternatively, the injection of mafic magma causes anatectic melting of previously emplaced crustal components. The absence of amphibole-controlled fractionation and true andesite representatives is consistent with magmatic trends in immature oceanic arcs and continental magmatic arcs placed over relatively young crust (Gill, 1981; Leeman, 1983). Interpretations of multielement chemical, field, and other petrologic data at present suggest that an extensional tectonic system has been superimposed on the earlier compressional regime. This change is marked by the onset of extension-related mafic volcanism along with subordinated vestiges of calc-alkaline magmatism. Analyses of representative central High Cascade mafic platform lavas by Hughes and Taylor (1986) lead to the chemical definition of at least two types of near-primary basaltic andesite magma. Moreover, Hughes and Taylor (1986) delineated trace-element boundaries for what could be considered normal and divergent High Cascade basalts and presented evidence for the separate petrogenesis of basalt and basaltic andesite primary magmas. Divergent basalt types having anomalous geochemical signatures were attributed to either crustal contamination or alternate lines of petrogenesis.

Average chemical abundances, shown normalized to primordial mantle values (Wood and others, 1979, 1981) in Figure 22, illustrate the effectiveness of multielement signatures for determination of separate magmatic histories. Chemical patterns of dacites and rhyodacites, which result from extreme fractionation and/or crustal anatexis, show overall enrichments in incompatible elements as well as changes in elemental ratios relative to mafic compositions. In all compositions, the higher patterns of elements mobile in water $(\mathrm{K}, \mathrm{Rb}, \mathrm{Sr}, \mathrm{Cs}, \mathrm{Ba})$ relative to more stable elements ( $R E E, H f, T a, T h$, etc.) can be attributed to enrichment factors due to elevated $\mathrm{H}_{2} \mathrm{O}$ during magma evolution. These relations likely represent enrichments from fluids derived from a subduction-zone component, whereas the refractory incompatible elements reflect enrichments of the lower lithospheric source region (e.g., Pearce, 1983). Models of basalt and basaltic andesite magma genesis (Hughes and Taylor, 1986) require source enrichments in mobile elements that are greater than would be expected from strictly magmatic processes and thereby confirm the presence of water-rich fluids derived from a subducted slab.

Although overall geochemical trends have been established for well-known calc-alkaline andesitic systems (e.g., Gill, 1981; Thorpe, 1982; Grove and Kinzler, 1986), multielement variations in central High Cascade volcanic rocks reflect magma evolution in a unique tectonic setting that can be better understood after a more comprehensive petrochemical program. Acquisition of high-quality major- and trace-element data on representative whole-rock and mineral samples would yield the definition of local nuances as well as regional chemical imprints and would help to delineate depths and sizes of magmatic hearths. Combination of these data with isotopic and age constraints will enable an assessment of the total heat budget in the province as well as the proportions of silicic to mafic magmas that may be trapped as thermal reservoirs. 
Isotopic data. The combination of ${ }^{87} \mathrm{Sr} /{ }^{86} \mathrm{Sr}$ and ${ }^{143} \mathrm{Nd} /{ }^{144} \mathrm{Nd}$ isotopic data with multielement analyses will greatly enhance the definition of magmatic sources, magma batches, and mixing in the Cascades province. Global scenarios of the isotopic evolution of subcontinental lithosphere (lower crust and upper mantle) have been developed recently (e.g., Menzies, 1983; Hawkesworth and others, 1983; Zindler and Hart, 1986) during chemical studies of mantle-derived xenoliths and major volcanic provinces. Such studies have revealed an overall enrichment of the continental lithosphere in large-ion lithophile elements (LILE) leading to higher ${ }^{87} \mathrm{Sr} / /^{86} \mathrm{Sr}$ and lower ${ }^{143} \mathrm{Nd} /{ }^{144} \mathrm{Nd}$ ratios relative to a primordial mantle composition, but trends vary between provinces, and the presence of a depleted convecting uppermantle component (relatively low ${ }^{87} \mathrm{Sr} /{ }^{86} \mathrm{Sr}$ and high $143_{\mathrm{Nd} /{ }^{14} 4 \mathrm{Nd}}$ ratios) plays an important role in oceanic and some continental systems. Zindler and Hart (1986) argue for a prevalent mantle composition

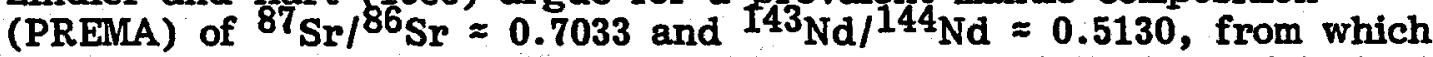
other mantle components, which have evolved to relatively enriched or depleted reservoirs, are readily distinguished.

Isotopic $\mathrm{Sr}$ and $\mathrm{Nd}$ data by Menzies and others (1983) for Cenooic volcanic rocks in the western United States indicate mantle heterogeneities between the southern Basin and Range, Sierra Nevada, and Snake River Plain-Yellowstone provinces. They suggest that Basin and Range volcanic rocks were likely derived from a mantle source similar to that of E-type mid-ocean ridge basalts, which, although exhibiting short-term enrichments, have been depleted over long periods of time relative to the bulk earth value. The Sr-Nd signature of E-type mantle is actually similar to the PREMA composition. An equivalent isotopic signature is probably appropriate for the Cascade province, in light of Sr data (Leeman, 1983) presented for that and other subduction-related systems.

Crustal involvement can be adequately constrained using combined $\mathrm{Sr}-\mathrm{Nd}$ isotopic systematics such as in recent studies of continental basalts (e.g., Carlson and others, 1981; Mahoney and others, 1982; Carlson, 1984; Mantovani and others, 1985; Hughes and others, 1986). In young crustal terranes such as the Cascades, the crustal signature may not be widely different from that of the mantle but can likely be distinguished with detailed analyses. The Sr-Nd studies of Cascade rocks will therefore reflect long-term mantle signatures as well as provide information on less obvious crustal components that have been incorporated into some compositions. Specifically, isotopic analyses of units that exhibit obvious trace-element signatures of contamination (Hughes and Taylor, 1986) will provide useful measures of crustal isotopic systematics. Analyses of numerous selected samples should enable an accurate delineation of such subtleties in the volcanic pile and in the underlying crust/mantle regimes. Moreover, the measure of influence due to older accretionary terranes beneath the Cascades as well as the definition of time-integrated mantle compositions would be crucial to the understanding of Cascade arc evolution.

Statement of work

Geologic map coverage. The geologic maps of the Cascadia, Sweet Home, and Browns ville $1^{\prime}$ topographic quadrangles will be produced at a scale of 1:62,500. Isotopic age determination will be accomplished for 
critical stratigraphic units within these map areas and in previously mapped parts of the Santiam Pass transect.

Stratigraphic and structural analysis. The geologic maps will include interpretive cross sections and text that will define the major structures in each area. A report that integrates the data from previous mapping and from Phase I drill holes will also be produced to explain structures across the entire Santiam Pass transect. As a minimum, this report will contain an interpretive cross section of the entire transect and a text explaining the geologic history.

Stratigraphic correlations will be accomplished by detailed sampling and analysis of all major rock units within the Santiam Pass transect, including the Phase I drill holes. Mineralogic, textural, chemical, and radiometric age determinations will be utilized in making correlations. New data on outcrops will be generated primarily within the new map areas in the western part of the transect, but outcrops in previously mapped areas will also be sampled as needed to establish correlations.

Petrochemical studies. Objective 1 of the petrochemical studies will entail the acquisition of major-, minor-, and trace-element abundances on core samples and selected surface samples along with bulk chemical analyses of important mineral phases. Elemental data will be obtained by XRF (X-ray fluorescence), INAA (instrumental neutron activation analysis) and EMP (electron microprobe analysis). These techniques will be supplemented by additional procedures including RNAA (radiochemical NAA), ICP-MS (inductively coupled plasma mass spectrometry) and coincidence-noncoincidence INAA counting, which will allow accurate determination of extremely low-level abundances in appropriate samples. XRF and INAA will be used for the routine determination of (1) all major elements ( $\mathrm{Si}, \mathrm{Ti}, \mathrm{Al}, \mathrm{Fe}, \mathrm{Mn}, \mathrm{Mg}, \mathrm{Ca}, \mathrm{Na}, \mathrm{K}$ ); (2) minor transition metals ( $\mathrm{Sc}, \mathrm{V}, \mathrm{Cr}, \mathrm{Co}, \mathrm{Ni}, \mathrm{Zn}$ ); (3) alkali and alkali earths ( $\mathrm{Rb}, \mathrm{Sr}, \mathrm{Cs}, \mathrm{Ba}$ ); and (4) high-field-strength metals, rare earths, and other lithophile elements $(Y, Z r, N b, S b, L a, C e, N d, S m$, $\mathrm{Eu}, \mathrm{Tb}, \mathrm{Dy}, \mathrm{Ho}, \mathrm{Tm}, \mathrm{Yb}, \mathrm{Lu}, \mathrm{Hf}, \mathrm{Ta}, \mathrm{Th}, \mathrm{U})$. Increased accuracy for selected elements will be attained using coincidence-noncoincidence INAA counting as well as RNAA and ICP-MS. Mineral-separate data obtained using recently developed INAA procedures for samples as small as $\approx 10 \mu \mathrm{g}$ will be checked against electron-probe microanalyses in order to determine the states of equilibration, partition coefficients, and the effects of mineral extraction or addition on magmatic evolution.

The isotopic content of $87 \mathrm{Sr} /{ }^{86} \mathrm{Sr}$ and $143 \mathrm{Nd} /{ }^{144} \mathrm{Nd}$ will be determined in representative samples selected on the basis of enriched or depleted trace-element characteristics. These data will be used to constrain further the time of source enrichment or depletion, crustal involvement, and the possibility of magma mixing scenarios within the Cascade system. In addition, it is expected that isotopic analyses will also yield information concerning residence times of certain magmas in regard to isotopically defined amounts of assimilative mixing.

Central to the petrochemical and geological objectives of this research will be the determination of a time scale for the volcanic stratigraphy. Radiometric dating techniques will provide precise absolute ages for selected volcanic units from the core material recovered by drilling. These ages will provide the basis for correlations, estimation of eruption rates, the time period for magma events (such as crystal 
fractionation, injection of new liquid compositions), and the timing of any significant periods of quiescence in the volcanic record.

The standard radiometric method for determining the crystallization age of volcanic rocks is $\mathrm{K}$-Ar dating. This method has been used successfully since the early 1960's (Dalrymple and Lanphere, 1969). Because of the relatively high concentrations of potassium in volcanic rocks, this method has been generally applicable in dating rocks in the age range of 500,000 years to the age of the earth $\left(4.6 \times 10^{9}\right.$ years). With recent improvements in mass spectrometry and argon-extraction facilities, the lower limit of datable material is approaching 50,000 years on a routine basis (Cassignol and Gillot, 1982).

For volcanic rocks that have been altered by chemical exchange with hydrothermal fluids or have experienced a mild regional metamorphism, the ${ }^{40} \mathrm{Ar}-{ }^{39} \mathrm{Ar}$ radiometric technique has been very successful in determining their primary crystallization age. Fluids may add potassium, and radiogenic argon may be lost from the rock by diffusion during the formation of secondary minerals. Both effects lower the measured $\mathrm{K}-\mathrm{Ar}$ age. By neutron irradiation of these samples and artificial decay production of ${ }^{39} \mathrm{Ar}$ from ${ }^{39} \mathrm{~K}$, the argon gas contribution of the alteration phases can be removed, and the primary crystallization age revealed (Duncan, 1984). Altered rocks from the Cascades have been successfully dated by this technique (Lux, 1982).

\section{TASK 7 - HYDROTHERMAL ALTERATION STUDIES}

\section{Objectives}

The chief goal of this task is to contribute to an understanding of metamorphic processes, particularly hydrothermal alteration, in the Cascade Range. The investigation has the following specific objectives:

1. Identification and characterization of burial diagenesis or regional metamorphic facies with depth.

2. Identification of hydrothermal alteration superimposed upon regional metamorphism.

3. Explanation of differences between drill-hole temperatures and temperatures predicted by the alteration mineralogy.

4. Identification and determination of the metamorphic effects of hot-water aquifers that may be encountered.

5. Investigation of mesothermal and epithermal mineralization processes.

\section{Background}

In considering metamorphism and alteration that will be encountered in the Cascades drilling program, several processes must be considered as well as simply "grade" of metamorphism. Similar grades of alteration from different geologic processes may result in the same mineral assemblages. Where possible, definition of the process of alteration is as important as the mineral assemblages. For example, outcrops investigated in the Cascade Range have mineral assemblages that can be attributed to either diagenesis, low-temperature regional 
metamorphism, or hydrothermal alteration. The definitions of these processes may overlap, but an important objective of the study of metamorphism and alteration in the Cascade Range is to attempt to differentiate these processes by studying mineral assemblages and textures in geologic context. considered:

The following types of metamorphism and alteration are to be

1. Diagenesis and weathering. We know that alteration of volcanic rocks to clay minerals and zeolites takes place at low temperatures. Recognizing the difference in low-temperature processes--diagenesis from depth of overburden or hydrothermal alteration at low temperatures--is significant. Diagenesis or burial metamorphism is typical in the Western Cascades, which have been uplifted and eroded, exposing rocks that are altered both diagenetically and hydrothermally at the present surface. Alteration includes (1) incipient clay (smectite) alteration, (2) zeolite-clay alteration, and (3) lower greenschist-facies alteration. Volcaniclastic layers and ash-flow tuffs, such as the Breitenbush Tuff, are more readily altered or metamorphosed than are massive lava flows.

Western Cascade rocks from the Sunedco drill hole at Breitenbush (A. Waibel, unpublished data, 1985) and the EWEB 1 drill hole on the west side of Santiam Pass (Keith and Boden, 1981) exhibit mineralogy characteristic of diagenesis of low-grade regional metamorphism with zeolite facies and, in the deeper Breitenbush hole, lower greenschist facies. This sequence, reflecting increasing temperature with depth at a gradient of about $60^{\circ} \mathrm{C} / \mathrm{km}$ (see discussion of regional heat flow in Task 1), will be found in any of the Western Cascades rocks because of exposure by uplift and erosion. Beneath the High Cascades at the crest of Santiam Pass, the underlying older Cascades rocks may show a higher grade of metamorphism because of the additional effects of an overlying pile of younger lavas and because of contact effects of multiple dikes feeding hot lava to the High Cascades lava flows.

\section{Hydrothermal alteration associated with fossil hot spring} systems. This alteration will probably be $10 \mathrm{w}$-temperature $\left(150^{\circ} \mathrm{C}\right.$ ) zeolitic alteration, perhaps with associated quartz, calcite, and pyrite or hematite. In deeper parts of these systems, temperatures could have been higher, resulting in propylitic alteration. These minerals may be found in faults, fractures, and pore spaces that served as channels for upflowing thermal waters.

If any high-angle faults are encountered during drilling, the alteration mineralization will depend upon the temperature and composition of the fluids that might have moved through the fault and will again probably consist of zeolitic and propylitic assemblages. According to present hypotheses, the waters will probably be hotter closer to the axis of the High Cascades. High-angle faulting may provide upflow channels for water heated beneath the High Cascades, bringing hot water upward to an aquifer through which it flows outward (subhorizontally) without reaching the surface. Shallow strata-bound hot-water aquifers have been identified at Newberry volcano adjacent to a ringfault system (Black and others, 1984) and at Breitenbush (Waibel, unpublished data, 1985).

3. Contact alteration. This type of alteration will be encoun- 
tered within and adjacent to small plutons and feeder dikes. More permeable types of volcanic rocks will be more susceptible. Small plutons with adjacent and internal propylitic alteration are exposed along the Western Cascades. Several unexposed plutons are suspected because of concentrations of randomly oriented dikes and epithermal mineralization. Contact alteration by feeder dikes and by lava flows over wet flow breccias and volcaniclastic layers may result in concentration of zeolite and clay minerals (i.e., lower temperature alteration than adjacent to plutons), although local higher temperature assemblages are certainly possible. This type of alteration is generally associated with epithermal vein deposits, as explained below.

4. Epithermal vein deposits. Epithermal vein mineralization is found associated with most of the exposed small plutons in the Western Cascades. Examples are the Laurel Hill pluton west of Mount Hood and the Halls diorite porphyry southwest of Breitenbush Hot Springs (Figure 3). Similar veins could be intersected during drilling of the deepest Phase I holes. Characteristic mineralogy includes epidotequartz-chlorite-calcite and sulfides or oxides; significant textures include evidence of veining and intrusive brecciation. Characterization of the composition of rocks and fluids in ective epithermal zones of the deepest drill holes may offer a unique opportunity for in-situ study of the mineral deposition process.

The Halls diorite porphyry is a good site for study of epithermal mineralization. The roof of the pluton is well exposed along a major highway where the U.S. Army Corps of Engineers has extensively excavated the contact zones. Its intermediate composition is similar to that of many of the long-lived volcanic centers in the Cascade Range. Previous geologic mapping of the contacts and mineralized zones (Thayer, 1939; Pungrassami, 1970; Hammond and others, 1982) provides the basis for further work.

5. Mesothermal mineralization/alteration. None of the Phase I drill holes are expected to penetrate active mesothermal hydrothermal systems. This type of system can be studied in the Western Cascades, where erosion has reached deeply enough to expose Miocene magmatic systems that have deposited mesothermal mineral deposits.

The Iittle North Santiam mining district, located about $20 \mathrm{~km}$ west of Breitenbush Hot Springs, is a relatively well-studied example. The district has potassic alteration zones, tourmaline breccia pipes, and copper-lead-zinc mineralization (Olson, 1978) typical of mesothermal ore deposits (Lindgren, 1907, 1922). The alteration zones are adjacent to an intrusive complex similar in composition to local stratocones of the High Cascades (Olson, 1978; Priest, 1983). An investigation of the district may therefore offer insights into currently active mineralization processes under the stratocones. The studies proposed here will take advantage of extensive mapping and laboratory studies of the alteration, . mineralization, and fluid inclusions of the district that have already been accomplished or are in progress (Callaghan and Buddington, 1938; Olson, 1978; Cummings and Pollack, 1984; Pollack, 1985; Pollack and Cummings, 1985a,b, 1986; Winters, 1985; Pollack and others, 1986).

6. Vapor-phase (deuteric) alteration. Alteration due to vaporphase transport during cooling of the volcanic rocks is generally found in association with relatively young volcanic rocks. Some of this vapor- 
phase alteration still persists in younger lavas of the Western Cascades, but it is more typical of the Quaternary lavas in the High Cascades. This alteration is typified by red, orange, yellow, brown, and black iron oxide coatings and stains in lag breccias, flow breccias, and domes and on fracture surfaces in lava flows. Temperatures involved are very high, because this process begins immediately upon emplacement at the surface as the lava begins to solidify. This type of alteration may not be of general interest, but certainly it is widespread enough that it should be identified. This is the first stage of iron (yielding the characteristic coloration) and other element mobilization during alteration in the Cascade Range. During zeolitic and propylitic (or greenschist) alteration-metamorphism, this iron is reduced and goes into clays and sulfides or into epidote, chlorite, and hematite. A late cooling stage of this alteration is near-surface deposition in fractures and vesicles of clear to white opal and cristobalite from silica carried in wet steam.

\section{Statement of work}

As previously explained, preliminary determinations of lithology and alteration of cores and cuttings will be accomplished as part of the drilling tasks. This task, which covers additional detailed studies of the hydrothermal alteration that will be done to complement the preliminary examination, includes studies of outcrops in the Western Cascades and additional studies of the drill-hole samples.

Throughout the hydrothermal alteration study, the rock and fluid studies must be interfaced (water-rock interaction) in order to provide a complete interpretation of the hydrothermal alteration. Both fluids and rocks are necessary for hydrothermal alteration to take place. During the alteration process, both rocks and fluids are altered in response to changing temperature, $\mathrm{pH}$, chemistry, permeability, and other physical and chemical factors. The data developed here will be integrated with data from fluid samples (i.e., Task 7) and analyses of fluid inclusions where possible.

The following studies will be accomplished:

General characterization.

1. Mineral identification. Samples of rock alteration observed at the surface and in the drill holes in the Santiam Pass transect and in the Breitenbush Hot Springs area will be collected for study and described in geologic perspective. Sampling and analysis of drill holes will be much more detailed than in the preliminary examination. Petrographic study, including X-ray diffraction and thin sections of samples, will show textural relations and provide mineral identifications necessary for determining alteration characteristics and controls. These studies can be used to document such features as rock permeability, selfsealing, and history of alteration. Whole-rock assemblages are significant in determining environment of alteration. The paragenetic sequence of mineral assemblages can be used to outline the evolution of a hydrothermal system.

Chemical analyses of whole-rock samples will include major oxides by XRF and selected constituents, such as $\mathrm{H}_{2} \mathrm{O}^{+}, \mathrm{H}_{2} \mathrm{O}^{-}, \mathrm{SO}_{4}$, and $\mathrm{Cl}$, and trace elements by an appropriate analytical technique (1.e., semiquantitative spectrographic analysis, INAA, RNAA, and ICP).

Mineral identification and determination of chemical composition of 
phases resulting from hydrothermal alteration give information on conditions of deposition of those minerals. The following techniques are to be used:
a. Mineral identification by X-ray diffraction and by optical techniques.
b. Determination of chemical composition of individual minerals by electron microprobe analysis.
c. Determination of morphology and textural relations of minerals by use of the scanning electron microscope (SEM). Qualitative chemical analyses of unique and unstable phases
can be obtained by use of energy dispersive X-ray analyses in conjunction with the SEM.
d. Use of specialized techniques of mineral identification such as powder camera $X$-ray diffractometry and single-crystal structural study for unique minerals that may be encountered. Methods such as DTA and infrared may be used for clay mineral studies.
e. Analysis of fluid inclusions in various hydrothermal minerals, usually quartz, for determination of homogenization temperatures and the chemical composition of fluids during crystallization.

2. Isotope studies. The oxygen and hydrogen isotopic composition of alteration minerals (expressed as $\delta^{18} \mathrm{O}$ and $\delta D$, respectively) are dependent upon the temperature of formation, as well as the isotopic compositions of primary minerals and circulating hydrothermal fluids (e.g., Taylor, 1971). The $\delta^{18} \mathrm{O}$ and $\delta \mathrm{D}$ compositions of the fresh igneous rocks and fracture-filling secondary minerals will be utilized to infer temperatures and compositions for the fluids that circulated through the system. It is possible to analyze compositions of samples as small as $1 \mathrm{mg}$ by utilizing current mass spectrometric techniques. This small sample size will allow examination of the time sequence of changing temperatures and fluid compositions from small mineral separates scraped sequentially from fractures. The history of geothermal activity can be reconstructed from such data.

Numerous other isotopes such as sulfur and lead can be used for specific problems of interest, especially if ore mineralization is encountered. These isotopes are of less general use than the light stable isotopes and probably should be reserved for highly specialized investigations outside the scope of this task.

Study of epithermal mineralization. Zones of epithermal mineralization may possibly be intercepted in the deepest Phase I drill holes, where in-situ samples of ore-bearing fluids and associated mineralized rocks may be sampled. Ore deposits in subduction-related volcanic systems have been described from Central and South America, so there is a potential for active epithermal mineralization in the Cascade Range. Drill-hole rock samples with mineralogical compositions indicative of epithermal conditions will be analyzed, utilizing specialized trace-element analytical techniques with low limits of detection such as SWR spectrometry and INAA to search for ore metals. This information will be compared to compositional data on associated fluids, if available, to test chemical models of the ore-deposition process.

Epithermal mineralization and alteration in and around the Halls 
diorite porphyry southwest of Breitenbush Hot Springs will be studied by the techniques outlined above for the general studies. Detailed studies of fluid inclusions, trace elements, isotopes, and alterationmineral zonation will be employed to test three-dimensional models of the hydrothermal circulation system and attendant chemical changes that deposited the ore minerals. For instance, in areas that are characterized by downward convecting hydrothermal fluids, alteration and mineralization zones will generally be widened relative to areas of former upward-convecting fluids (Elders and others, 1980). Careful mapping of chemical and mineralogical zonation may therefore delineate the direction of migration of the hydrothermal fluids. Temperature-sensitive mineral reactions and fluid-inclusion heating experiments will allow mapping of paleoisotherms. Analysis of the fluids and gases of the fluid inclusions will give clues to the composition of hydrothermal fluids.

Study of mesothermal mineralization. Zones of mesothermal mineralization are most easily studied in the deeply eroded mesothermal mineral deposits of the Western Cascades. As previously explained, the Iittle North Santiam mining district is a good site for this part of the study. Studies analogous to those outlined above for epithermal mineralization will be accomplished.

\section{TASK 8 - GAS AND HYDROGEOCHEMICAI STUDIES}

\section{Objectives}

The overall objective of this task is to help characterize the chemical evolution and current flow paths of hydrothermal fluids and gases in the Cascade Range. The investigation will complement the studies of fluids and gases outlined in the preliminary examination for the drilling tasks with soil geochemical surveys and quantitative modeling of fluid and gas data from drill holes and surface waters. Specific objectives include the following:

1. Utilize gas and fluid geochemistry to determine the age and origin (magmatic versus meteoric) of hydrothermal fluids.

2. Utilize stable-isotope ratios and major- and trace-element compositions of altered and relatively fresh rocks along with measured and calculated chemical geothermometer temperatures to evaluate quantitative reaction-path models.

3. Use a soil geochemical survey of accessible parts of the Cascade heat-flow anomaly in the Santiam Pass transect to explore for surface indications of recent hydrothermal circulation.

4. Determine the type of subsurface geothermal systems that might be present and the magnitude and geologic history of hydrothermal circulation in Blue Lake.

\section{Background}

Understanding the chemical and physical dynamics of hydrothermal fluid circulation is vital to understanding both the mineral and geothermal potential of the Cascade Range. A model of the hydrothermal convective process can be developed by studying the distribu- 
tion of hydrothermal systems and the composition of the fluids and gases.

Hydrothermal convection systems with surface expressions are not common in the Cascade Range, particularly in the young permeable volcanic rocks of the High Cascades. As previously explained (Task 3), most Cascade hot springs occur in the eastern margin of the Western Cascades and are not obviously related to any individual High Cascade volcano. Whereas most of these springs have been sampled and chemically analyzed, relatively few data on the isotopic composition of fluids and gases are available. There are even fewer data on thermal fluids in the High Cascades. Thermal springs are rare in the High Cascades, probably because of the masking effect of shallow ground water. It is not known at present whether there is any significant hydrothermal circulation in the High Cascades in mafic volcanic provinces such as the Santiam Pass area. The only indications of potential thermal springs in the High Cascades in the Santiam Pass transect are (1) the slightly elevated chloride content of surface water in the Metolius River and Blue Lake (Mariner, 1985; Johnson and others, 1985), and (2) a very weakly thermal $\left(25^{\circ} \mathrm{C}\right.$ ) aquifer encountered in drill hole $13 \mathrm{~S} / 7 \mathrm{E}-32 \mathrm{D}$ on the westernmost edge of the High Cascades (Figures 7, folded, separate sheet, and 8) (Youngquist, 1980; Blackwell and others, 1981). No data are available on fluids in the drill hole. The chloride anomaly in the Metolius River may be explained without hydrothermal processes (Mariner, unpublished geochemical interpretation, 1985). Blue Lake will be explored by the heat-flow study of Task 9 and by geochemical sampling proposed here.

The inflow of thermal springs is a major factor controlling the major- and trace-element composition of some lakes in Oregon (Johnson and others, 1985). The presence of hot springs in these lakes is in most cases inferred by anomalous bulk-lake chemistry (and occasionally by rumor). The geochemistry and heat flux associated with these hydrothermal systems are generally unknown. Extensive geochemical studies have been carried out at Crater Lake, Oregon, where deep-lake hydrothermal activity was demonstrated (Williams and Von Herzen, 1983; Holbrook and others, 1985). Studies of trace-metal distributions and limitation of algal growth in Crater Lake, Blue and Suttle Lakes in Santiam Pass, and Paulina and East Lakes in Newberry Crater have also been accomplished (Rueter, Petersen, and Collier, unpublished data, 1986). These lakes demonstrate varied chemistries that reflect the complexities of their individual geologic environments. All of them have concentrations of major and trace elements that are well above the local systems dominated by nonhydrothermal meteoric inputs. For instance, the metals vanadium, molybdenum, and nickel are as much as one to two orders of magnitude more concentrated in these lakes than in other Oregon lakes. These metals and other nutritionally significant elements (e.g., iron, phosphorus, and sulfur) may help to determine the ecology of the lake and are useful indicators of the magnitude of active hydrothermal circulation. Blue Lake, which is probably the source of much of the high metal content of Suttle Lake, would be a good target for a detailed hydrogeochemical study in the Santiam Pass area.

Studies of radon and other constituents of Blue Lake will, when integrated with the heat-flow investigation (Task 9), elucidate the nature of hydrothermal inputs into the lake. Radon-222 is a radioactive dissolved gas that is significantly enriched in all geothermal springs, 
including those in the Oregon Cascades (Dymond and Perhats, unpublished data, 1986). Because of its rapid decay rate ( $t \frac{1}{2}=3.85$ days), detection of excess radon in deep lake water offers a sensitive prospecting tool for hydrothermal activity in lakes. Furthermore, if the radiochemical composition and temperature of active hydrothermal springs can be determined, estimates of total heat and elemental flux into the lake could be derived by integrating excess radon in the lake (Dymond and others, 1983; Kadko and others, 1986). For example, elevated concentrations of radon found in the hydrothermal (south) basin of Crater Lake are well above those that could be supported by diffusive inputs from the sediments (Collier and Dymond, unpublished data and interpretations, 1986).

"Blind" hydrothermal circulation systems may. exist without any surface manifestations other than elevated heat flow and anomalously high mercury, arsenic, or other trace elements in soils. In areas of highly active circulation of cold ground water, as in the High Cascades, even these manifestations may be masked. Studies at Newberry volcano demonstrated that an area with a drilled high-temperature hydrothermal system known to be masked by cooler aquifers had no soil-mercury anomaly at the surface, whereas other areas with probable zones of vertical permeability had mercury anomalies (Priest and others, 1983a). This result suggests that hydrothermal systems in similar young layered volcanic terranes at Santiam Pass may be detected by doing mercury or other soil geochemical surveys on structures with vertical permeability.

Low-mass gaseous elements and compounds may be less affected than mercury by low-permeability layers and rapidly flowing ground water. As previously mentioned, the High Cascades have a great deal of rapidly flowing shallow ground water. Sampling of soil gases utilizing the Petrex method (Viellehave and others, 1967) may be a more effective means of detecting geothermal systems at depth in the High Cascades. Calibration of such a survey could be accomplished by analysis of soil samples from Breitenbush Hot Springs and Newberry volcano, where areas with and without hydrothermal systems have been drilled.

\section{Drilling program}

A hole will be drilled by rotary methods to about $300 \mathrm{~m}$ at the site of drill hole 13S/7E-32D (Figure 7 , folded, separate sheet). The aquifer at about $230 \mathrm{~m}$ will then be sampled by air lift, swabbing, and downhole sampling. The hole will be monitored for temperature over the next year. The drilling program will proceed as follows:

1. Prepare a drilling pad.

2. Mobilize rig and rig up.

3. Drill at $31 \mathrm{~cm}$ to about $35 \mathrm{~m}$.

4. Set about $37 \mathrm{~m}$ of $25-\mathrm{cm}$ casing.

5. Air rotary drill at $20 \mathrm{~cm}$ to about $300 \mathrm{~m}$.

6. Run temperature log to make sure the aquifer was intercepted.

7. Air lift and swab a fluid sample. Take downhole sample of fluid and gas.

8. Run full suite of geophysical logs.

9. Clean hole. 
10. Set 5-cm pipe, capped, filled with water, and surrounded by heavy mud; monitor temperature over the next year.

11. Plug and abandon after pulling pipe. Cement aquifers and put in 15-m-deep surface plug.

12. Restore site.

Statement of work

Drill-hole and hot-spring studies. A shallow hole will be drilled into the thermal aquifer at the site of hole 13S/7E-32DC (see drilling program above), and the thermal fluids will be sampled and analyzed as in the preliminary examination of Task 1. Planning, permitting, contracting, information dissemination, and sample curation will be conducted as in Task 1. Gas and fluid data from the preliminary examination of all Phase I drill holes (Tasks 1-4) will be utilized to calculate fluid ages. Gas and fluid data equivalent to those of the preliminary examination of the drill holes will also be collected from Breitenbush Hot Springs. Compositional data of Task 6 will be integrated with gas and fluid data to calculate reaction-path models in order to trace the chemical evolution of fluids and minerals in the hydrothermal systems.

Soil geochemical surveys. The soil geochemical study will be restricted to the part of the Santiam Pass transect lying in the Cascade heat-flow anomaly as defined by Black and others (1983). Highly accessible roaded areas will be the primary focus of the survey, because the data will be utilized principally to aid drill site selection. Soil samples will be collected in a grid pattern at a spacing of about one sample per $2.6 \mathrm{~km}^{2}$. Samples will be analyzed for mercury with a goldfilm-type detector (i.e., Jerome type) and for a broad range of gaseous compounds with the Petrex mass spectrometric method (e.g., Viellehave and others, 1967). Sample spacing will be about one per $0.1 \mathrm{~km}^{2}$ in areas of Santiam Pass with suspected vertical permeability (e.g., near fault zones and vent alignments).

The Santiam Pass soil survey will be compared to identical surveys of areas with hydrothermal phenomena and drill-hole data that are available to the public in order to obtain the chemical "finger print" of hydrothermal systems and areas of background heat flow. Drill sites and hot springs at Newberry volcano and Breitenbush Hot Springs will be the target of this part of the study. Samples will be collected at a spacing of one per $0.1 \mathrm{~km}^{2}$ within a radius of $0.2 \mathrm{~km}$ from hot springs and from intermediate-depth ( $400 \mathrm{~m}$ or deeper) drill holes with temperature data that are available to the public. The sampling programs at Newberry volcano, Breitenbush Hot Springs, and Santiam Pass will be conducted contemporaneously to minimize transient effects caused by weather and other factors.

Geochemical sampling of Blue Lake. In order to better evaluate the significance of hydrothermal circulation in Blue Lake, a systematic geochemical study should be included to complement the heat-flow study of Task 9. The study should have two components: (1) a water sampling and analysis program to determine the major- and minor-element compositions of the various limnologic units and specific hot springs in the lake; and (2) collection and analysis of representative sediment cores and pore waters from the lake to evaluate diffusive fluxes into the deep lake and to examine the sediment record for the history of 
hydrothermal activity.

Water sampling and chemical analyses should be carried out using state-of-the-art trace-metal and radiochemical methods. This work should cover the major limnologic units of the lake with a special emphasis on identified high-heat-flow areas and specific hot springs. Sampling should be carried out in conjunction with the heat-flow work (Task 9), using noncontaminating, large-volume samplers ( 5 to 20 liters / sample) deployed from a Kevlar or stainless steel hydrowire. Chemical analyses should include the major cations $\left(\mathrm{Na}^{+}, \mathrm{K}^{+}, \mathrm{Ca}^{2+}\right.$, $\mathrm{Mg}^{2+}$ ), anions $\left(\mathrm{Cl}^{-}, \mathrm{SO}_{4}{ }^{2-}\right.$ [or $\left.\mathrm{HS}^{-1}\right]$ ), nutrients, alkalinity, $\mathrm{pH}$, bulk conductivity and density, and several trace elements of hydrothermal origin ( $\mathrm{Fe}, \mathrm{Mn}, \mathrm{Mo}, \mathrm{V}, \mathrm{Cu}, \mathrm{Ni}, \mathrm{Ba}, \mathrm{Li},{ }^{222} \mathrm{Rn}$ and ${ }^{226} \mathrm{Ra}$ ).

Sediment cores should be taken at several points in the lake, especially near hot springs, to examine the record of hydrothermal activity in the lake and to estimate the diffusive flux of $222 \mathrm{Rn}$ and other trace components out of the sediments. Box cores should be used to collect an undisturbed sample of the critical sediment-water interface. Gravity cores can be used to obtain deeper samples.

Although all of the above mentioned equipment is commonly used in oceanographic sampling, the limitations of lake access, boat size, and power make proper sampling of these hydrothermal systems difficult. However, previous experience at Crater Lake and Lake Tahoe suggest that the required samples can be collected. The scientific value and cost-effectiveness of this work would increase if it were combined with concurrent field programs such as heat-flow surveys (Task 9) and ecological studies of the lake plankton communities.

\section{TASK 9 - DRIL-SITE GEOPHYSICAL SURVEYS}

\section{Objectives}

The primary objectives of local geophysical surveys around each drill site are to determine the surficial structure and the possible location, thickness, and lateral continuity of hydrothermal aquifers. Physical parameters determined from open-hole geophysical logs and mineralogic parameters determined from cores and cuttings will be used to help constrain the geophysical models. Shallow heat-flow measurements will be utilized in Blue Lake to explore for active hydrothermal systems thought to be present there.

\section{Background}

Surface mapping and a single drill hole do not usually provide enough information to construct a three-dimensional geologic picture of an area. To obtain information about areas that are deeper than and away from the drill hole, surface geophysical surveys should be made. Geophysical surveys are particularly useful in a setting such as the High Cascades, where so little of the geologic section and structure can be mapped. The geophysical-survey data used for mapping hydrothermal aquifers, altered zones, sediment layers, and volcanic rock units are made more valuable with the addition of open-hole geophysical logs (SP resistivity, temperature neutron porosity, density, and sonic 
velocity, for example) and with supporting information on fractures, petrology, authigenic minerals, and water-rock geochemistry that can be obtained from studies of cores and cuttings. The integrated analysis of geophysical surveys and drill-hole data will provide a clearer understanding of the present-day and past hydrothermal conditions.

All of the available geophysical surveys of the study areas, with the exception of the aeromagnetic work, have insufficient detail to delineate fine-scale shallow crustal structure and hydrothermal systems. There are some regional surveys of gravity (Couch and others, 1982a), magnetotellurics (Stanley, 1982, 1984), seismic refraction (Leaver and others, 1984), and heat flow (Black and others, 1982, 1983), but none of these data can be utilized for detailed analysis of upper crustal structural and thermal features.

Proposed surveys

Gravity.

1. Objectives. The objective of this survey is to define upper crustal structure by integrating the gravity data with measurements of density of rack units from the drill holes and from seismic surveys. To enhance our knowledge of the structural environs of the potential drill sites in the Santiam transect, we propose to establish 100 to 150 gravity stations in addition to the gravity stations presently available for the area. Data from these stations, when tied to the Corvallis base station and reduced to residual anomalies compatible with those published for the area (Couch and others, 1981), will delineate intermediate-size structures of the upper crust in the region of the Santiam Pass.

2. Background. The analysis of gravity measurements made in Oregon (Thiruvathukal and others, 1970) indicates that the Cascade Range is located along a transition zone in crustal thickness. West of the Cascades, the Cenozoic crust is approximately 20 to $25 \mathrm{~km}$ thick; east of the Cascades, however, the crust is approximately 35 to $40 \mathrm{~km}$ thick.

This marked increase in crustal thickness causes a steep gradient in the gravity field in the vicinity of the Cascade Range. Couch and others (1982a), after removing the regional gradient, interpret the residual-gravity anomalies of and proximal to the Cascades as outlining a large, filled graben. Within the 60-km-wide Cascades graben lies a narrower and less well-developed High Cascades graben. The very linear west wall of the Cascades graben lies within the Western Cascades and exhibits throws of 2 to $4 \mathrm{~km}$. The younger High Cascades graben, downdropped more than $2 \mathrm{~km}$, contains the Pliocene-Pleistocene stratovolcanoes that mark the present axis of the volcanic arc.

Bounding faults of the High Cascades graben are visible in some areas of the Cascades, most noticeably extending southward from the east and west flanks of Mount Jefferson (Hales, 1975; Taylor, 1980, 1981; Black and others, 1987). The larger and older Cascades graben, however, is completely filled and covered by flows and pyroclastic rocks of late Tertiary age, and its location and configuration is primarily delineated by gravity measurements.

In this respect, gravity measurements have been remarkably successful in outlining the major structures of the Cascades beneath the young, ubiquitous volcanic cover (Couch and others, 1982a; Couch and Foote, 1983). This success is due primarily to the large density con- 
trast between the dense andesites and basaltic flows and intrusions and the much lighter tephra and ash and mud flows.

Although the gravity measurements have outlined large-scale structures of the Cascade volcanic arc, the date spacing (greater than' $8 \mathrm{~km}$ between stations and exceeding $12 \mathrm{~km}$ in the vicinity of the intersection of the arc axis and the Santiam Pass) is too great to outline intrusives, flows, and faults of intermediate and smaller size. Additional gravity measurements are essential to outline the structures around the proposed drill sites, to allow the lateral extrapolation of the drilling results, to establish the structural setting of the drill sites with respect to the major structures of the volcanic arc, and to demonstrate that the results of the drill hole are not unique to the locale of the hole.

3. Statement of work. A network of gravity stations will be occupied around each drill hole to provide fill-in data, as necessary, to augment the existing network of gravity stations established in central Oregon and along the axis of the High Cascades (i.e., Couch and others, $1982 a, b)$. Approximately 100 to 150 gravity stations based on the Corvallis Datum will be occupied in the vicinity of the Santiam Pass. Gravity measurements will be reduced to residual anomalies using elevations obtained from stereo air photos and a reduction density statistically determined for the area. These data will be merged with existing regional data and subsequently analyzed by various filtering techniques. The data will generate maps of anomalies attributable to crustal structures and to anomalies possibly attributable to shallow-bore-holescale features.

\section{Electrical surveys}

1. Objectives. The objectives of this work are to define shallow crustal structure and its relation to hydrothermal alteration, possible aquifers, and other resistivity variations in the Santiam Pass and Breitenbush areas.

2. Background. No detailed electrical data are available in the study areas, but deep electromagnetic soundings have been made at widely spaced magnetotelluric (MT) stations on several transects across the Cascades (Stanley, 1981; 1982) (Figure 23). A preliminary resistivity interpretation of data taken along line 4, passing between Mount Jefferson and Three Sisters, is shown in Figure 24. An extensive conductor ( $<10 \mathrm{ohm} . \mathrm{m})$ underlies the entire region at depths of $<20 \mathrm{~km}$ and is shallowest near the crest of the High Cascades. No other electrical data are available in the study areas.

3. Statement of work. Controlled-source and/or magnetotelluric soundings will be made at an array of stations around each drill hole. The type of technique to be used, the station locations, and station density will be dependent on local conditions such as geology, topography, and road or trail access. The sounding data will be interpreted in terms of $1-D, 2-D$, and 3-D geoelectric models for the local area around the drill hole. The sounding results will be augmented, where possible, by the information from available regional sounding results. For the interpretation, the model parameters will be constrained by drill-hole and other geophysical data. The geoelectric model will pro-vide information on structures and resistivity variations associated with alteration, thermal aquifers, and host-rock lithology to depths of 2 to 3 $\mathrm{km}$. The geoelectric model will be synthesized with geological and other 
geophysical data, primarily heat-flow, gravity, and seismic, to obtain a better understanding of the present-day and past hydrothermal system.

Seismic surveys

1. Objectives. The objective of this investigation is to develop a three-dimensional model of the upper crust in the vicinity of the proposed drill holes (Tasks 1 and 2) in the Santiam Pass area.

2. Background. No high-resolution seismic data are available for the study areas, although a COCORP line was completed across McKenzie Pass about $10 \mathrm{~km}$ south of Santiam Pass, and a regional, northstriking seismic refraction line crosses part of the study area (Figure 25). The COCORP reflection survey was not very successful in delineating upper crustal structure in the Cascades, because of the unusually low-quality data compared to most COCORP data (C.J. Potter, personal communication, 1985; Keach, 1986; Keach and others, 1986). However, some discontinuities in seismic reflectors were interpreted as faults with $2.0-2.5 \mathrm{~km}$ of offset bounding the west side of the High Cascades graben (Keach, 1986; Keach and others, 1986). Only minimal offset was noted on the east side of the graben (Keach, 1986; Keach and others, 1986). The only other data are from a north-southtrending seismic refraction line along the west flank of the High Cascades (Leaver and others, 1984) that was not designed to delineate fine-scale upper-crustal structure. In any case, the refraction line crosses only a very small part of the study areas (compare Figures 25 and 3).

The study of Leaver and others (1984) and two other USGS seismic experiments within or near the Oregon Cascades provided valuable experience and were used as a guide for proposed work. The other two experiments are the studies of Mount Hood (Kohler and others, 1982) and of Newberry caldera (Stauber and others, 1985; Catchings and Mooney, in preparation). In particular, these investigations provide guidance regarding (1) the number, spacing, and size (mass) of seismic shots needed, (2) the drill-hole depth necessary for effective seismic shots, (3) the expected seismic propagation characteristics in the Cascades (attenuation, scattering, etc.), and (4) the necessary recorder spacings needed to resolve subsurface details in this highly heterogeneous structure.

Because seismic reflection usually fails in volcanic terrains and local seismicity is rare in the Santiam Pass area (Kollmann, 1984), the seismic experiment most appropriate for the delineation of local structure is a "NeHT" (Nercessian, Hirn, and Tarantola, 1984) highresolution three-dimensional active-imaging experiment. The NeHT ("net") method is capable of delineating three-dimensional velocity structure in the upper 5 to $10 \mathrm{~km}$ of the crust at better than $1-\mathrm{km}$ resolution. As such, it samples in three dimensions the volume to be sampled in one dimension by deep drilling and is highly complementary to the drilling.

3. Statement of Work. The seismic survey will be composed of two parts: (a) a short profile with smaller shots and close shot points for rather shallow penetration (1 to $2 \mathrm{~km}$ ), and (b) a longer profile with larger shots and somewhat broader shot spacing for upper crustal structure (2- to 7-km depth).

a. Shallow crustal survey. This study will consist of a 25-km-long NeHT profile (Figure 25) entirely within the High 
Cascades with shot points every $5 \mathrm{~km}$ and recorders every $200 \mathrm{~m}$. A total of eight shot points will be fired, including an offset shot at each end. Each shot hole will be drilled to a depth of $30 \mathrm{~m}$ and will be loaded with $340 \mathrm{~kg}$ of ammonium nitrate. Data analysis will be accomplished by using existing, well-tested seismic inversion methods, and the resultant model will be checked by forward modeling and further constrained with avallable geophysical and geologic information.

b. Upper crustal survey. This profile will provide information regarding the structure "ahead of the drill bit" for use in hydrologic modeling, geologic interpretation of the drill-hole cuttings, and site selection for the deeper drill hole. The profile (Figure 25) will be $80 \mathrm{~km}$ long with seven shot points spaced 20 $\mathrm{km}$ apart, including an offset shot at each end. The portable seismic recorders will be spaced $750 \mathrm{~m}$ apart to provide high resolution on the upper crustal structure. Seismic shot holes will be drilled to $43 \mathrm{~m}$ depth and loaded with 450 to $910 \mathrm{~kg}$ of ammonium nitrate. Data analysis will be accomplished using both inverse and forward modeling methods and will be constrained by magnetic, gravity, and geologic information.

c. Permitting. Necessary permits and authorizations will be obtained from the relevant authorities and land owners.

\section{Heat flow}

1. Objectives. The objective of this study is to make heat-flow measurements in the mud bottom of Blue Lake primarily to (1) investigate the hypothesis that a hot-spring system is responsible for the anomalous chemistry of the lake, and (2) attempt to establish a heatflow value along the crest of the High Cascade Range. The proposed studies will also further understanding of the limnology of fresh-water lakes affected by hydrothermal systems.

2. Background. Blue Lake is a small, deep, natural lake situated near the Cascade Range crest in sec. 27, T, 12 S, , R, 8 E. (Figure 7 , folded, separate sheet). The lake is in a basaltic andesite explosion crater that formed about 3,500 years ago (Taylor, 1981). Because of its volcanic origin, the lake is quite deep, in excess of $90 \mathrm{~m}$ in some places, and has very steep sides (Johnson and others, 1985). It is fed by large springs at about $73-\mathrm{m}$ depth near the east shore (Johnson and others, 1985). As previously mentioned, the lake has an anomalously high chloride content, possibly indicative of hydrothermal fluids (Johnson and others, 1985). Because of its location, access, and geology, the Blue Lake area has been proposed as a site for intermediate-depth $(1,200 \mathrm{~m})$ and deep $(>3,000 \mathrm{~m})$ drilling along the Cascade axis.

The possible existence of a hot spring near the crest of the High Cascades has important geothermal implications. The only known hot springs at high elevations are associated with the stratovolcanoes and are in or near wilderness areas, where access is either difficult or impossible. Geologically, it is certainly possible that geothermal systems associated with the extensive 3,500-year-ago volcanic episode exist in this area. Drilling sponsored by the Eugene Water and Electric Board (EWEB) and USDOE near Clear Lake, $10 \mathrm{mi}$ south of Blue Lake, encountered a region typical of the distal edges of a geothermal system (Blackwell and others, 1982a). Because of the thick cover of porous lava in most places, however, the "rain curtain" effect prevents heat- 
flow/temperature-gradient studies in typical 150-m-deep holes. The presence of the lake implies impermeable rocks in the local area and suggests that useful heat-flow data might be obtained. Lake heat-flow measurements at Yellowstone Lake (Morgan and others, 1977; Blackwell and others, 1986b) and at Crater Lake (Williams and von Herzen, 1983) demonstrate the utility of such studies.

Conductive heat flow and hydrothermal circulation into deep lakes like Blue Lake can significantly affect the vertical stability and physical mixing processes that distribute nutrients throughout the water column. A complete heat-flow study of the lake will therefore further understanding of the limnology, especially when integrated with the geochemical-studies of Task 8 .

3. Statement of work. A boat capable of acting as a platform for heat-flow studies will be launched on Blue Lake. The heat-flow probe will be transported to and assembled in the boat. During the studies, accurate microwave navigation and high-resolution bottomsounding equipment need to be on board. A sufficient number of drops will be made to characterize the temperatures in the mud in parts of the lake deeper than about $30 \mathrm{~m}$. This study will be carried out as early in June as possible to be in the most favorable time window relative to the annual thermal cycle of the bottom water. Water temperatures will be monitored during the year to establish the magnitude and timing of the thermal cycle. The amount of field-work time required to complete these tasks to establish the bottom-water thermal cycle is estimated to be approximately two weeks in June plus 11 day trips to the lake over the period of a year.

During the measurements, temperature and in-situ thermal conductivity will be obtained. Several core samples for thermal conductivity measurements and geological studies (see Task 1) will be taken. The data will be corrected for the annual temperature cycle of the bottom water, sedimentation effects, and terrain. The results will provide important thermal information for the High Cascade Range.

\section{TASK 10 - REGIONAL SEISMIC EXPERIMIENT}

\section{Objectives}

The principal objectives of the regional seismic experiment are to map the configuration of the subducted oceanic slab and to search for zones of magma or partially molten rock in the crust and upper mantle. This information will be used to constrain possible tectonic and thermal models for the volcanic arc that will emerge from the other Phase I studies in the Santiam Pass and Breitenbush areas.

\section{Background}

The measurement of the compressional and shear-wave velocity structure of the crust and upper mantle is fundamental to the geophysical, geologic, and thermal characterization of volcano-tectonic regions. When combined with geologic knowledge, such as detailed surface geologic mapping, petrology, geochronology, and geochemistry, and additional geophysical knowledge, such as heat flow and the regional mag- 
netic and gravity field, the P-wave and S-wave velocity structure may be used to infer the composition and physical state of the crust. For example, low velocities in the uppermost crust in crystalline terrains provide evidence of pervasive fracturing to depths of a kilometer or more, and an upper crustal low-velocity zone detected beneath Long Valley Caldera, California, has been identified as a silicic magma chamber (Hill, 1976; Steeples and Iyer, 1976; Sanders, 1984; Luetgert and Mooney, 1984).

Figure 26 summarizes available teleseismic and seismic refraction data along an east-west profile through Santiam Pass, Oregon $\left(44^{\circ} 25.49^{\prime}\right.$ N. lat). The model of the subducted oceanic plate was inferred from the teleseismic travel-time profile of Michaelson and Berge (written communication, 1985). Only the extreme limits of possible slab positions are shown. This range of slab positions is illustrative of the uncertainties in the present teleseismic data and is due simply to the very large interstation gaps in the area.

As previously mentioned, a COCORP line crossed central Oregon immediately south of the Santiam Pass transect. The west end of the COCORP line delineated crustal structure in the Coast Range and Willamette Valley and found east-dipping reflections at depths of $37-40 \mathrm{~km}$ that may be the decollement above the subducting oceanic plate (Figure 27) (Keach, 1986; Keach and others, 1986). The extension of this line into the Cascades was not very successful in receiving deep reflections and was thus not useful for interpreting the regional structure or the configuration of the subducted plate in the volcanic arc (Figure 27) (C.J. Potter, personal communication, 1985; Keach, 1986; Keach and others, 1986). Upper crustal structure interpreted from this line is discussed above (Task 10).

\section{Statement of work}

The most essential seismic experiment proposed for the Santiam Pass and Breitenbush areas is whole-crust refraction. This experiment should include at least two north-south lines (Western Cascades or Willamette Valley, and eastern High Cascades or Deschutes Valley) and a long east-west line through Santiam Pass (Figure 25). The northstriking lines, combined with the line of Leaver and others (1984), provide essential constraints for interpreting the east-striking line. An additional east-west line will be completed to test the Santiam Pass line structure for two-dimensionality. This refraction experiment should also be combined with the fine-scale teleseismic imaging experiment discussed in Task 7 to take full advantage of both methods.

The second critical seismic experiment for the Santiam Pass area consists of running one or more deep-sounding teleseismic lines through this part of the Cascades to determine local subduction geometry and to detect any deep magmatic sources (Figure 25). If two or more parallel lines are used, the data will give three-dimensional deep structure, including the true dip of the slab. A single line will give one northweststriking vertical cross section. The deep-sounding experiment should be combined with $5-\mathrm{km}$ resolution teleseismic soundings of the crust beneath the central High Cascades. This fine-scale experiment is complementary to the refraction lines and should be interpreted jointly with them.

Together, the deep and fine-scale teleseismic experiments will 
detect any silicic crustal melt zones larger than $5 \mathrm{~km}$ and any mantle partial melt zones larger than $20 \mathrm{~km}$ and should detect any large intermediate-composition magma chambers as well. Mafic partial melts might escape detection in the crust; solidified mafic intrusives, however, will appear as high-velocity anomalies. It should be noted that the rocks making up most batholiths, if partially melted, will be detected by teleseismic sounding if the magma chambers exceed $5 \mathrm{~km}$ in diameter. The absence of such anomalies in all parts of the Cascades tested so far strongly suggests that magma chambers present there must be small, transient, mafic in composition and therefore seismically identical to the surrounding crust, or some combination of these. The location of the slab, when combined with crustal structure from refraction and fine-scale teleseismic experiments, should shed light on the mechanics of magma genesis and provide important constraints for interpreting deep heat-flow data. Present models of Cascades magmatic systems do appear to conflict with deep-sounding data. Any models generated as a result of deep drilling should be constrained to be consistent with observed deep structure.

Delineation of small-scale lateral structure variations with the NeHT experiment of Task 9 and larger scale variations determined from refraction and teleseismic experiments will allow full regionalization of the drilling results and constraints for heat-flow interpretations.

Refraction. A whole-crust refraction experiment will be conducted. This experiment will include two north-south lines (Western Cascades or Willamette Valley, and eastern High Cascades or Deschutes Valley) and a long east-west line through Santiam Pass (Figure 25). An additional east-west line will be completed to test the Santiam Pass line structure for two-dimensionality.

A number of shallow (100-m-deep) drill holes will be drilled and used for explosive charges to create seismic shock waves. Necessary permits and authorizations will be obtained from the relevant authorities and land owners.

Teleseismic experiments. Both deep and fine-scale teleseismic experiments are proposed. Two deep-sounding teleseismic lines will be combined with the results of a fine-scale teleseismic experiment with 5$\mathrm{km}$ resolution to produce a three-dimensional $\mathrm{S}$ - and $\mathrm{P}$-wave velocity model of the crust and mantle. The teleseismic lines will trend northwest across the volcanic arc (Figure 25).

\section{TASK 11 - PATEOMAGNETIC STUDIES}

\section{Objectives}

objectives:

Paleomagnetic studies will be undertaken to satisfy three primary

1. The paleomagnetism (PM) of fully oriented drill-core segments and nearby exposed units will be studied to increase understanding of the tectonic evolution of the Western Cascades.

2. The magnetostratigraphy (MS) of the drill cores will be used for dating and cross-correlations between boreholes. 
3. The drill-core magnetic properties and downhole trends will be measured to determine the nature of the crustal layer responsible for the observed anomalies.

\section{Background.}

PM results from the Oregon Coast Range (OCR) and the Western Cascades have shown that western Oregon has rotated clockwise by up to $70^{\circ}$ since the early Eocene (e.g., Figure 28) (Simpson and Cox, 1977; Beck, 1980; Beck and Plumley, 1980; Magill and others, 1981). It is not clear, however, precisely how these rotations have occurred and which forces have caused them. Because of an insufficient number of dated units, the previous PM studies in the Western Cascades were unable to determine the rotation versus time dependence for the Western Cascades.

One model advanced by Magill and others (1981) as an extension of earlier models by Simpson and Cox (1977) advocates a "two-stage rotation model, the first phase being Eocene clockwise rotation accompanying accretion of sea floor to the continent, and the second phase being associated with post-middle Eocene extension in the Basin and Range province." For the first phase, Magill and Cox (1980) envision rotation about Simpson and Cox's southern pivot point, near the boundary between the Klamath Mountains and Tertiary terranes of southwestern Oregon. The pirot point for phase 2 of the rotation is in southwestern Washington, very near Simpson and Cox's northern rotation axis. According to Magill and others (1981), the phase 1 rotation occurred between about 50 and $42 \mathrm{Ma}$, for a total clockwise rotation of $46^{\circ}$. Basin and Range extension at a rate of about $1.5^{\circ}$ per million years for the past $20 \mathrm{~m} . \mathrm{y}$. has caused a clockwise rotation of about $30^{\circ}$. In this model, no rotation occurred between 42 and $20 \mathrm{Ma}$. Beck and Plumley (1980) and Bates and others (1981) prefer a tectonic model whereby rotation at a rate of about $1.5^{\circ}$ per million years been approximately continuous since the early Eocene. They contend that the existing PM results are insufficient and do not support the 22-m.y. hiatus in rotation. Beck and Plumley $(1980)$ and Bates and others (1981) prefer the constant rotation rate model because of its relative simplicity and because it is equally consistent with the PM results.

Previous PM results from the Western Cascades from northern California to southern Washington (Beck and Burr, 1979; Magill and Cox, 1980; Bates and others, 1981; Beck and others, 1986) are all consistent with clockwise rotations that are not significantly different considering their age uncertainties and the 95-percent confidence limits of the PM results. Because there were not enough dated units, the previous PM studies in the Western Cascades were precluded from testing the time dependence of rotation during the Tertiary.

During the past few years, nearly 100 additional Western Cascades lavas have been radiometrically dated by the $\mathrm{K}-\mathrm{Ar}$ method (Sutter, 1978; Lux, 1982; Duncan and Pierce, unpublished data, 1986), yielding ages ranging from 42 to $10 \mathrm{~m} \cdot \mathrm{y}$. A PM study using these dated lavas might be able to distinguish between the one- and twophase rotation models for western Oregon. Depending on the availability of dated units for particular time intervals, the flows will be divided to represent five- to $10-\mathrm{m} . \mathrm{y}$. increments. Thus, we hope to establish 
whether the period from 42 to $20 \mathrm{Ma}$ is best described by a rotation hiatus in western Oregon, as predicted by Magill and others (1981), or whether the model of continuous rotation is more consistent with the PM results (Bates and others, 1981).

As an independent dating and correlation tool (objective 2), magnetostratigraphy would be most successfully employed for the proposed boreholes at Santiam Pass (described under Tasks 1 and 2), where it is known that volcanism has continued essentially to the present day. The presence or absence of the Brunhes-Matuyama boundary $(\approx 0.73 \mathrm{Ma})$ in any of the boreholes would be a very important age constraint and would permit making estimates of the rates of volcanism in terms of both total section accumulation and the frequency of alternating lithologies. In addition to obvious changes in polarity, sometimes unusual or excursion PM directions (inclinations) can be useful cross-correlation markers.

Magnetostratigraphy of samples in boreholes in the older Western Cascades (discussed under Tasks 3 and 4) would be practical only in conjunction with radiometric dating, in which case magnetostratigraphy could be useful for correlating between sections and for determining their rates of accumulation.

PM studies will also determine the nature of the crustal magneticanomaly source layer (objective 3 ). Over the past few years, detailed aeromagnetic surveys have been flown over the Cascades, including the Santiam Pass and Breitenbush areas (Couch and others, 1978, 1985). From the magnetic-anomaly spectra, the depths and thicknesses of the magnetic source layers were inferred. In addition, by using generalized properties of titanomagnetite minerals in basalts, depths to the Curie-point isotherm were also estimated (Connard and others, 1983). We shall undertake actual downhole measurements of the magnetic susceptibility, remanence intensity, and direction to provide "ground truth" data for forward magnetic-anomaly modeling over the boreholes. Obviously, it is essential to know the Curie temperatures downhole, because it is important for geothermal exploration to establish whether the temperature at the bottom of the magnetized layer (the Curie-point isotherm) is $150{ }^{\circ} \mathrm{C}$ or $5800^{\circ} \mathrm{C}$. The former is the Curie point of titanomagnetite with about 60 percent mole percent ulvospinel, and the latter is the Curie temperature of pure titanium-free magnetite.

\section{Statement of work}

Paleomagnetic directions of fully oriented core segments in the drill cores and of mapped exposed flows in the Breitenbush and Santiam Pass areas will be used to estimate associated tectonic rotations of these areas. To determine rotations, enough cooling units must be measured to permit time averaging of the ubiquitous geomagnetic secular variation. Hence, at least between 10 to 20 cooling units should be studied in each area.

Magnetostratigraphy of the cored boreholes together with radiometric dating will be used to date the drilled sections, to determine rates of volcanic activity, and to make correlations between drill holes. At the latitude of Santiam Pass $\left(44.4^{\circ}\right.$ N.), the inclinations would be sufficient for establishing the magnetic polarity; hence, azimuthal orientation of the cores is not needed for magnetostratigraphic polarity zonation, although "up-down" orientation of all core segments is absolutely 
critical.

The primary magnetostratigraphic effort will be for the Santiam Pass boreholes, including one of the shallow, $1.2-\mathrm{km}-$ deep, fully cored boreholes (Task 1) and also the deeper, 2.7-km-deep borehole that will be entirely cored below the depth of $1.2 \mathrm{~km}$ (Task 2). The paleomagnetic directions (inclinations) will be determined for every cooling unit, measuring from two to five independent specimens from each. By measuring multiple specimens per unit, one can determine the average PM direction (inclination) with the associated statistical parameters that define the confidence intervals. At least one specimen from each unit will be stepwise demagnetized thermally or with alternating fields (AF) to establish the optimum demagnetization procedure for recovering the primary directions. The results from these detailed pilot demagnetizations will be used to establish the demagnetization procedure for the remaining samples. The final product for the magnetostratigraphy would be the downhole polarity zonation for selected boreholes with inclination and error shown at 95-percent confidence limits. Based on the results from the $2.7-1 \mathrm{~m}$ composite section, we will develop a strategy for the MS studies of the remaining boreholes at Santiam Pass. As a minimum, the magnetic polarity of the bottom few cooling units would have to be determined for each borehole.

Downhole trends of the magnetic properties will be examined to assess the progressive effects of burial and prolonged hydrothermal alteration.

To accomplish this paleomagnetic objective, the PM properties of selected drill cores will be measured. The remanence direction and intensity will be determined for each cooling unit. In addition to these data, which will be available also for magnetostratigraphy, the magnetic susceptibility will be obtained for each unit. These results will be used to calculate the Koenigsbergen ratio $(q)$, which describes the relative importance of induced versus remanent magnetization. $\left(Q_{\mathbf{n}}=\right.$ (remanent/induced) magnetization; for $Q_{n}>1$, the remanence dominates, whereas for $Q_{n}<1$, the induced magnetic moment is dominant.) Curiepoint determinations and microscopic observations of the opaque minerals will be used to examine downcore variations in the magnetic minerals.

Finally, the magnetic properties and their downhole trends will be used as input for forward modeling of the magnetic anolmalies over the borehole(s) and compared with results from the aeromagnetic surveys.

\section{SUMMARY}

The preceding sections of this plan have described an integrated program of drilling and scientific studies aimed at exploring the thermal regime and geologic history of the Cascade Range. The proposed research is an unprecedented undertaking that will shed light on fundamental processes operative in subduction-related volcanic arcs worldwide. Figure 4 illustrates schematically the environments that will be sampled by each of the proposed drill holes. The four $1.2-\mathrm{km}$-deep holes to be drilled in the High Cascades at Santiam Pass (Task 1) will help to define the thermal regime across the axis of Quaternary volcanism. The proposed $2.7-\mathrm{km}$-deep hole (Task 2) will sample deep thermal fluids and gases in the High Cascades. The 2.0-km-deep hole to be drilled southeast of Breitenbush Hot Springs (Task 3 ) will sample 
a typical Western Cascade hydrothermal system. Work on the Sunedco Well No. 58-28 (Task 4) will provide additional data on the Breitenbush hydrothermal system and allow sampling of rocks and fluids down to a depth of $4.0 \mathrm{~km}$. Deepening the 2.5-km-deep Sunedco hole to $4.0 \mathrm{~km}$ will be a definitive test of the vertical extent of the regional heat-flow anomaly and will offer invaluable data on pre-Cascade basement rocks.

A number of geological and geophysical studies were proposed to enhance the drilling program. These tasks (Tasks 5-11) are aimed at describing the regional stress regime, the structure of the upper crust and mantle, the configuration of the subducted oceanic plate, the history of hydrothermal circulation, and the geologic history in the Breitenbush and Santiam Pass areas. Much of the research in this part of the investigation takes advantage of geologic perspectives offered by the Oligocene and older volcanic rocks of the deeply eroded Western Cascades. These studies offer the opportunity to view the drilling results in the context of the last $37-40 \mathrm{~m} . \mathrm{y}$. of geologic history of the volcanic arc. 
PHASE I MANAGEMENT PLAN

\section{MANAGEMENTT}

\section{Introduction}

The organization of the management team reflects the complexity of completing all of the Phase I tasks within about three to five years. This time frame will require concurrent drilling of two or more holes during a single field season and rapid resolution of complex environmental and logistical problems. The management structure is therefore designed to augment the efficiency of the decision-making process for Phase I. Policy decisions and screening of scientific proposals, will be handled by committees, whereas day-to-day management will be conducted by the full-time Project Coordinator, the Chief Scientist, and the Chief Engineer. This management structure will allow drilling decisions to be made quickly without the need to assemble a large committee on short notice.

\section{Organization}

The proposed organization of the project management team is summarized in Figure 29. The organization chart does not reflect contractual relationships, because these are not known. The contractual relationships and financial management responsibilities will likely cause the organization to be modified. Chief authority for managing the project will reside with the Scientific Steering Committee (SSC). The SSC will screen scientific proposals and be the final authority on major programmatic decisions. Close cooperation between the government agencies responsible for managing, funding, and regulating the project will be effected by the Interagency Coordinating Committee (ICC), which will offer advice to the SSC on environmental, institutional, and policy issues. The Project Coordinator and his staff, by preventing conflicts and duplication of efforts, will facilitate day-to-day management of the diverse research and engineering teams. The Chief Scientist will serve as chairman of the SSC and will advise the Project Coordinator on management of scientific tasks. The Chief Engineer will design the drill holes and manage the drilling project in cooperation with the Project Coordinator. A more detailed description of the responsibilities and authorities of the various members of the project team appears below. 
Key responsibilities and membership

Interagency Coordinating Committee (ICC). The ICC will be responsible for resolution of policy issues that may arise, particularly environmental and institutional problems. The ICC will advise the the SSC on modifications of the science plan that may be necessary to resolve environmental and institutional problems. The ICC will also advise the SSC on overall goals and priorities for the project.

The ICC should consist of representatives from the chief funding agencies, agencies responsible for regulating the drilling and other activities, and agencies that will be managing the project. The chief regulatory agencies include the U.S. Forest Service (USFS), the U.S. Bureau of Land Management (USBLM), and the Oregon Department of Geology and Mineral Industries (DOGAMI). Possible funding agencies include the U.S. Department of Energy (USDOE), the U.S. Geological Survey (USGS), and National Science Foundation (NSF). Managing agencies could include the USGS, national laboratories, participating universities, and state geological surveys. The membership should be limited to about eight or nine persons, in order to facilitate the decision making process.

Scientific Steering Committee (SSC). The SSC is the final authority for management decisions on the project. The SSC will prioritize project objectives, screen research proposals, and review scientific plans and the progress of the program. Disagreements between the Chief Scientist, the Chief Engineer, and the Project Coordinator will be resolved by the SSC.

The SSC will consist of scientists representing the major participating research organizations. Membership should be kept to a maximum of about eight to nine persons, consisting of one member from each of the participating groups within the USGS, universities, national laboratories, and state geological surveys.

Chief Scientist. The Chief Scientist will chair the SSC and will be the point of contact between the SSC and the ICC, the Chief Engineer, and Project Coordinator. The Chief Scientist will be directly responsible for scientific planning for the project. The Chief Scientist will approve the drilling operation plans for each site, which are prepared by the Chief Engineer, in direct consultation with the appropriate principal investigators and the Project Coordinator. The Chief Scientist will work with the Project Coordinator and Chief Engineer to plan and monitor fluid sampling, hydraulic tests, and logging operations for all drill sites. Supervision and coordination of the activities of the drillsite geologists/hydrologists will be the responsibility of the Chief Scientist.

The Chief Scientist will work with the Project Coordinator to ensure that all required rock and fluid samples are collected, handled, and stored according to the "Continental Scientific Drilling Program Sample Management Policy and Procedures." The Chief Scientist will supervise prompt publication of preliminary results from the drill sites including (1) the scientific findings, (2) lithologic logs, (3) borehole logs and surveys, (4) fluid samples and hydraulic tests, and (5) the drilling history. The Chief Scientist will serve as the point of contact for the external flow of data from the drill sites and, as such, will make certain that core boxes and fluid samples are inspected to assure 
their integrity before delivery to the CSDP curator.

Principal Investigators. The principal investigators for the scientific studies will be responsible for assuring that the scientific objectives of their projects are met within the constraints of the proposed project schedule. They will coordinate their investigations with the Project Coordinator after the projects have been reviewed and approved by the SSC and Chief Scientist.

Project Coordinator. The Project Coordinator is primarily responsible for making the project operate smoothly and within budget. The Project Coordinator will supervise daily operations of the project, including contracting and procuring. Responsibilities of the Project Coordinator include (1) expediting and facilitating subcontracting, (2) assuring proper documentation of project plans, (3) controlling project costs, (4) controlling project schedule, (5) assuring the high quality of scientific output, (6) coordinating the drilling operation with scientific experiments in and around the drill holes, (7) arbitrating disagreements between the principal investigators or the Chief Scientist and the Chief Engineer, and (8) hiring consultants or convening advisory panels to create or review engineering alternatives.

Chief Engineer. The Chief Engineer or his delegated representative is primarily responsible for design of the drill holes and supervision of the drilling operation. The Chief Engineer will provide all information needed by the Project Coordinator to solicit bids for the drilling tasks. The Chief Engineer will then advise the Project Coordinator on selection of the drilling and logging contractors. When drilling begins, the Chief Engineer will have responsibility for and authority over the activities of all coring and drilling subcontractors. In addition, the Chief Engineer will develop and maintain the drilling operation plan for each site and will have this plan reviewed by reviewers to be designated by the funding agency (e.g., for USDOE Office of Basic Energy Science, the Drilling Office is the reviewer). Major changes in the planned drilling program necessitated by unpredictable drilling conditions will be made in consultation with the Project Coordinator and the Chief Scientist to ensure that budgetary and scientific needs are not compromised. The Chief Engineer will assist the Project Coordinator with land access, acquire permits, and prepare needed environmental assessment documents. He will supervise all logging, surveying, and other downhole services and have a log analyst witness these activities. In addition, he will make sure that records of all drilling-related activities, including subcontractor records, are maintained in the drill-site record file and transmitted to the Project Coordinator. Safety of all personnel at the drill site is the responsibility of the Chief Engineer.

Principal investigators wishing to conduct experiments in the drill holes must submit descriptions of their projects for approval by the Chief Engineer. The Chief Engineer may suggest alternatives to the principal investigators in order to optimize data collection relative to efficient drilling practices. If the principal investigators cannot reach a compromise with the Chief Engineer, then the Project Coordinator will convene a meeting with the Chief Engineer, Chief Scientist, concerned principal investigators, and any expert advisors deemed necessary to decide the issue. 
Drill-site geologists. Drill-site geologists will work with the Chief Scientist to ensure that lithologies are described in an accurate and uniform fashion and that all of the needs of the principal investigators are met. The drill-site geologists are responsible for (1) preliminary descriptions (lithologic logs) of core and cuttings; (2) record keeping, including changes in drilling conditions such as penetration rate, mud temperature, or fluid and gas flow; (3) appropriate care of cores and cuttings, including marking, tagging, and boxing according to curatorial protocol; (4) communication with visitors to the site; and (5) cooperative work with investigators with regard to special cores and experiments.

A drill-site geologist will be at the drill site whenever active drilling takes place. The drill-site geologists will be in continual communication with the Chief Scientist, relaying information about the progress of the hole.

Sample Curator. With the cooperation of the principal investigators, the Curator will evaluate and respond to all requests for samples from the core holes: The Curator will spot-check curation protocol and techniques during drilling and assure that core and other samples are transferred to the appropriate temporary and permanent curation facilities. Curation will be handled according to standard USDOE guidelines (Goff, 1986). The Curator will supervise temporary storage of samples in a facility close to the site where the core can be photographed and where initial dissemination of samples can be accomplished. As a minimum, measurement of density and electrical resistance of all lithologic units in each hole will be determined at this facility. The core repository at the School of Oceanography at Oregon State University, Corvallis, Oregon, is the closest facility of this kind to the Phase I drill sites. The Curator will also be responsible for transfer of the core to an appropriate USDOE repository for permanent storage.

Preliminary Scientific Report Team. The Preliminary Scientific Support Team will be made up of the Chief Scientist, drill-site geologists, a well-log analyst, a hydrologist or hydrogeochemist, a geophysicist, and a technical editor. After completion of each hole, a preliminary report on the geology, geochemistry, and geophysics must be prepared quickly to be circulated to the scientific community. This report, which must be a brief (less than 100 pages) but comprehensive overview, will serve as the basis for new studies and sample requests and must be published three months after completion of each hole. This report will be released at a workshop, the purpose of which will be to expedite the transfer of information to the scientific community. The workshop will also serve as a forum for establishing working groups and encouraging proposal writing.

Key documents and records

Scientific plan. The present document is the overall scientific plan for the project. It has been prepared by DOGAMI in cooperation with the ad hoc Cascade Task Force. In future years, this document can be modified by the Chief Scientist in collaboration with the SSC.

Drilling operations plan. This document will be prepared by the Chief Engineer for each drill hole. 
Drill-site records file. These records will be the responsibility of the well-site geologists under the supervision of the Chief Scientist.

Curation records. The Curator will maintain the curation records.

Project-records file. The Project Coordinator, with the assistance of the principal investigators, the Chief Scientist, and the Chief Engineer, will maintain this file.

Periodic reports. Monthly reports will be prepared by the principal investigators. During drilling operations, written progress reports will be delivered to the appropriate funding agency on a weekly basis by the Project Coordinator.

\section{Communication Interfaces}

The Chief Scientist and principal investigators will be responsible for external communications concerning the project. It will be their re: sponsibility to keep the funding agency and other members of the scientific community informed concerning the progress of the project. The Project Coordinator is responsible for keeping the principal investigators informed about drilling and experiment schedules as well as availability of data.

\section{Procedures}

When deemed necessary, standardized procedures will be formalized. These will include, at a minimum, procedures for the well-site geologists and procedures for emergencies.

\section{CORE CURATION}

Cores, cuttings, liquids, gases, and other samples and data from the proposed research drill holes will be handled in accordance with established USDOE curation policy and procedures (Goff, 1986). All personnel handling core at the drill site will be familiar with the CSDP curation procedures and will be responsible for round-the-clock sample handling that will include completing detailed field records, as well as labeling, numbering, boxing, and photographing the cores.

All sample requests will be reviewed by the Chief Scientist to allow coordination of the sampling program. Principal investigators and other scientists may take sample splits of recovered materials or "subsamples" only after the preliminary investigation has been completed but before the samples are sent to the permanent sample repository. Preliminary investigations, which must be completed first, include logging in the materials and completing the field description. The amount of subsample that a principal investigator or other scientist takes must be consistent with the amount specified in the proposal detailing scientific investigations to be performed. Responsibilities for subsample collection in the field will reside with the curation facility representative. After field descriptions and initial work are completed to the Chief Scientist's satisfaction, the cores and cuttings will be shipped to the permanent repository.

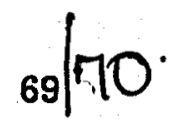





\section{PHASE I - SCHEDULE AND BUDGET}

\section{SCHEDULE}

A possible schedule for Phase $I$ is shown in Table 4. The program could begin in 1987 with a site selection survey in the High Cascades at Santiam Pass (Task 1). At the same time, initial preparations for workover operations and later, deeper drilling/coring at the Sunedco Well No. 58-28 (Task 4) and an appropriate abandoned oil and gas exploration well (see Task 5) would commence. Permitting for the 2.0$\mathrm{km}$-deep hole east of the Sunedco site (Task 3) could be accomplished in 1987. Surface geological and geophysical surveys (Tasks 6-10) and paleomagnetic studies (Task 11) could also begin in 1987.

Drilling on the four 1.2-km-deep holes at Santiam Pass (Task 1) and the 2.0-km-deep hole southeast of Breitenbush Hot Springs (Task 3) could begin in 1988. Workover operations and drilling on the abandoned oil-and-gas well (Task 5) and the Sunedco site (Task 4) could also begin in 1988. Surface geological surveys would continue.

Site selection and permitting for the $2.7-\mathrm{km}$-deep hole in the Santiam Pass area (Task 2) should be completed in early 1989 after analysis of data from the $1.2-\mathrm{km}$-deep holes. Drilling can begin on the 2.7-km-deep hole in the summer of 1989. Geologic mapping would continue.

Maps and reports synthesizing the data could be published in 1989 and early. 1990, although interim reports would be made available is various data sets are developed.

This schedule was prepared to illustrate how soon Phase I could be completed. Actual scheduling will be dependent on the availability of funds to support the proposed work. As many as fire years could be required, depending on unforeseen delays.

\section{BUDGET}

Task 1 - Drill four 1.2-km-deep holes, Santiam Pass

1. Planning ................................. 58,000

2. Drilling .....................................1,630,000

3. Preliminary science ............................330,000

4. Curation and sample distribution ................. 240,000 TOTAL .............................. \$2,258,000

Task 2 - Drill one 2.7-km-deep hole, Santiam Pass

1. Planning $\ldots \ldots \ldots \ldots \ldots \ldots \ldots \ldots \ldots \ldots \ldots \ldots \ldots \ldots \ldots \ldots, 81,000$

2. Drilling $\ldots \ldots \ldots \ldots \ldots \ldots \ldots \ldots \ldots \ldots \ldots \ldots \ldots \ldots \ldots \ldots \ldots \ldots \ldots \ldots \ldots \ldots \ldots \ldots \ldots, 829,000$ 
3. Preliminary science $\ldots \ldots \ldots \ldots \ldots \ldots \ldots \ldots \ldots \ldots \ldots, \ldots \ldots, 0, \ldots \ldots$

4. Curation and sample distribution $\ldots \ldots \ldots \ldots \ldots \ldots \ldots \ldots, 150,000$ TOTAL $. . \ldots \ldots \ldots \ldots \ldots \ldots \ldots \ldots \ldots \ldots \ldots \ldots \ldots \ldots \$ 2, \mathbf{2 2 4 , 0 0 0}$

Task 3 - Drill one 2.0-km-deep hole, Breitenbush area

1. Planning $\ldots \ldots \ldots \ldots \ldots \ldots \ldots \ldots \ldots \ldots \ldots \ldots \ldots \ldots \ldots, 23,000$

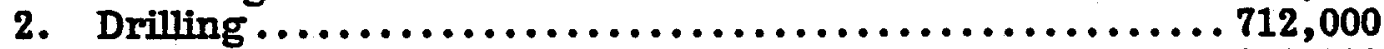

3. Preliminary science $. \ldots \ldots \ldots \ldots \ldots \ldots \ldots \ldots \ldots \ldots \ldots \ldots, 109,000$

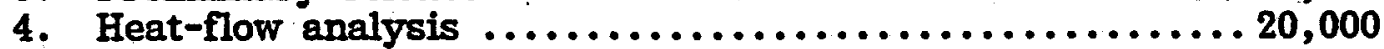

5. Curation and sample distribution ..................100,000 TOTAL $. . \ldots \ldots \ldots \ldots \ldots \ldots \ldots \ldots \ldots \ldots \ldots \ldots \ldots \ldots, \$ 964,000$

Task 4 - Drill one 4.0-km-deep hole, Breitenbush area

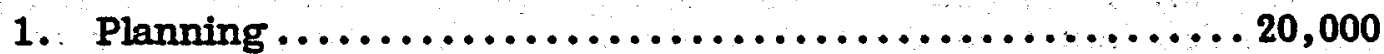

2. Drilling ......................................2, 101,000

3. Preliminary science $\ldots \ldots \ldots \ldots \ldots \ldots \ldots \ldots \ldots \ldots \ldots \ldots 17,000$

4. Curation and sample distribution .................8 80,000 TOTAL .................................\$2,380,000

Task 5 - State-of-stress experiments

1. Drilling $. \ldots \ldots \ldots \ldots \ldots \ldots \ldots \ldots \ldots \ldots \ldots \ldots \ldots \ldots \ldots \ldots, 304,000$

2. Scientific support $\ldots \ldots \ldots \ldots \ldots \ldots \ldots \ldots \ldots \ldots \ldots \ldots \ldots 240,000$

3. Televiewer logs $\ldots \ldots \ldots \ldots \ldots \ldots \ldots \ldots \ldots \ldots \ldots \ldots \ldots \ldots 34,000$ TOTAL $\$ 578,000$

Task 6 - Geologic and petrologic studies

1. Salaries and travel...........................6612,000

2. Analytical expenses and supplies ................, 300,000

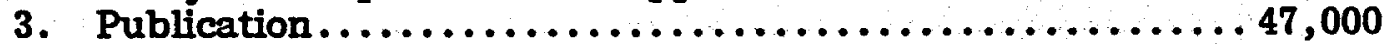

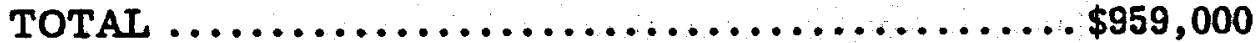

Task 7 - Hydrothermal-alteration studies

1. Salaries, travel, and publication $\ldots \ldots \ldots \ldots \ldots \ldots \ldots, 411,000$

2. Laboratory expenses ........................ 367,000

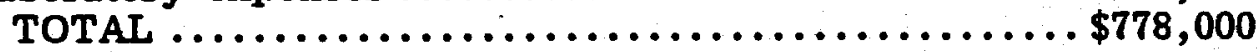

Task 8 - Hydrogeochemical studies

1. Drilling $\ldots \ldots \ldots \ldots \ldots \ldots \ldots \ldots \ldots \ldots \ldots \ldots \ldots, 9,0,00$

2. Drill-hole and hot-springs studies ................38,000

3. Soil geochemical study .......................55,000

4. Geochemical sampling of Blue Lake ................25,000

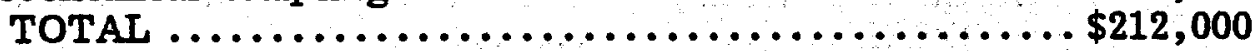

Task 9 - Drill-site geophysics

1. Gravity $\ldots \ldots \ldots \ldots \ldots \ldots \ldots \ldots \ldots \ldots \ldots \ldots \ldots \ldots \ldots \ldots, 45,000$

2. Resistivity $. \ldots \ldots \ldots \ldots \ldots \ldots \ldots \ldots \ldots \ldots \ldots \ldots \ldots \ldots \ldots, 182,000$

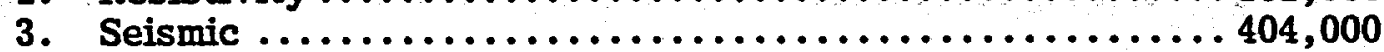


4. Blue Lake heat flow............................ 50,000 TOTAL ................................\$681,000

Task 10 - Regional seismic experiment

1. Seismic refraction $. . \ldots \ldots \ldots \ldots \ldots \ldots \ldots \ldots \ldots \ldots \ldots \ldots \ldots, 196,000$

2. Teleseismic $P$ and $S$ residual profiles .............158,000

TOTAL .................................\$354,000

Task 11 - Paleomagnetic studies

1. Salaries $. . \ldots \ldots \ldots \ldots \ldots \ldots \ldots \ldots \ldots \ldots \ldots \ldots \ldots \ldots \ldots \ldots, 136,000$

2. Supplies, travel, and publication................28,000

TOTAL ................................\$164,000

The estimated budget for successfully accomplishing all Phase I tasks is about $\$ 11.5$ million. The essential drilling tasks (Tasks 1-4) will require about $\$ 7.8$ million. The remaining $\$ 3.7$ million is for support for studies that enhance the drilling effort. 


\section{REFERENCES CITED}

Allen, J.E., 1966, The Cascade Range volcano-tectonic depression of Oregon, in Benson, G.T., ed., Lunar Geological Field Conference, Bend, Oregon, August 1965, Transactions: Oregon Department of Geology and Mineral Industries Open-File Report 0-66-1, p. 21-23.

Avramenko, W., 1981, Volcanism and structure in the vicinity of Echo Mountain, central Oregon Cascade Range: Eugene, Oreg., University of Oregon master's thesis, $156 \mathrm{p}$.

Bacon, C.R., 1983, Eruptive history of Mount Mazama and Crater Lake caldera, Cascade Range, U.S.A.: Journal of Volcanology and Geothermal Research, $\nabla$. 18, p. 57-115.

Baldwin, E.M., 1974, Eocene stratigraphy of southwestern Oregon: Oregon Department of Geology and Mineral Industries Bulletin 83, 40p.

Barnett, B., 1986, Geothermal gradient drilling project for the state of Washington: Washington Division of Geology and Earth Resources Open-File Report 86-2, $34 \mathrm{p}$.

Bates, R.G., Beck, M.E., Jr., and Burmester, R.F., 1981, Tectonic rotations in the Cascade Range of southern Washington: Geology, v. 9, no. 4, p. 184-189.

Beck, M.E., Jr., 1980, Paleomagnetic record of plate-margin tectonic processes along the western edge of North America: Journal of Geophysical Research., $\nabla .85$, no. B12, p. 7115-7131.

Beck, M.E., Jr., Burmester, R.F., Craig, D.E., Gromme, C.S., and Wells, R.E., 1986, Paleomagnetism of middle Tertiary volcanic rocks from the western Cascade Series, northern California: Journal of Geophysical Research, $\nabla .91$, in press.

Beck, M.E., Jr., and Burr, C.D., 1979, Paleomagnetism and tectonic significance of the Goble Volcanic Series, southwestern Washington: Geology, v. 7 , no. 4, p. 175-179.

Beck, M.E., Jr., and Plumley, P.W., 1980, Paleomagnetism of intrusive rocks in the Coast Range of Oregon: Microplate rotations in middle Tertiary time: Geology, $\forall . .8$, no. 12, p. 573-577.

Berg, J.W., Jr., Trembly, L., Emilia, D.A., Hutt, J.R., King, J.M., Long, L.T., McKnight, W.R., Sarmah, S.K., Souders, R., Thiruvathukal, J.V., and Vossler, D.A., 1966, Crustal refraction profile, Oregon Coast Range: Seismological Society of America Bulletin, $\cdot \nabla, 56$, no. 6 , p. 1357-1362.

Black, G.L., Blackwell, D.D., and Steele, J.I., 1982, Heat flow of the Oregon Cascades, in Priest, G.R., and Vogt, B.F., eds., Geology and geothermal resources of the Cascades, Oregon: Oregon Department of Geology and Mineral Industries Open-File Report O$82-7$, p. $152-171$.

-.-1983, Heat flow in the Oregon Cascades, in Priest, G.R., and Vogt, B.F., eds., Geology and geothermal resources of the central Oregon Cascade Range: Oregon Department of Geology and Mineral Industries Special Paper 15, p. 69-76. 
Black, G.L., Priest, G.R., and Woller, N.M., 1984, Temperature data and drilling history of the Sandia National Laboratories well at Newberry caldera: Oregon Geology, v. 46, no. 1, p. 7-9.

Black, G.L., Woller, N.M., and Ferns, M., 1987, Geologic map of the Crescent Mountain area, Linn County, Oregon: Oregon Department of Geology and Mineral Industries, Geological Map Series GMS-47, scale 1:62,500.

Blackwell, D.D., Black, G.L., and Priest, G.R., 1981, Geothermalgradient data (1979): Oregon Department of Geology and Mineral Industries Open-File Report 0-81-3B, $98 \mathrm{p}$.

----1982a, Geothermal-gradient data (1981): Oregon: Department of Geology and Mineral Industries Open-File Report 0-82-4, $430 \mathrm{p}$.

$----1986 a$, Geothermal-gradient data for Oregon (1982-1984): Oregon Department of Geology and Mineral Industries Open-File Report O86-2, $107 \mathrm{p}$.

Blackwell, D.D., Morgan, P., Spafford, R., and Steele, J., 1986b, Heat flow from Yellowstone Lake, Yellowstone Caldera, Wyoming [abs.]: EOS, $\nabla .67$, no. 44, p. 1226.

Blackwell, D.D., Bowen, R.G., Hull, D.A., Riccio, J.F., and Steele, J.L., 1982b, Heat flow, arc volcanism, and subduction in northern Oregon: Journal of Geophysical Research, v. 87, no. B10, p. 8735-8754.

Blackwell, D.D., Hull, D.A., Bowen, R.G., and Steele, J.L., 1978, Heat flow of Oregon: Oregon Department of Geology and Mineral Industries Special Paper 4, $42 \mathrm{p}$.

Blackwell, D.D., and Steele, J.L., 1983, A summary of heat flow studies in the Cascade Range: Geothermal Resources Council, Transactions, $\nabla .7$, p. 233-236.

Callaghan, E., and Buddington, A.F., 1938, Metalliferous mineral deposits of the Cascade Range in Oregon: U.S. Geological Survey Bulletin 893, $141 \mathrm{p}$.

Cantwell, T., Nelson, P., Webb, J., and Orange, A.S., 1965, Deep resistivity measurements in the Pacific Northwest: Journal of Geophysical Research, v. 70, no. 8, p. 1931-1937.

Cantwell, T., and Orange, A., 1965, Further deep resitivity measurements in the Pacific Northwest: Journal of Geophysical Research, v. 70 , no. 16 , p. 4068-4072.

Carey, S.W., 1958, The tectonic approach to continental drift, in - Carey, S.W., ed., Continental drift--a symposium: Hobart, Australia, University of Tasmania, p. 177-355.

Carison, R.W., 1984, Isotopic constraints on Columbia River flood basalt genesis and the nature of the subcontinental mantle: Geochimica et Cosmochimica Acta, $\nabla .48$, no. 11, p. 2357-2372.

Carlson, R.W., Lugmair, G.W., and McDougall, J.D., 1981 Columbia River volcanism: The question of mantle heterogeneity or crustal contamination: Geochimica et Cosmochimica Acta, V.45, no. 12, p. 2483-2499.

Cassignol, C., and Gillot, P.Y., 1982, Range and effectiveness of unspiked potassium-argon dating: Experimental groundwork and application, in Odin, G.S., ed., Numerical dating in stratigraphy: London, U.K., John Wiley and Sons, p. 160-179.

Catchings, R.D., and Mooney, W.D., in preparation, Crustal structure of the Columbia Plateau from detailed seismic refraction. 
Church, S.E., LeHuray, A.P., Grant, A.R., Delevaux, M.H., and Gray, J.E., 1986, Lead-isotopic data from sulfide minerals from the Cascade Range, Oregon and Washington: Geochimica et Cosmochimica Acta, v. 50, p. 317-328.

Clayton, C.M., 1976, Geology of the Breitenbush Hot Springs area, Cascade Range, Oregon: Portland, Oreg., Portland State University master's thesis, $79 \mathrm{p}$.

Connard, G.G., 1980, Analysis of aeromagnetic measurements from the central Oregon Cascades: Corvallis, Oreg., Oregon State University master's thesis, $101 \mathrm{p}$.

Connard, G.G., Couch, R.W., and Gemperle, M., 1983, Analysis of aeromagnetic measurements from the Cascade Range in central Oregon: Geophysics, $\nabla .48$, no 3, p. 376-390.

Conrey, R.M., 1985, Volcanic stratigraphy of the Deschutes Formation, Green Ridge to Fly Creek, north-central Oregon: Corvallis, Oreg., Oregon State University master's thesis, 349 p.

Couch, R.W., and Baker, B., 1977, Geophysical investigations of the Cascade Range in central Oregon: U.S. Geological Survey Extramural Geothermal Research Program, Technical Report no. 2, 55 p.

Couch, R.W., and Foote, H.P., 1983, Graben structures of the Cascade Range in Oregon [abs.]: EOS, $\checkmark .69$, no. 45, p. 887.

Couch, R.W., and Gemperle, M., 1979, Gravity measurements in the area of Mount Hood, in Geothermal-resource assessment of Mt. Hood: Oregon Department of Geology and Mineral Industries Open-File Report 0-79-8, p. 137-189h.

Couch, R.W., Gemperle, M., and Connard, G.G., 1978, Total-field aeromagnetic anomaly map, Cascade Mountain Range, central Oregon: Oregon Department of Geology and Mineral Industries Geological Map Series GMS-9, scale 1:250,000.

Couch, R.W., Gemperle, M., and Peterson, R., 1985, Total-field aeromagnetic anomaly maps, Cascade Mountain Range, northern Oregon: Oregon Department of Geology and Mineral Industries Geological Map Series GMS-40, scale 1:250,000.

Couch, R.W., and Lowell, R.P., 1971, Earthquakes and seismic energy release in Oregon: Oregon Department of Geology and Mineral Industries, Ore Bin, $v .33$, no. $4, \mathrm{p} .61-84$.

Couch, R.W., Pitts, G.S., Braman, D.E., and Gemperle, M., 1981, Free-air gravity anomaly map and complete Bouguer gravity anomaly map, Cascade Mountain Range, northern Oregon: Oregon Department of Geology and Mineral Industries Geological Map Series GMS-15, scale 1:250,000.

Couch, R.W., Pitts, G.S., Gemperle, M., Braman, D.E., and Veen; C.A., 1982a, Gravity anomalies in the Cascade Range in Oregon: Structural and thermal implications:- Oregon Department of Geology and Mineral Industries Open-File Report 0-82-9, $66 \mathrm{p}$.

Couch, R.W., Pitts, G.S., Gemperle, M., Veen, C.A., and Braman, D.E., 1982b, Residual gravity maps of the northern, central, and southern Cascade Range, Oregon: Oregon Department of Geology and Mineral Industries Geological Map Series GMS-26, scale $1: 250,000$.

Couch, R., Thrasher, G., and Keeling, K., 1976, The Deschutes valley earthquake of April 12, 1976: Ore Bin, $\nabla .38$, no. 10, p. 151161. 
Cummings, M.L., and Pollack, J.M., 1984, Field guide to the northern Cascade Range in Oregon from Zigzag to Jawbone Flats, Oregon, with overviews of Poop Creek, Sisi Butte, and Pinhead Buttes: Portland, Oregon, Portland State University, Department of Geology (prepared for Penrose Conference: Geochemistry of the Environment near a high-level nuclear waste repository), 59 p..

Dalrymple, G.B., and Lanphere, M.A., 1969, Potassium-argon dating-principles, techniques, and applications to geochronology: San Francisco, Calif., W.H. Freeman and Co., 258 p.

Davie, E.I., II, 1980, The geology and petrology of Three Fingered Jack, a High Cascade volcano in central Oregon: Eugene, Oreg., University of Oregon master's thesis, $138 \mathrm{p}$.

Dehlinger, P., Couch, R.W., and Gemperle, M., 1968, Continental and oceanic structure from the Oregon coast westward across the Juan de Fuca Ridge: Canadian Journal of Earth Sciences, $\nabla .5$, no. 4, pt. 2, p. 1079-1090.

Dehlinger, P., Couch, R.W., McManus, D.A., and Gemperle, M., 1970, Northeast Pacific structure, in Maxwell, A.E., ed., The Sea, $\nabla$. 4, pt. 2: New York, John Wiley, p. 133-189.

Duncan, R.A., 1984, Age-progressive volcanism in the New England seamounts and the opening of the central Atlantic Ocean: Journal of Geophysical Research, $\nabla .89$, p. 9980-9990.

Dymond, J., Cobler, R. Gordon, L., Biscay, P., and Mathieu, G., $1983,226 \mathrm{Ra}$ and $222 \mathrm{Rn}$ contents of Galapagos Rift hydrothermal waters--the importance of low-temperature interactions with crustal rocks: Earth and Planetary Science Letters, v. 64, p. 417-429.

Elders, W.A., Hoagland, J.R., and Williams, A.E., 1980, Hydrothermal alteration as an indicator of temperature and flow regime in the Cerro Prieto geothermal field of Baja California: Geothermal Resources Council Transactions, v.4, p. 121-124.

Engebretson, D.C., 1982, Relative motions between oceanic and continental plates in the Pacific Basin: Stanford, Calif., Stanford University doctoral thesis, $211 \mathrm{p}$.

Fiebelkorn, R.B., Walker, G.W., MacLeod, N.S., McKee, E.H., and Smith, J.G., 1982, Index to K-Ar age determinations for the State of Oregon: U.S. Geological Survey Open-File Report 82596, 40 p. [also 1983, Isochron/West, no. 37, p. 3-60].

Foote, R.W., 1986, Curie-point isotherm mapping and interpretation from aeromagnetic measurements in the northern Oregon Cascades: Corvallis, Oreg., Oregon State University master's thesis, $115 \mathrm{p}$.

Gill, J.B., .1981, Orogenic andesites and plate tectonics: New York, . Springer Verlag, 390 p.

Goff, F., and Decker, E.R., 1983, Candidate sites for future hot dry rock development in the U.S.: Journal of Volcanology and Geothermal Research, v. 15; p. 187-221.

Goff, F., and Nielson, D.L., eds., 1986, Caldera processes and magmahydrothermal systems, continental scientific drilling programthermal regimes, Valles caldera research, scientific and management plan: Los Alamos National Laboratory Report LA-10737OBES, $163 \mathrm{p}$.

Goff, S., 1986, Curatorial policy guidelines and procedures for the continental scientific drilling program: Los Alamos National Laboratory Report LA-10542-OBES, 23 p. 
Grant, W.C., Weaver, C.S., and Zollweg, J.E., 1984, The 14 February 1981 Elk Lake, Washington, earthquake sequence: Seismological Society of America Bulletin, v. 74, no. 4, p. 1289-1309.

Grove, T.L., and Kinzler, R.J., 1986, Petrogenesis of andesites: Annual Review of Earth and Planetary Science, $\nabla .14$, p. 417-454.

Haimson, B., and Kim, K., 1982, Deep borehole hydrofracturing: A stress measurement in the Columbia Basin at the Hanford site [abs.]: EOS,, .63, p. 1120.

Hales, P.O., 1975, Geology of the Green Ridge area, Whitewater River quadrangle, Oregon: Corvallis, Oreg., Oregon State University master's thesis, $90 \mathrm{p}$.

Hamilton, W., and Myers, W.B., 1966, Cenozoic tectonics of the western United States: Reviews of Geophysics, v. 4, no. 4, p. 509-549.

Hammond, P.E., Geyer, K.M., and Anderson, J.L., 1982, Preliminary geologic map and cross sections of the upper Clackamas and North Santiam Rivers area, northern Oregon Cascade Range: Portland, Oreg., Portland State University Department of Earth Sciences, scale $1: 62,500$.

Hawkesworth, C.J., Erlank, A.J., Marsh, J.S., Menzies, M.A., and Calsteren, P. Van, 1983, Evolution of the continental lithosphere: Evidence from volcanics and xenoliths in southern Africa, in Hawkesworth, C.J., and Norry, M.J., eds., Continental basalts and mantle xenoliths: Cheshire, U.K., Shiva Publications, Ltd., p. 111-138.

Hill, D.P., 1976, Structure of Long Valley Caldera, California, from a seismic refraction experiment: Journal of Geophysical Research, V. 81, no. 5 , p. 745-753.

Holbrook, S.R., Collier, R., and Dymond, J., 1985, Dissolved and particulate trace element distributions in Crater Lake, Oregon [abs.]: EOS, v.66, p. 1326.

Hughes, S.S., 1983, Petrochemical evolution of High Cascade volcanic rocks in the Three Sisters region: Corvallis, Oreg., Oregon State University doctoral dissertation, $199 \mathrm{p}$.

Hughes, S.S., and Taylor, E.M., 1986, Geochemistry, petrogenesis, and tectonic implications of central High Cascade mafic platform lavas: Geological Society of America Bulletin, v. 97, no. 8, p. 1024-1036.

Ingebritsen, S.E., and Sorey, M.L., 1985, A quantitative analysis of the Lassen hydrothermal system, north-central California: Water Resources Research, $v .21$, no. 6, p. 853-868.

Iyer, H.M., Rite, A., and Green, S.M., 1982, Search for geothermal heat sources in the Oregon Cascades by means of teleseismic Presidual technique [abs.]: Society of Exploration Geophysicists, 52nd annual meeting, Dallas, Tex., Technical Program Abstracts, p. $479-482$.

Johnson, D.M., Peterson, R.R., Lycan, D.R., Sweet, J.W., Neuhaus, M.E., and Schaedel, A.L., 1985, Atlas of Oregon lakes: Corvallis, Oreg., Oregon State University Press, 317 p.

Kadko, D., Lupton, J., Collier, R., Lilley, M., and Pak, H., 1986, Endeavour Ridge hydrothermal plume study [abs.]: EOS, $\nabla .67$, p. 1027 .

Keach, R.W., II, 1986, Cenozoic active margin and shallow Cascades structure: COCORP results from western Oregon: Ithaca, New York, Cornell University master's thesis, $51 \mathrm{p}$. 
Keach, R.W., II, Potter, C.J., Oliver, J.E., Brown, L.D., 1986, Cenozoic active margin and shallow Cascades structure: COCORP results from western Oregon [abs.]: Geological Society of America Abstracts with Programs, V. 18, no. 6, p. 652.

Keith, T.E.C., and Boden, J.R., 1981, Volcanic stratigraphy and alteration mineralogy of drill cuttings from EWEB 1 drill hole, Linn County, Oregon: U.S. Geological Survey Open-File Report 81-250. $11 \mathrm{p}$.

Kim, K., Dischler, S.A., Aggson, J.R., and Hardy, , M.P., 1986, The state of in-situ stresses determined by hydraulic fracturing at the Hanford Site: Richland, Wash., Rockwell Hanford Operations Report RHO-BW-ST-73P, 172 p.

Kohler, W.M., Healy, J.H., and Wegener, S.S., 1982, Upper crustal structure of the Mount Hood, Oregon, region revealed by time term analysis: Journal of Geophysical Research, v. 87, no. 1, p. 339-355.

Kollmann, A., and Zollweg, J., 1984, Oregon seismicity--August 1980 to October 1982: U.S. Geological Survey Open-File Report 84-832, 29 p.

Korosec, M.A., 1983, The 1983 temperature-gradient and heat-flow drilling project for the State of Washington: Washington Division of Geology and Earth Resources Open-File Report 83-12, 11 p.

Korosec, M.A., Phillips, W.M., and Schuster, J.E., 1983, The 19801982 geothermal resource assessment program in Washington: Washington Division of Geology and Earth Resources Open-File Report 83-7, 299 p.

Krogan, B.J., Bodvarsson, G., and Mesecar, R.S., 1971, Heat flow through the floor of the Cascadia Basin: Journal of Geophysical Research, v. 76, p. 4758-4774.

Kulm, L.D., and Fowler, G.A., 1971, Shallow structural elements of the Oregon continental margin within a plate-tectonic framework [abs.]: Geological Society of America Abstracts with Programs, v. 3 , no. 7 , p. 628 .

Langston, C.A., 1977, Corvallis, Oregon, crustal and upper mantle receiver structure from teleseismic $P$ and $S$ waves: Seismological Society of America Bulletin, v. 67, no. 3, p. 713-724.

Leaver,. D.S., 1982, A refraction study of the Oregon Cascades: Seattle, Wash., University of Washington master's thesis, $67 \mathrm{p}$.

Leaver, D.S., Mooney, W.D., and Kohler, W.M., 1984, A seismic refraction study of the Oregon Cascades: Journal of Geophysical Research, $\nabla$. 89, no. 5, p. 3121-3134.

Leeman, W.P., 1983, The influence of crustal structure on composition of subduction-related magma: Journal of Volcanology and Geothermal Research, $\nabla .18$, p. 561-588.

Iindgren, W., 1907, The relation of ore deposition to physical conditions: Economic Geology, v. 2, p. 105-127.

-..--1922, A suggestion for the terminology of certain mineral deposits: Economic Geology, v. 17, p. 292-294.

Luetgert, J.H., and Mooney, W.D., 1984, Crustal refraction profile of the Long Valley Caldera, California, from the January 1983 Mammoth Lakes earthquake swarm: Seismological Society of America Bulletin, v. 75 , no. 1, p. 211-221. 
Lux, D.R., 1982, K-Ar and 40Ar-39Ar ages of mid-Tertiary volcanic rocks from the Western Cascade Range, Oregon: Isochron/West, no. 33, p. 27-32.

Magill, J., and Cox, A., 1980, Tectonic rotation of the Oregon Western Cascades: Oregon Department of Geology and Mineral Industries Special Paper 10, 67. $\mathrm{p}$.

Magill, J., Cox, A., and Duncan, R., 1981, Tillamook Volcanic Series: Further evidence for tectonic rotation of the Oregon Coast Range: Journal of Geophysical Research, $\nabla .86$, no. 4, p. 2953-2970.

Mahoney, J., MacDougall, J.D., Lugmair, G.W., Murali, A.V., Sankar D. M., and Copalon, K., 1982, Origin of the Deccan Trap flows at Mahabaleshwar inferred from Nd and $\mathrm{Sr}$ isotopic and chemical evidence: Earth and Planetary Science Letters, v. 60, p. 47-60.

Mantovani, M.S.M., Marques, L.S., DeSousa, M.A., Civetta, L., Atalla, L., and Innocenti, F., 1985, Trace element and strontium isotope constraints on the origin and evolution of Parana continental flood basalts of Santa Catarina State (southern Brazil): Journal of Petrology, v. 26, p. 187-209.

Mariner, R.H., 1985, Geochemical features of Cascades hydrothermal systems, in Guffanti, M., and Muffler, L.J.P., eds., Proceedings of the workshop on geothermal resources of the Cascade Range: U.S. Geological Survey Open-File Report 85-521, p. 59-62.

Mase, C.W., Sass, J.H., Lachenbruch, A.H., and Munroe, R.J., 1982, Preliminary heat-flow investigations of the California Cascades: U.S. Geological Survey Open-File Report 82-150, 242 p.

McBirney, A.R., 1968, Petrochemistry of the Cascade andesite volcanoes, in Dole, H.M., ed., Andesite Conference guidebook: Oregon Department of Geology and Mineral Industries Bulletin 62, p. 101-107.

McLain, W.H., 1981, Geothermal and structural implications of magnetic anomalies observed over the southern Oregon Cascade Mountains and adjoining Basin and Range Province: Corvallis, Oreg., Oregon State University master's thesis, $151 \mathrm{p}$.

Menzies, M., 1983, Mantle ultramafic xenoliths in alkaline magmas: Evidence for mantle heterogeneity modified by magmatic activity, in Hawkesworth, C.J., and Norry, M.J.,, eds., Continental basalts and mantle xenoliths: Cheshire, U.K., Shiva Publications, Ltd., p. 230-249.

Morgan, P., Blackwell, D.D., Spafford, R.E., and Smith, R.B., 1977, Heat-flow measurements in Yellowstone Lake and the thermal structure of Yellowstone Caldera: Journal of Geophysical Research, จ. 82, no. 26, p. 3719-3732.

Mozley, E.C., 1982, An investigation of the conductivity distribution in the vicinity of a Cascade rolcano (Ph.D. thesis, University of California, Berkeley): Lawrence Berkeley Laboratory Report LBL-15671, $386 \mathrm{p}$.

Mozley, E.C., Goldstein, N.E., and Morrison, H.F., 1986, Magnetotelluric investigations at Mount Hood, Oregon: Journal of Geophysical Research, V. 91, no. B11, p. 596-610.

Muffler, L.J.P., Bacon, C.R., and Duffield, W.A., 1982a, Geothermal systems of the Cascade Range: Proceedings of the Pacific Geothermal Conference 1982, incorporating the 4th New Zealand Geothermal Workshop, p. 337-343. 
Muffler, L.J.P., Clynne, M.A., and Cook, A.L., 1982b, Mineral and geothermal resource potential of Wild Cattle Mountain and Heart Lake Roadless Areas, Plumas, Shasta, and Tehama Counties, California: U.S. Geological Survey Open-File Report 82-846, 32 p.

Nercessian, A., Hirn, A.M., and Tarantola, A., 1984, Threedimensional seismic transmission prospecting of the Mont Dore volcano, France: Geophysical Journal of the Royal Astronomical Society, v. 76, p. 307-315.

Olson, J.P., 1978, Geology and mineralization of the North Santiam mining district, Marion County, Oregon: Corvallis, Oreg., Oregon State University master's thesis, $135 \mathrm{p}$.

Palmer, A.R., 1983, Patton, H.J., 1976, P-wave fault plane solutions and the generation of surface waves by earthquakes in the western U.S.: Geophysical Research Letters, V. 12, p. 518-521.

Pearce, J.A., 1983, Role of subcontinental lithosphere in magma genesis in active continental margins, in Hawkesworth, C.J., and Norry, M.J., eds., Continental basalts and mantle zenoliths: Cheshire, U.K., Shiva Publications, Ltd., p. 230-249.

Peck, D.L., Griggs, A.B., Schlicker, H.G., Wells, F.G., and Dole, H.M., 1964, Geology of the central and northern parts of the Western Cascade Range in Oregon: U.S. Geological Survey Professional Paper 449, $56 \mathrm{p}$.

Peterson, N.V., Groh, E.A., Taylor, E.M., and Stensland, D.E., 1976, Geology and mineral resources of Deschutes County, Oregon: Oregon Department of Geology and Mineral Industries Bulletin $89,66 \mathrm{p}$.

Pollock, J.M., 1985, Geology and geochemistry of hydrathermal alteration, eastern portion of the North Santiam mining area: Portland, Oregon, Portland State University master's thesis, $100 \mathrm{p}$.

Pollock, J.M., and Cummings, M.L., 1985a, Structural controls of mineralization and alteration, Ruth Mine, North Santiam mining area, Oregon [abs.]: Geological Society of America Abstracts with Programs, v. 17, no. 6, p. 401.

-..--1985b, North Santiam mining area, Western Cascades--relations between alteration and volcanic stratigraphy: Discussion and field trip guide, Part I. Discussion: Oregon Geology, v.47, no. 12 , p. $139-145$.

1986, North Santiam mining area, Western Cascades--relations between alteration and volcanic stratigraphy: Discussion and field trip guide, Part II. Field trip guide: Oregon Geology, v. 48 , no. 1 , p. $3-8$.

Pollock, J.M., Thompson, G.D., Mestrovich, M.K., Cummings, M.L., and Howard, D.G., 1986, . Geologic processes in the subvolcanic portion of a porphyry copper deposit, North Santiam mining area, Western Cascades, Oregon: Geological Society of America Abstracts with Programs, $v, 18$, no. 6, p. 720.

Priest, G.R., 1983, Geothermal exploration in the central Oregon Cascade Range, in Priest, G.R., and Vogt, B.F., eds., Geology and geothermal resources of the central Oregon Cascade Range: Oregon Department of Geology and Mineral Industries Special Paper 15, p. 77-87.

$-----1985 a$, Continental scientific drilling--the Cascades as a target: Geothermal Resources Council Bulletin, $\nabla .14$, no. 6, p. 5-12. 
$----1985 b$, Geothermal exploration in Oregon, 1984: Oregon Geology, v. 47, no. 6, p. $63-66,69$.

Priest, G.R., Beeson, M.H., Gannett, M.W., and Berri, D.A., 1982a, Geology, geochemistry, and geothermal resources of the Old Maid Flat area, Oregon, in Priest, G.R., and Vogt, B.F., eds., Geology and geothermal resources of the Mount Hood area, Oregon: Oregon Department of Geology and Mineral Industries Special Paper 14; p. 16-30.

Priest, G.R., Hadden, M.M., Woller, N.M, and Brand, C.B., 1983a, Preliminary soil-mercury survey of Newberry volcano, Deschutes County, Oregon, in Priest, G.R., Vogt, B.F., and Black, G.L., eds., Survey of potential geothermal exploration sites at Newberry volcano, Deschutes County, Oregon: Oregon Department of Geology and Mineral Industries Open-File Report 0-83-3, p. 4567.

Priest, G.R., Vogt, B.F., and Black, G.L., eds,, 1983b, Survey of potential geothermal exploration sites at Newberry volcano, Deschutes County, Oregon: Oregon Department of Geology and Mineral Industries Open-File Report 0-83-3, $174 \mathrm{p}$.

Priest, G.R., Woller, N.M., Black, G.L., and Evans, S.H., 1982b, Overview of the geology and geothermal resources of the central Oregon Cascades, in Priest, G.R., and Vogt, B.F., eds., Geology and geothermal resources of the Cascades, Oregon: Oregon Department of Geology and Mineral Industries Open-File Report O82-7, p. 5-70.

-----1983c, Overview of the geology of the central Oregon Cascade Range, in Priest, G.R., and Vogt, B.F., eds., Geology and geothermal resources of the central Oregon Cascade Range: Oregon Department of Geology and Mineral Industries Special Paper 15, p. 3-28.

Priest, G.R., Woller, N.M., and Ferns, M.L., 1987, Geologic map of the Breitenbush River area, Linn and Marion Counties, Oregon: Oregon Department of Geology and Mineral Industries Geological Map Series GMS-46, scale 1:62,500, in press.

Pungrassami, T., 1970, Geology of the western Detroit Reservoir area, Quartzville and Detroit quadrangles, Iinn and Marion Counties, Oregon: Corvallis, Oreg., Oregon State University master's thesis, $76 \mathrm{p}$.

Riddihough, R.P., 1977, A model for recent plate interactions off Canada's West Coast: Canadian Journal of Earth Sciences, $\nabla .14$, p. 384-396.

---1984 , Recent movements of the Juan de Fuca Plate system: Journal of Geophysical Research, V. 89, no. B8, p. 6980-6994.

Rogers, G.C., 1985, Variation in Cascade volcanism with margin orientation: Geology, v. 13, no. 7, p. 495-498.

Sammel, E.A., 1981, Results of test drilling at Newberry volcano, Oregon: Geothermal Resources Council Bulletin, $\nabla .10$, no. 11, p. 3-8,

Sanders, C.0., 1984, Location and configuration of magma bodies beneath Long Valley, California, determined from anomalous earthquake signals: Journal of Geophysical Research, v. 89, p. 8287-8302. 
Schuster, J.E., Blackwell, D.D., Hammond, P.E., and Huntting, M.T., 1978, Heat-flow studies in the Steamboat Mountain-Lemei Rock area, Skamania County, Washington: Washington, Division of Geology and Earth Resources Information Circular 62, $56 \mathrm{p}$.

Scott, W.E., 1977, Quaternary glaciation and volcanism, Metolius River area, Oregon: Geological Society of America Bulletin, $\nabla .88$, no. 1, p. $113-124$.

Sherrod, D.R., 1986, Geology, petrology, and volcanic history of a portion of the Cascade Range between latitudes $43^{\circ}-44^{\circ} \mathrm{N}$, central Oregon, U.S.A.: Santa Barbara, Calif., University of California doctoral dissertation, $320 \mathrm{p}$.

Shor, G.G., Jr., Dehlinger, P., Kirk, H.K., and French, W.S., 1968, Seismic refraction studies off Oregon and Northern California: Journal of Geophysical Research, v. 73, no. 6, p. 2175-2194.

Simpson, R.W., and Cox, A., 1977, Paleomagnetic evidence for tectonic rotation of the Oregon Coast Range: Geology, $\nabla .5$, no. 10, p. 585-589.

Smith, G.A., 1982, Late Cenozoic structures on the Columbia Plateau: Implications for tectonics in the Pacific Northwest: EOS, $\nabla .63$, p. 1116 .

----1986 [compl. 1985], Stratigraphy, sedimentology, and petrology of Neogene rocks in the Deschutes Basin, central Oregon: A record of continental-margin volcanism and its influence on fluvial sedimentation in an arc-adjacent basin: Corvallis, Oreg., Oregon State University doctoral dissertation, $467 \mathrm{p}$.

Smith, G.A., Snee, L.W., and Taylor, E.M., 1987, Stratigraphic, sedimentologic, and petrologic record of late Miocene subsidence of the central Oregon High Cascades: Geology, $\nabla .15$, no. 5, p. 389-392.

- Smith, J.G., Page, N.J., Johnson, M.G., Moring, B.C., and Gray, F., 1982, Preliminary geologic map of the Medford $1^{\circ}$ by $2^{\circ}$ quadrangle, Oregon and California: U.S. Geological Survey Open-File Report 82-955, scale 1:250,000.

Snaveley, P.D., Jr., Wagner, H.C., and Lander, D.L., 1980, Geologic cross section of the central Oregon continental margin: Geological Society of America Map and Chart Series MC-28J, 8 p., scale $1: 250,000$.

Stanley, W.D.,1981, Magnetotelluric survey of the Cascade volcanoes region, Pacific Northwest [abs.]: Society of Exploration Geophysicists, 51st annual international meeting, Los Angeles, Calif., Geothermal Special Session 3, Technical Program Abstracts, G3.7.

----1982 , A regional magnetotelluric survey of the Cascade Range region, northwestern United States: U.S. Geological Survey Open-File Report 82-126, 387 p.

----1984 , Tectonic study of the Cascade Range and Columbia Plateau in Washington State, based on magnetotelluric soundings: Journal of Geophysical Research, v. 89, no. B6, p. 4447-4460.

Stauber, D.A., and Berge, P.A., 1984, P-velocity structure of Mount Shasta, California, and Newberry volcano [abs.]: EOS, V. 66, p. 25.

Stauber, D.A., Iyer, H.M., Mooney, W.D., and Dawson, P.B., 1985, Three-dimnesional P-velocity structure of the summit caldera of Newberry volcano, Oregon: Geothermal Resources Council Transactions, v. 9, Part II, p. 411-415. 
Steele, J.L., Blackwell, D.D., and Robison, J.H., 1982, Heat flow in the vicinity of the Mount Hood volcano, Oregon, in Priest, G.R., and Vogt, B.F., eds., Geology and geothermal resources of the Mount Hood area, Oregon: Oregon Department of Geology and Mineral Industries Special Paper 14, p. 31-42.

Steeples, D.W., and Iyer, H.M., 1976, Low-velocity zone under Long Valley as determined from teleseismic events: Journal of Geophysical Research, $\nabla .81$, no. 5 , p. 849-860.

Stensland, D.E., 1970, Geology of part of the northern half of the Bend quadrangle, Jefferson and Deschutes Counties, Oregon: Corvallis, Oreg., Oregon State University master's thesis, $118 \mathrm{p}$.

Sutter, J.F., 1978, K/Ar ages of Cenozoic volcanic rocks from the Oregon Cascades west of $121^{\circ} 30^{\prime}$ : Isochron/West, no. 21, p. 1521.

Taylor, E.M., 1967, Recent volcanism between Three Fingered Jack and North Sister, Oregon Cascade Range: Pullman, Wash., Washington State University doctoral dissertation, $84 \mathrm{p}$.

----1968 , Roadside geology, Santiam and Mackenzie Pass Highways, Oregon, in Dole, H.M., ed., Andesite Conference guidebook: Oregon Department of Geology and Mineral Industries Bulletin 62, p. 3-33.

-.--1973, Geology of the Deschutes Basin, in Beaulieu, J.D., field trip chairman, Geologic field trips in northern Oregon and southern Washington: Oregon Department of Geology and Mineral Industries Bulletin 77, p. 29-32.

-----1978 , Field geology of S.W. Broken Top quadrangle, Oregon: Oregon Department of Geology and Mineral Industries, Special Paper 2, $50 \mathrm{p}$.

-1980 , Volcanic and volcaniclastic rocks on the east flank of the central Cascade Range to the Deschutes River, Oregon, in Oles, K.F., Johnson, J.G., Niem, A.R., and Niem, W. A., eds., Geologic field trips in western Oregon and southwestern Washington: Oregon Department of Geology and Mineral Industries Bulletin 101, p. 1-7.

-----1981, Central High Cascade roadside geology--Bend, Sisters, McKenzie Pass, and Santiam Pass, Oregon, in Johnston, D.A., and Donnelly-Nolan, J., eds., Guides to some volcanic terranes in Washington, Idaho, Oregon, and northern California: U.S. Geological Survey Circular 838, p. 55-58.

Taylor, H.P., Jr., 1971, Oxygen isotope evidence for large-scale interaction between meteoric ground waters and Tertiary granodiorite intrusions, Western Cascade Range, Oregon: Journal of Geophysical Research; $\nabla$. 76, no. 32, p. 7855-7874.

Thayer, T.P., 1936, Structure of the North Santiam River section of the Cascade Mountains in Oregon: Journal of Geology, v. 44, no. 6, p. 701-716.

---1939 , Geology of the Salem Hills and the North Santiam River basin, Oregon: Oregon Department of Geology and Mineral Industries Bulletin 15, $40 \mathrm{p}$.

Thiruvathukal, J.V., Berg, J.W., Jr., and Heinrichs, D.F., 1970, Regional gravity of Oregon: Geological Society of America Bulletin, v. 81, no. 3, p. 725-738.

Thorpe, R.S., ed., 1982, Andesites: Orogenic andesites and related rocks: New York, John Wiley, 724 p. 
Verplanck, E.P., and Duncan, R.A., 1984, Temporal and geochemical variations of the central Western Cascades in Oregon [abs.]: Geological Society of America Abstracts with Programs, v. 16, no. 6, p. 682 .

-..--1987, Temporal variations in plate convergence and eruption rates in the Western Cascades, Oregon: Tectonics, $v .6$, no. $2, p$. 197-209.

Viellehave, J.H., Sakai, S., Suga, S., and Bisque, R.E., 1967, Use of the Petrex fingerprint soil gas geochemical technique in multiplescale geothermal exploration. A case history at Okuaizu geothermal field, Japan: Pacific Rim Congress 87, Geology, structure, mineralisation, and economics of the Pacific Rim, Gold Coast, Australia, p. 1-6.

Waibel, A.F., in preparation, Summary of data from Sunedco well 58-28, Breitenbush area, Oregon: Oregon Department of Geology and Mineral Industries, Oregon Geology.

Walker, G.W., MacLeod, N.S., and Blakely, R.J., 1985, Mineral resource potential of the Bull of the Woods Wilderness, Clackamas and Marion Counties, Oregon: U.S. Geological Survey Open-File Report 85-247, $28 \mathrm{p}$.

Waters, A.C., 1962, Basalt magma types and their tectonic associations -Pacific Northwest of the United States, in The crust of the Pacific Basin: American Geophysical Union Geophysical Monograph 6, p. 158-170.

Weaver, C.S., Green, S.M., and Iyer, H.M., 1982, Seismicity of Mount Hood and structure as determined from teleseismic P-wave delay studies: Journal of Geophysical Research, $\nabla .87$, no. B4, p. 2782-2792.

Weaver, C.S., and Michaelson, C.A., 1983, Segmentation of the Juan de Fuca Plate and volcanism in the Cascade Range: EOS, $\nabla .64$, no. 45 , p. 886 .

----1985, Seismicity and volcanism in the Pacific Northwest: Evidence for the segmentation of the Juan de Fuca Plate: Journal of Geophysical Research Letters, $\nabla .12$, no. 4, p. 215-218.

Weaver, C.S., and Smith, S.W., 1983, Regional tectonic and earthquakehazard implications of a crustal fault zone in southwestern Washington: Journal of Geophysical Research, v.88, no. 10, p.371-383.

Wells, F.G., and Peck, D.L., 1961, Geologic map of Oregon west of the 121st meridian: U.S. Geological Survey Miscellaneous Investigations Series Map I-325, scale 1:500,000.

Wells, R.E., Engebretson, D.C., Snavely, P.D., Jr., and Coe, R.S., 1984, Cenozoic plate motions and the volcano-tectonic evolution of western Oregon and Washington: Tectonics, v. 3, no. 2, p. 275294.

White, C.M., 1980a, Geology of the Breitenbush Hot Springs quadrangle, Oregon: Oregon Department of Geology and Mineral Industries Special Paper 9, $26 \mathrm{p}$.

$---1980 \mathrm{~b}$, Geology and geochemistry of volcanic rocks in the Detroit area, Western Cascade Range, Oregon: Eugene, Oreg., University of Oregon doctoral dissertation, $178 \mathrm{p}$. 
White, C.M., and McBirney, A.R., 1978, Some quantitative aspects of orogenic volcanism in the Oregon Cascades, in Smith, R.B., and Eaton, G.P., eds., Cenozoic tectonics and regional geophysics of the western Cordillera; Boulder, Colo., Geological Society of America Memoir 152, p. 369-388.

Williams, D.L., and Finn, C., 1981, Evidence from gravity data on the location and size of subvolcanic intrusions: Preliminary results [abs.]: Society of Exploration Geophysicists, 51st annual international meeting, Los Angeles, Calif., Technical Program Abstracts, p. 15 .

-.--1983, Gravity and aeromagnetic study of the Goat Rocks Wilderness, Washington: EOS, $\nabla .64$, no. 45, p. 887 .

Williams, D.L. Hull, D.A., Ackermann, H.D., and Beeson, M.H., 1982, The Mount Hood region: Volcanic history, structure, and geothermal energy potential: Joumal of Geophysical Research, $\nabla$. 87, no. B4, p. 2767-2781.

Williams, D.L., and Von Herzen, R.P., 1983, On the terrestrial heat flow and physical limnology of Crater Lake, Oregon: Journal of Geophysical Research, v. 88. no. B2, p. 1094-1104.

Williams, H., 1942, The geology of Crater Lake National Park, Oregon, with a reconnaissance of the Cascade Range southward to Mount Shasta: Carnegie Institution of Washington, Publication 540, 162 p.

----1957 , A geologic map of the Bend quadrangle, Oregon, and a reconnaissance geologic map of the central portion of the High Cascade Mountains: Oregon Department of Geology and Mineral Industries Quadrangle Map, scales 1:125,000 and 1:250,000.

Winters, M.B., 1985, An investigation of fluid inclusions and geochemistry of ore formation in the Cedar Creek breccia pipe, North Santiam mining district, Oregon: Bellingham, Wash., Western Washington University master's thesis, $104 \mathrm{p}$.

Woller, N.M., Black, G.L., and Priest, G.R., 1986, Geothermal exploration in Oregon, 1985: Oregon Geology, $\nabla .48$, no. 7, p. 81-85.

Woller, N.M., and Priest, G.R., 1982, Geology of the Lookout Point area, Lane County, Oregon, in Priest, G.R, and Vogt, B.F., eds., Geology and geothermal resources of the Cascades, Oregon: Oregon Department of Geology and Mineral Industries Open-File Report 0-82-7, p. 119-134.

----1983, Geology of the Lookout Point area, Lane County, Oregon, in Priest, G.R., and Vogt, B.F., eds., Geology and geothermal resources of the central Oregon Cascades: Oregon Department of Geology and Mineral Industries Special Paper 15, p. 49-56.

Wood, D.A., Joron, J.L., Treuil, M., Norry, M., and Tarney, J., 1979, Elemental and Sr isotopic variations in basic lavas from Iceland and the surrounding ocean floor. Nature of mantle source inhomogeneities: Contributions to Mineralogy and Petrology, $v$. 70, p. 319-339.

Wood, D.A., Tarney, J, and Weaver, B.L., 1981, Trace-element variations in Atlantic Ocean basalts and Proterozoic dykes from northwest Scotland:. Their bearing upon the nature and geochemical evolution of the upper mantle: Tectonophysics, v. 75, p. 91-112. 
Yogodzinski, G.M., 1986 [compl.1985], The Deschutes Formation-High Cascade transition in the Whitewater River area, Jefferson County, Oregon: Corvallis, Oreg., Oregon State University master's thesis, $165 \mathrm{p}$.

Youngquist, W.I., 1980, Geothermal gradient drilling, north-central Cascades of Oregon, 1979: Oregon Department of Geology and Mineral Industries Open-File Report 0-80-12, $47 \mathrm{p}$.

Zindler, A., and Hart, S.R., 1986, Chemical geodynamics: Annual Review of Earth and Planetary Science, v. 14, p. 493-571.

Zoback, M.L, and Zoback, M.D., 1980, States of stress in the conterminous United States: Journal of Geophysical Research, 8. 85, p. 6113-6156.

-----in preparation, Tectonic stress field of the continental U.S. 


\section{FIGURES}

Note:

Figures 7 and 11 are on separate sheets in back pocket 


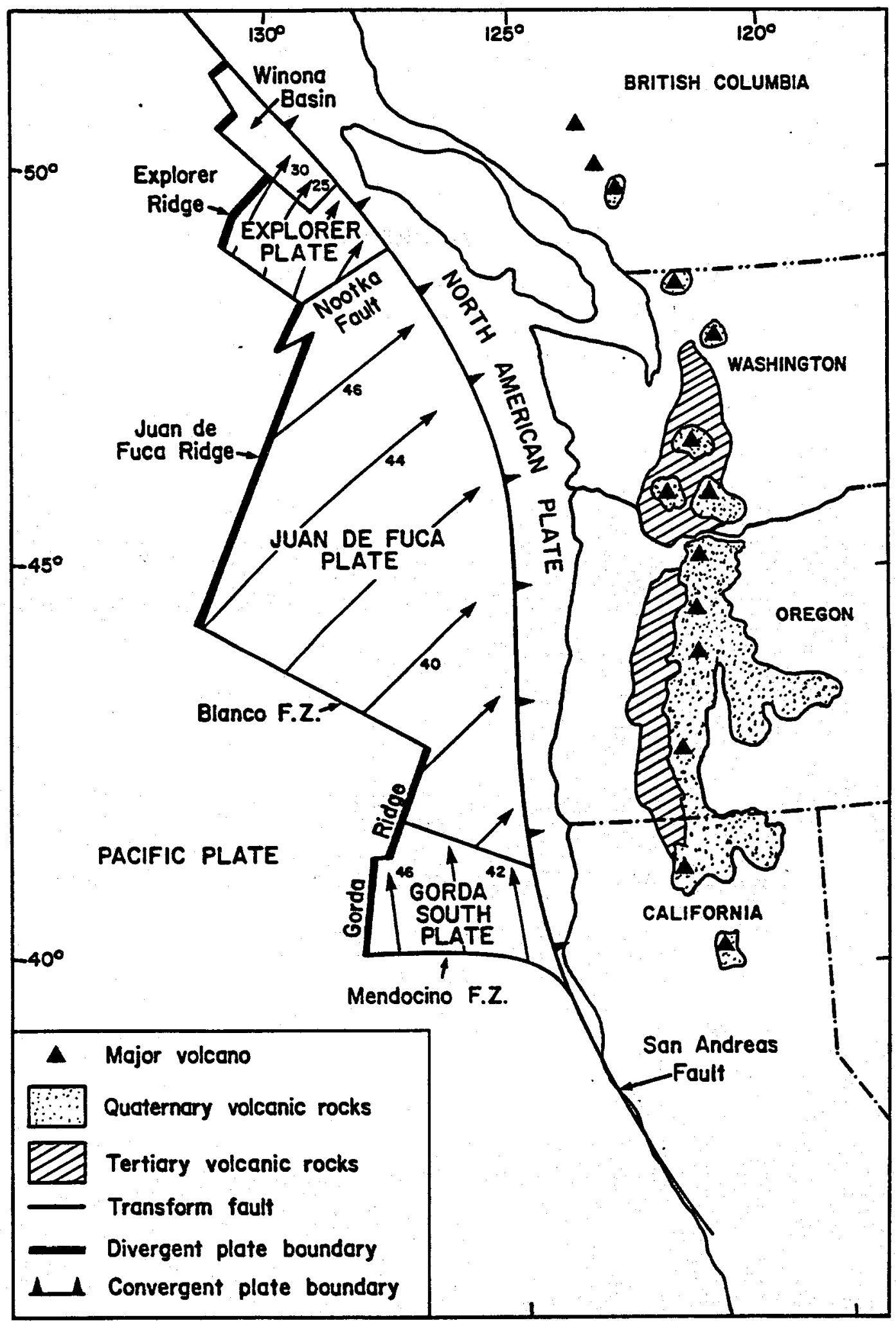

Figure 1. Plate-tectonic map of the coast of the northwestern American continent showing major crustal boundaries. Arrows show the directions of net convergence in millimeters per year. Figure modified from McBirney (1968) and Riddihough (1984). 


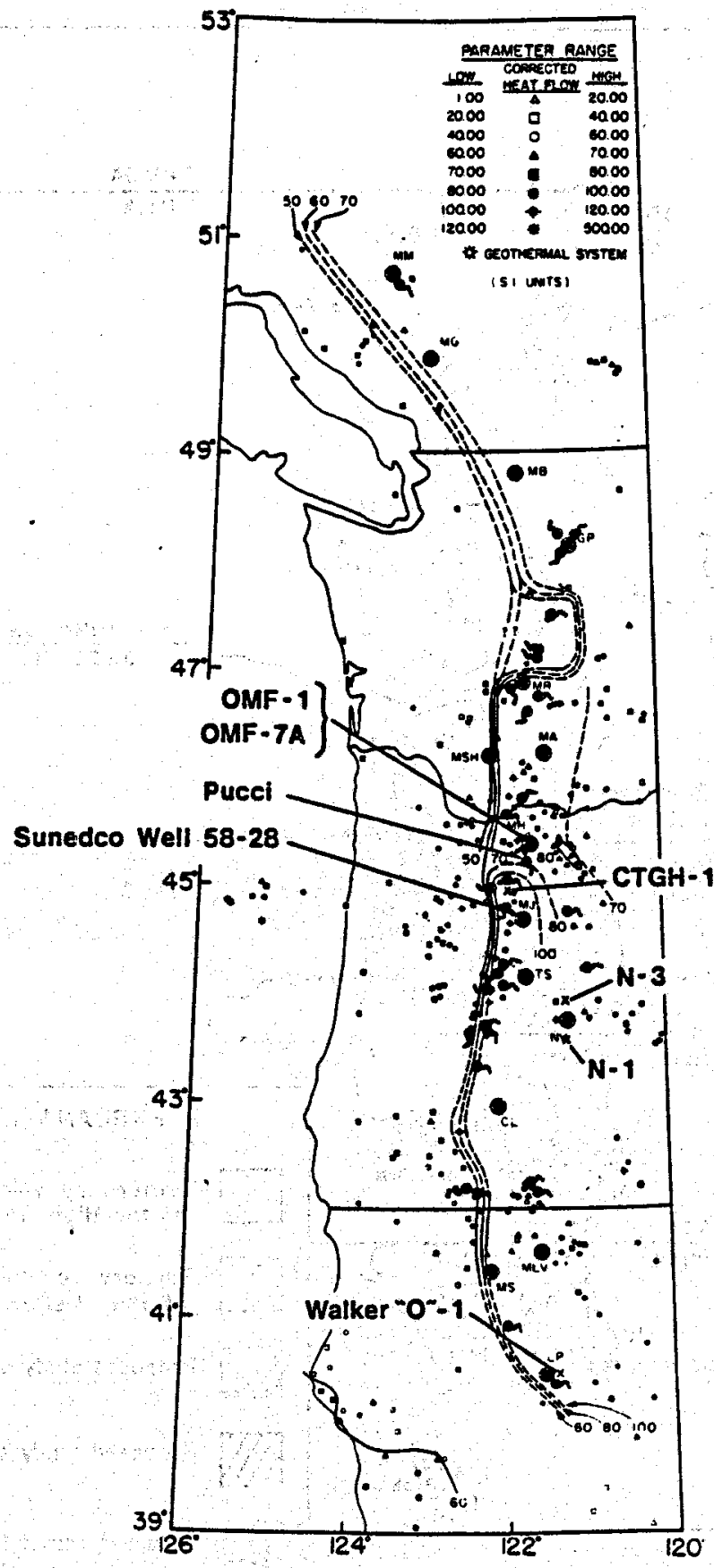

Figure 2. Map of western British Columbia, Washington, Oregon, and northern California, showing lines of constant heat flow in milliwatts per square meter in the Cascade Range. Dots with tails are hot springs; large stars with circles are major volcanoes ( $M M$ Mountain; MG = Mount Garibald; MB = Mount Baker; GP = Glacier Peak; MR = Mount Rainier; MSH = Mount St. Helens; MA = Mount Adams; MH = Mount Hood; MJ $=$ Mount Jefferson; $T S=$ Three Sisters; NV = Newberry Volcano; $C L=$ Crater Lake; MLV = Medicine Lake Volcano; MS = Mount Shasta; and LP = Lassen Peak). Labeled points are holes deeper than $1,000 \mathrm{~m}$ that are located in the U.S. Cascades and that have data that are publically available. Figure modified from Blackwell and Steele (1983). 


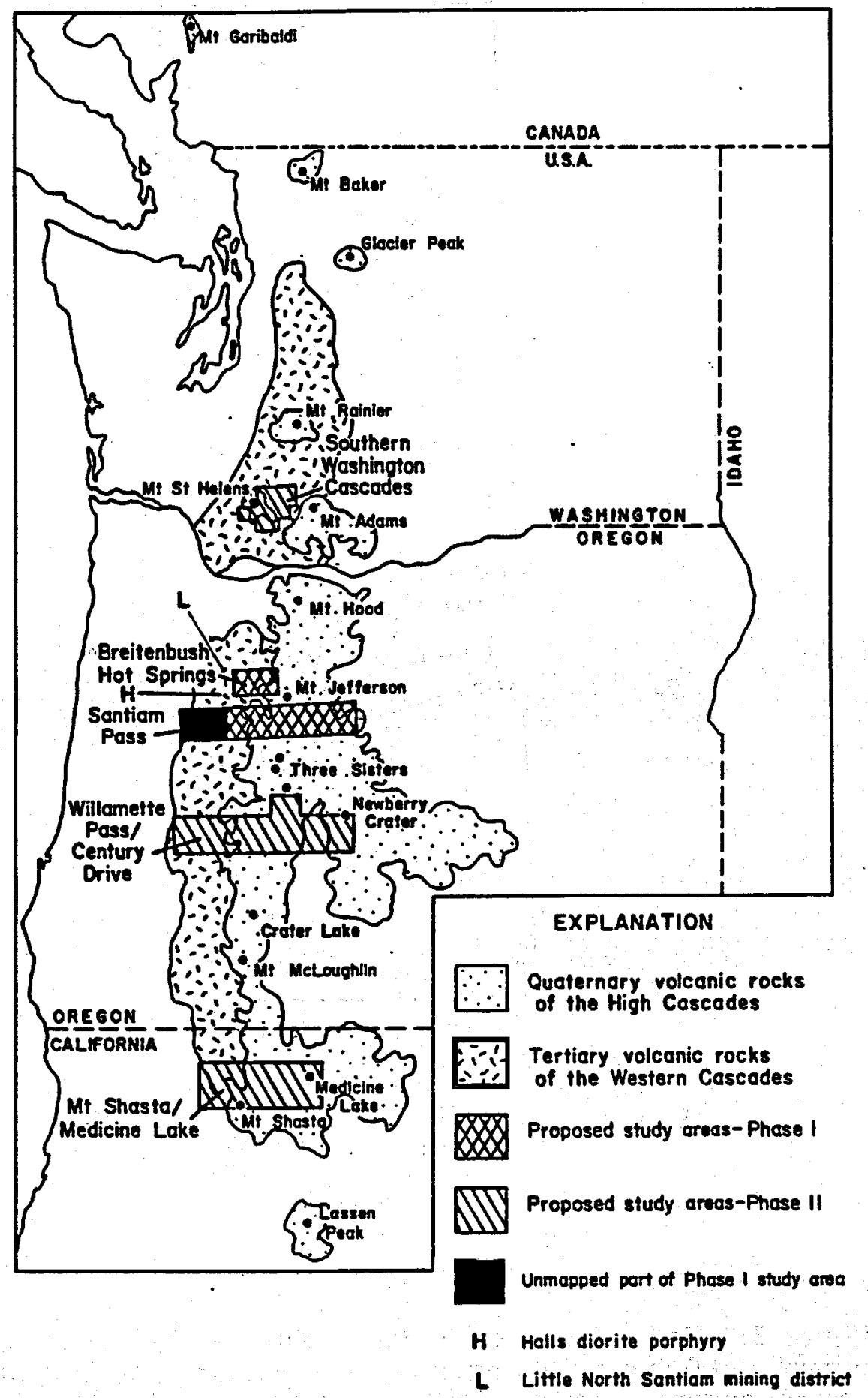

Figure 3. Map showing locations of the five proposed study areas of Phases I and II of the Program for Scientific Drilling in the Cascades. Four of the proposed areas are east-west transects across the Cascade Range. Map shows the distribution of Quaternary rocks of the High Cascades and Tertiary volcanic rocks of the Western Cascades. L $=$ Little North Santiam mining district; $H=$ Halls diorite porphyry; solid part of the Santiam Pass transect is the location of the Brownsville, Sweet Home, and Cascadia 15' quadrangles (new geologic mapping proposed in Phase I, Task 6). Figure modified from McBirney (1968). 


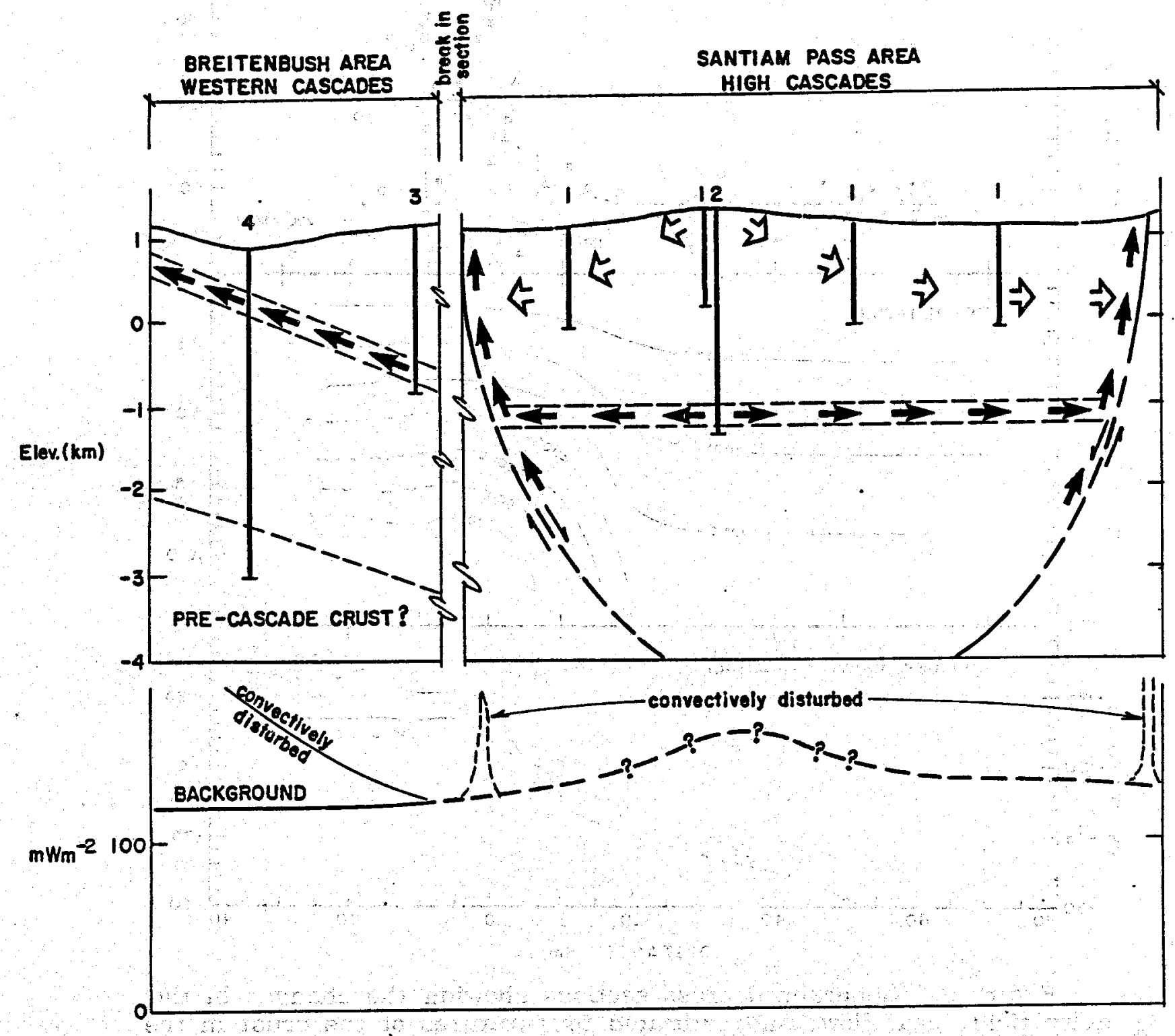

Figure 4. Schematic cross section showing the geologic environments to be sampled by the major Phase I drilling tasks (Tasks 1-4). Numbers above each drill hole refer to the respective task. A possible heat-flow profile is shown below the geologic cross section; solid lines on both illustrations indicate relatively well-constrained parts; dashed lines are hypothetical. Arrows indicate possible directions of fluid circulation (open arrowhead = cool fluids; solid arrowhead = thermal fluids). 


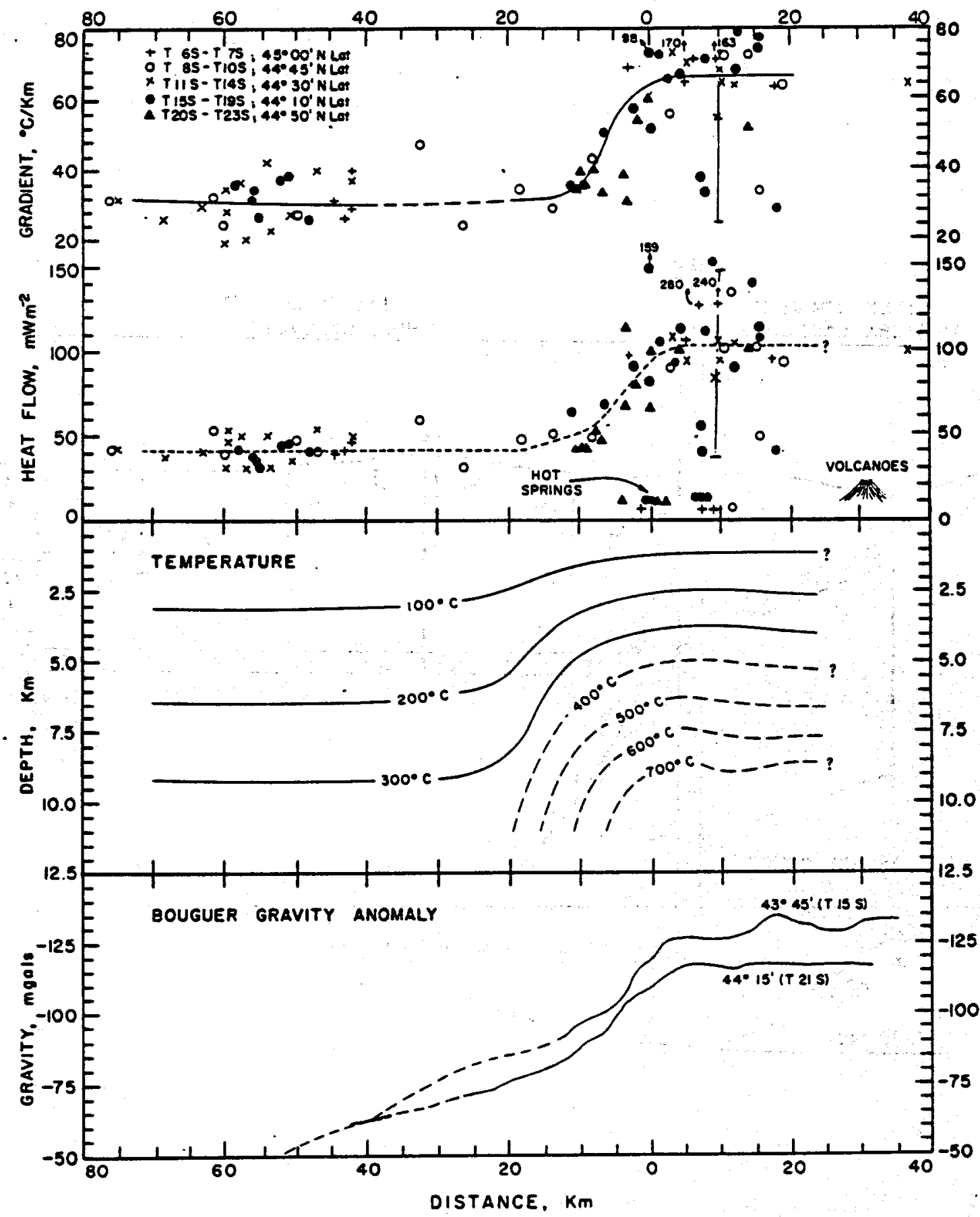

Figure 5. Generalized cross sections showing the changes in the gravity field, heat flow, and estimated temperatures of the crust in the northern Oregon Cascade Range. Heat-flow data between latitudes $43^{\circ} 15^{\prime} \mathrm{N}$. and $45^{\circ} 15^{\prime} \mathrm{N}$. are projected onto the profile. Any one of the isotherms could generate the heat flow seen at the surface. For instance, $200{ }^{\circ} \mathrm{C}$ fluids flowing westward from the High Cascades at a depth of $2.5-3.0 \mathrm{~km}$ could cause the part of the anomaly located in the inactive Western Cascade volcanic belt. Blackwell and others (1982b) argue that the Curie-point isotherm (i.e., Connard, 1980) and gravity data are most consistent with a $600^{\circ}-800{ }^{\circ} \mathrm{C}$. heat source at a depth of 7-10 km under the entire anomaly, including the Western Cascades portion. Gravity data from Couch and Baker (1977). Figure from Blackwell and others (1982b). 


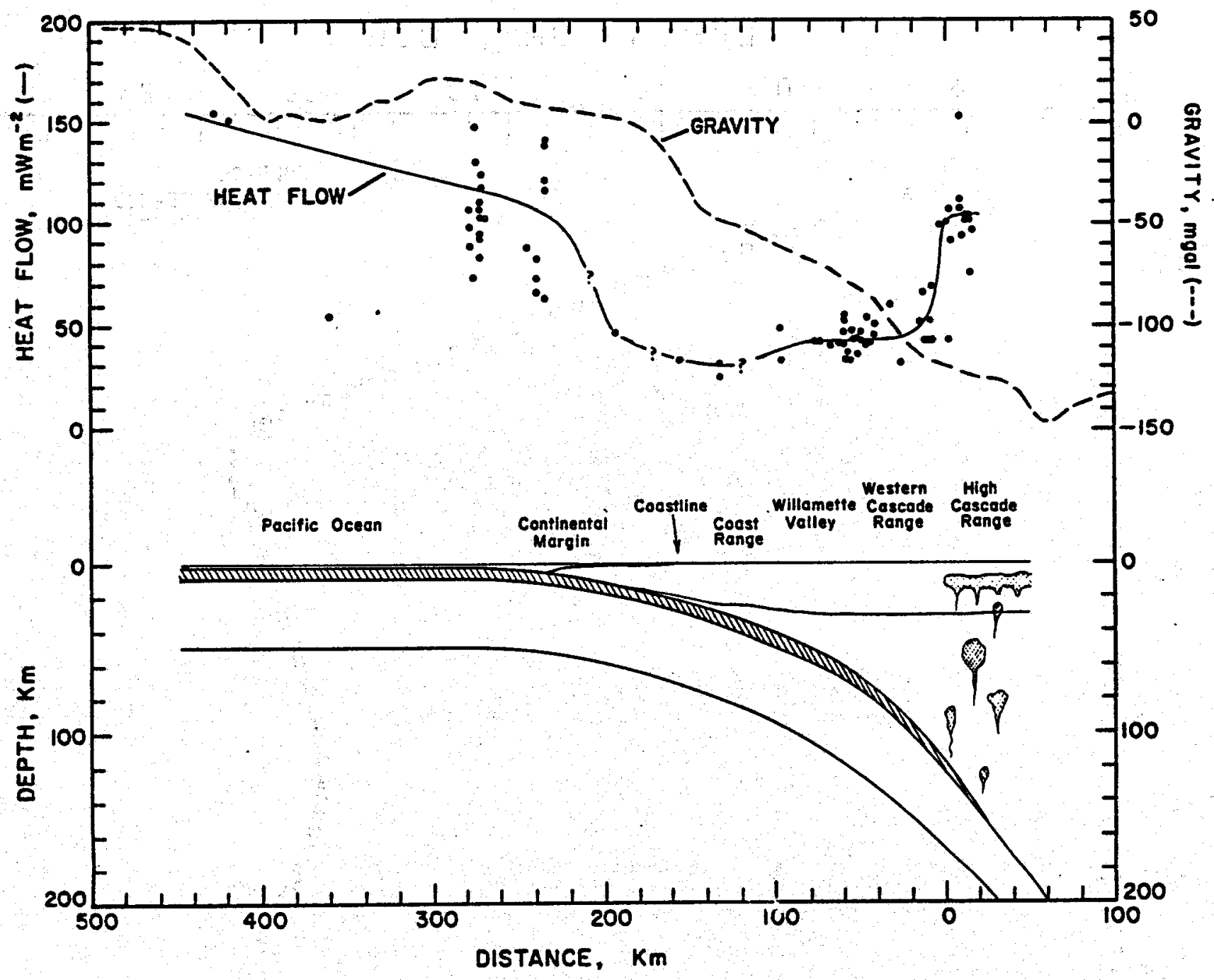

Figure 6. Schematic cross section showing the relationship of heat flow and gravity to subduction in the Cascade Range. The preferred model of Blackwell and others (1982b) requires a general zone of magma accumulation at depths of $7-10 \mathrm{~km}$ in the continental crust beneath the anomaly. The low heat flow along the coast is caused by subduction of cool oceanic crust. Figure from Blackwell and others (1982b), with offshore heat-flow data from Krogan and others (1971). 


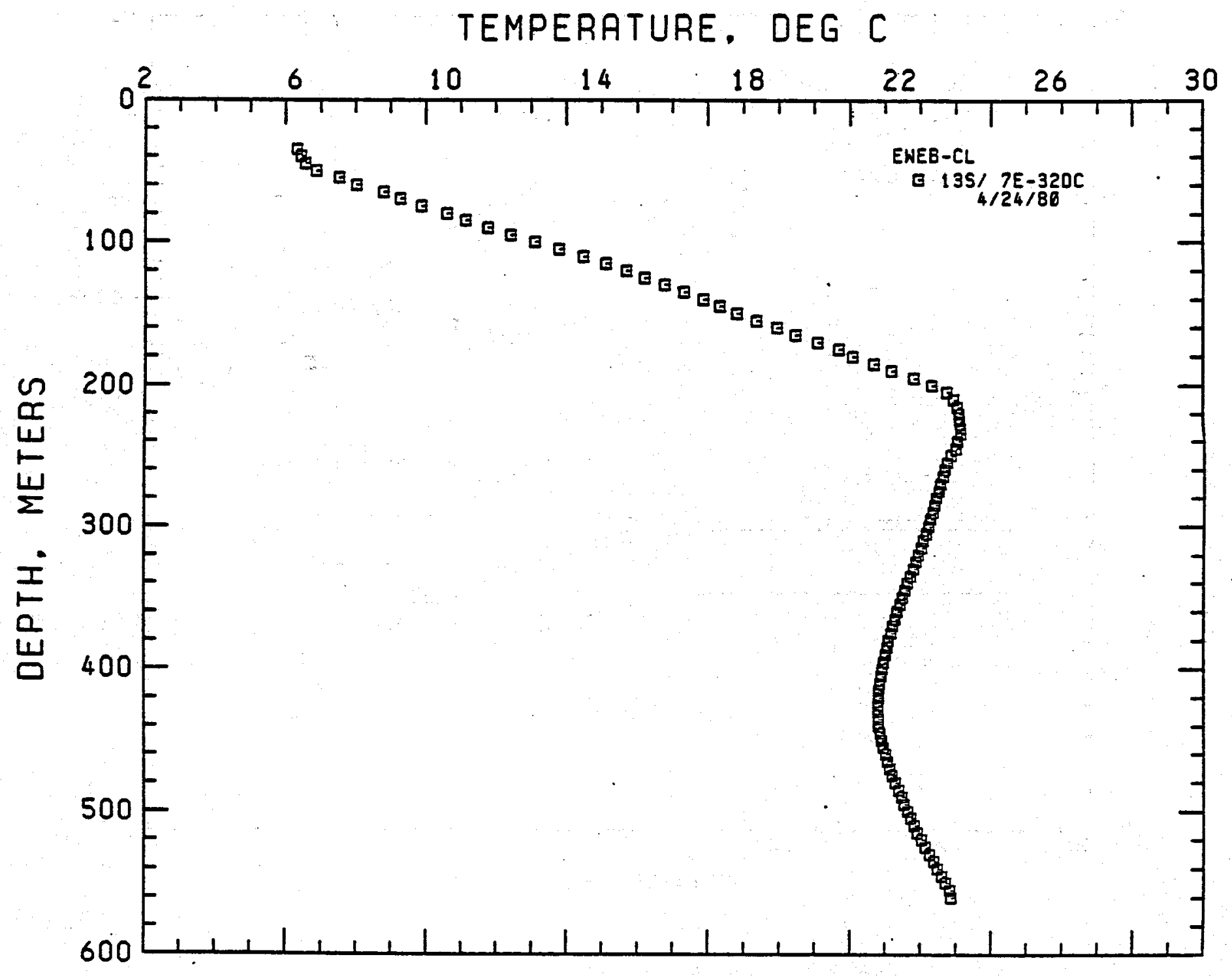

Figure 8. Temperature-depth curve from a 557-m-deep hole (13S/R7E-32DC) on the west flank of the High Cascades showing the effects of a weakly thermal aquifer (from Youngquist, 1980; Blackwell and others, 1981). Location of hole is shown on Figure 7 (folded, separate sheet). 


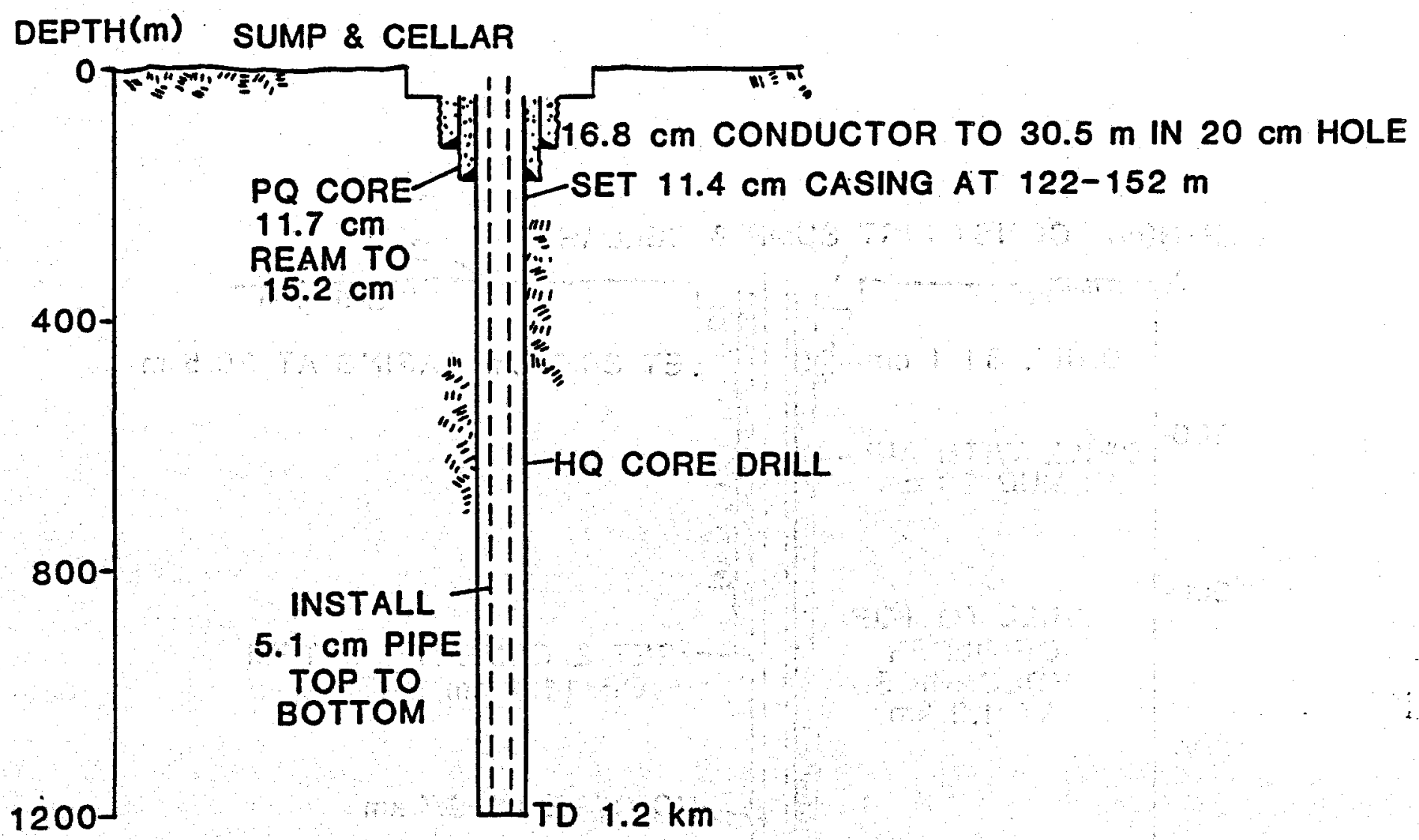

TESTS PROPOSED

1. GEOPHYSICAL LOGS

2. LIFT \& SAMPLE DEEP AQUIFERS

3. IN-SITU STRESS DETERMINATION

4. LONG TERM TEMPERATURE GRADIENT MONITORING

Figure 9. Illustration of drill-hole design for four 1.2-km-deep diamond core holes in the Santiam Pass area. 


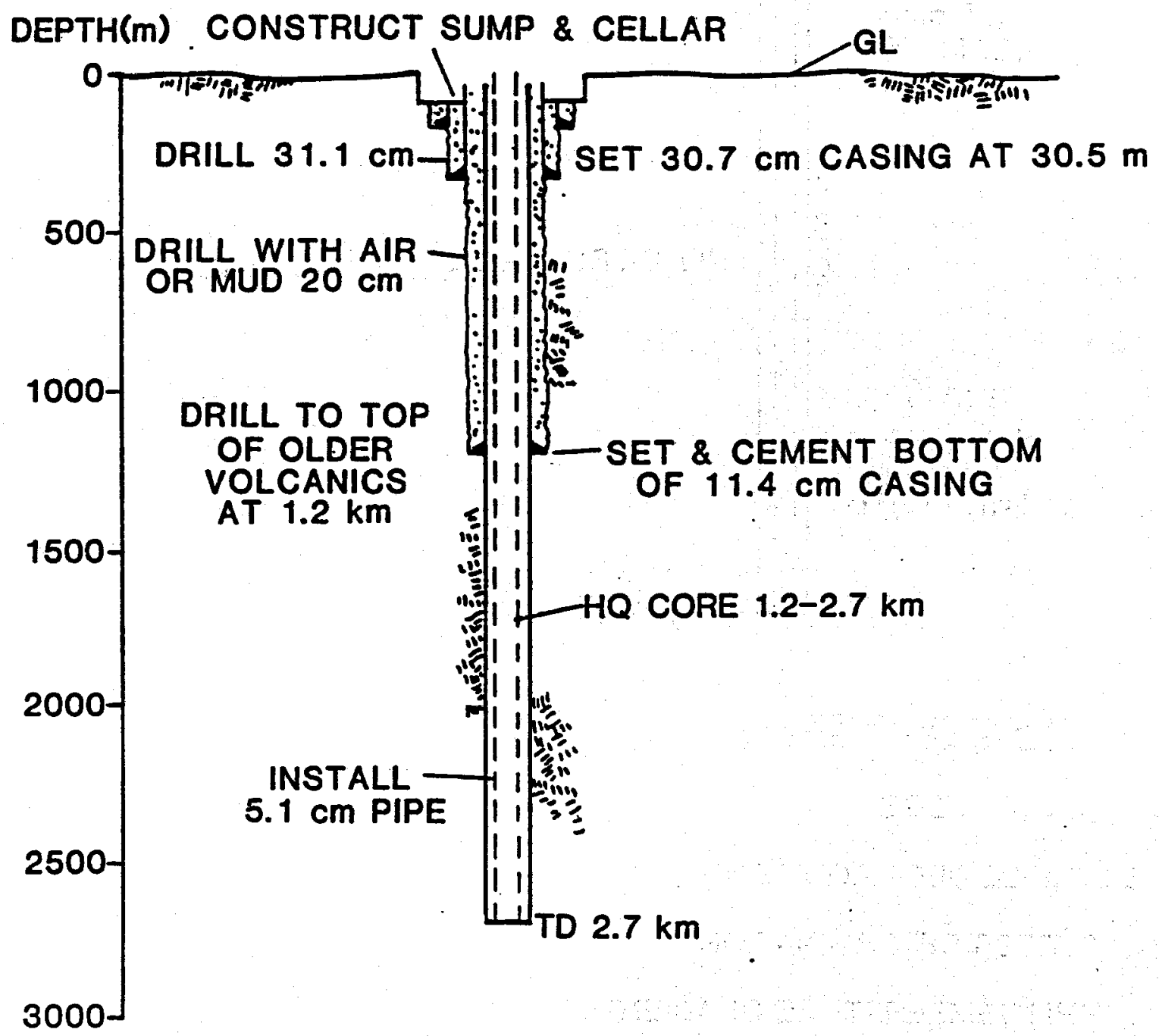

Figure 10. Illustration of drill-hole design for a 2.7-km-deep drill hole in the Santiam Pass area. 


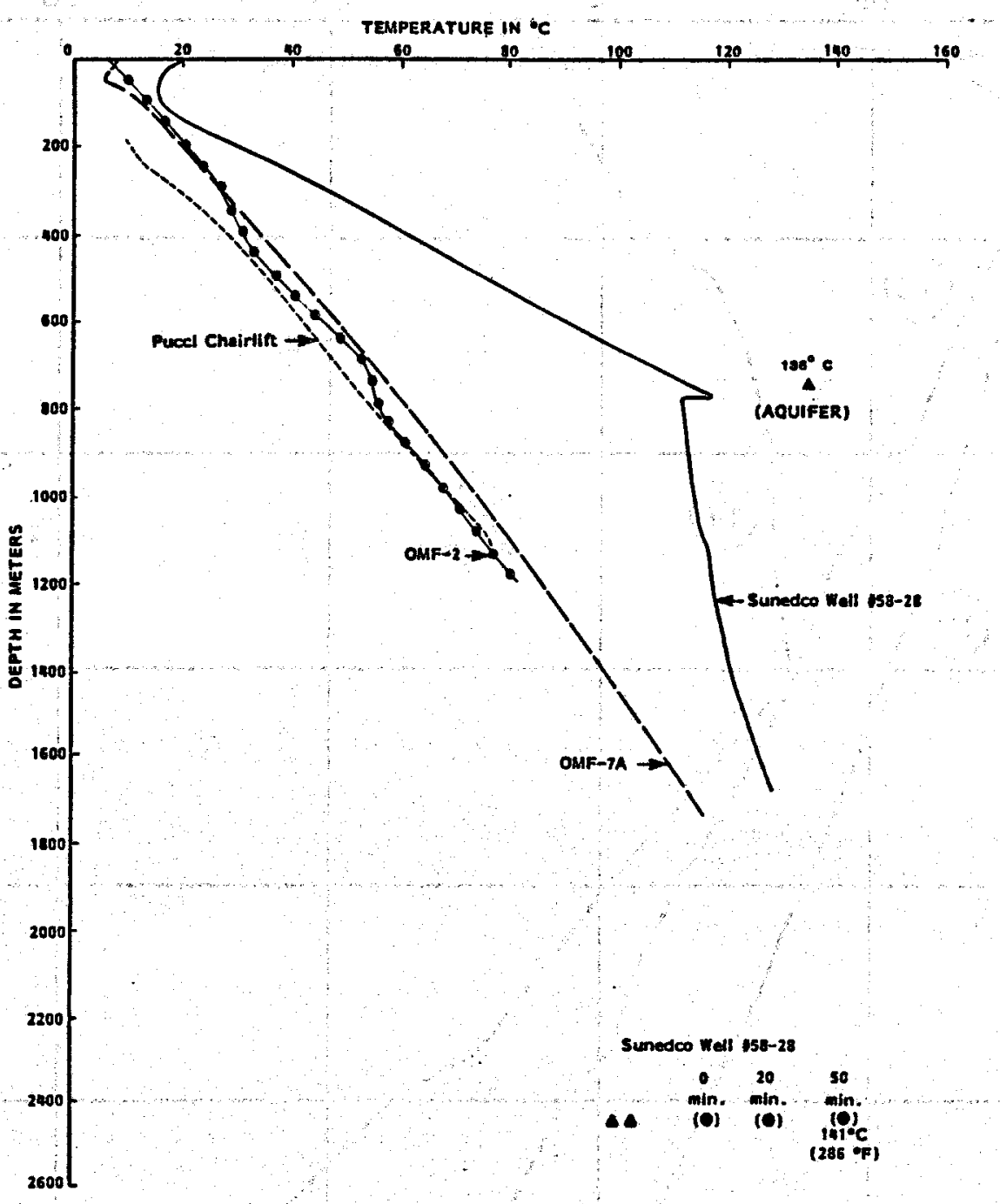

Figure 12. Temperature-depth data from Sunedco Well No. 58-28 and other moderately deep wells in the northern Oregon Cascade Range. Sources for the data are as follows: 1 . Pucci Chairlift (T. 3 S., R. 9 E., 7Ad) - Blackwell and others (1982a). 2. OMF-2 (T. 2 S., R. 8 E., 15Dd) - Blackwell and others (1981). 3. OMF-7A (T. 2 S., R. 8 E., 15Dd) - Blackwell and others (1982a). 4. Sunedco Well No. 58-28 (T. 9 S., R. 7 E., 28Dc) - Blackwell and others (1986a) and Al Waibel (unpublished data, 1986). Solid line is a thermistor log taken about eight months after drilling (stopped short of bottom due to stuck tool; data from Blackwell and others, 1986a); triangles are maximum-reading thermometer values taken immediately after the end of drilling; dots with parentheses are from a Pruett Kuster tool about 48 hours after mud circulation (Al Waibel, unpublished data, 1986). The Kuster tool was read three times over a 50-minute period. The essentially linear increase in temperature of the successive readings shows that the tool had not warmed up to the drill-hole temperature at the time of the last reading. Except for the disturbance caused by the aquifer, the overall gradient of the Sunedco well is probably similar to that of the other deep Cascade wells. 


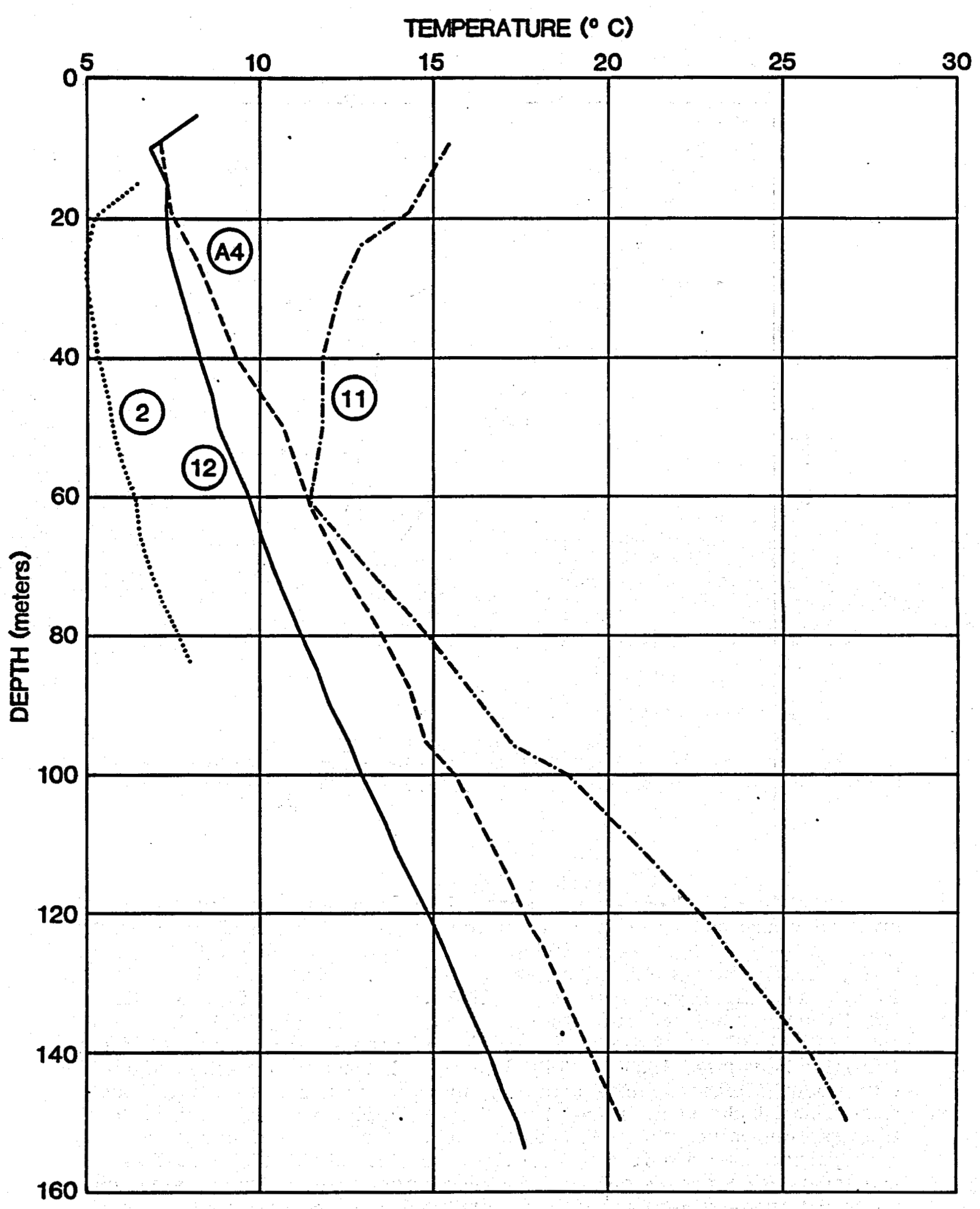

Figure 13. Temperature-depth curves for shallow drill holes in the Breitenbush Hot Springs area. Locations are shown on Figure 11 (folded, separate sheet). Note the gradual decrease in gradients west to east from hole number 11. This is interpreted as evidence of a dipping hydrothermal heat source (see Figure 14). 
THERMAL PROFILE

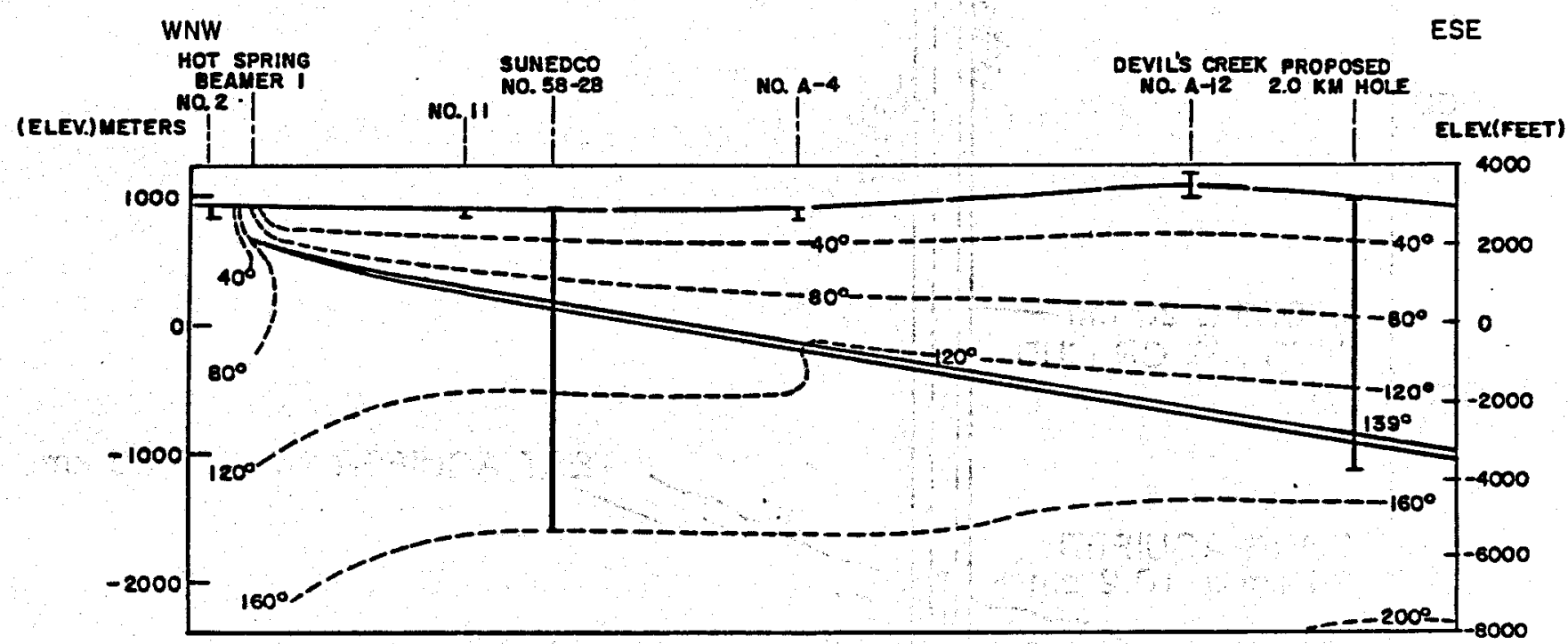

Figure 14. Cross section trending N. $70^{\circ}$ W. with temperaturegradient holes projected into the line of section along the $\mathrm{N} \cdot 20^{\circ} \mathrm{E}$. strike of the stratigraphic sequence. The section shows a preliminary, speculative temperature model for the Breitenbush area assuming that (1) the temperature data from the holes can be extrapolated downward without corrections for terrain effects; (2) a stratigraphically controlled thermal aquifer dipping about $10^{\circ} \mathrm{S}, 70^{\circ} \mathrm{E}$. has raised the temperature above background; and (3) the background heat flow is about $126 \mathrm{mWm}^{-2}$. Locations of wells and temperature-gradient holes are shown on Figure 11 (folded, separate sheet). 


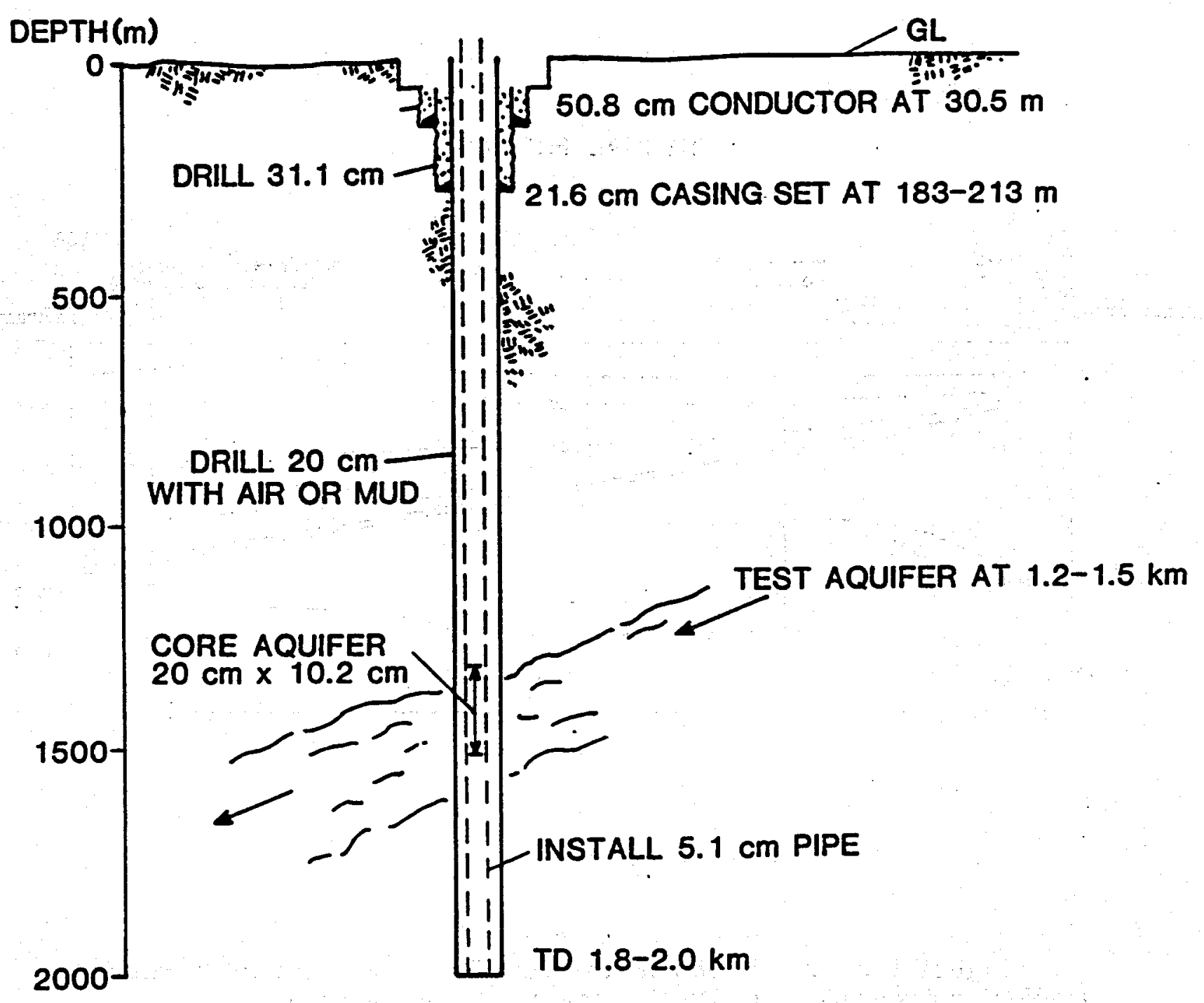

Figure 15. Drill-hole design for a 1.8 - to $2.0-\mathrm{km}$-deep hole southeast of Breitenbush Hot Springs. 


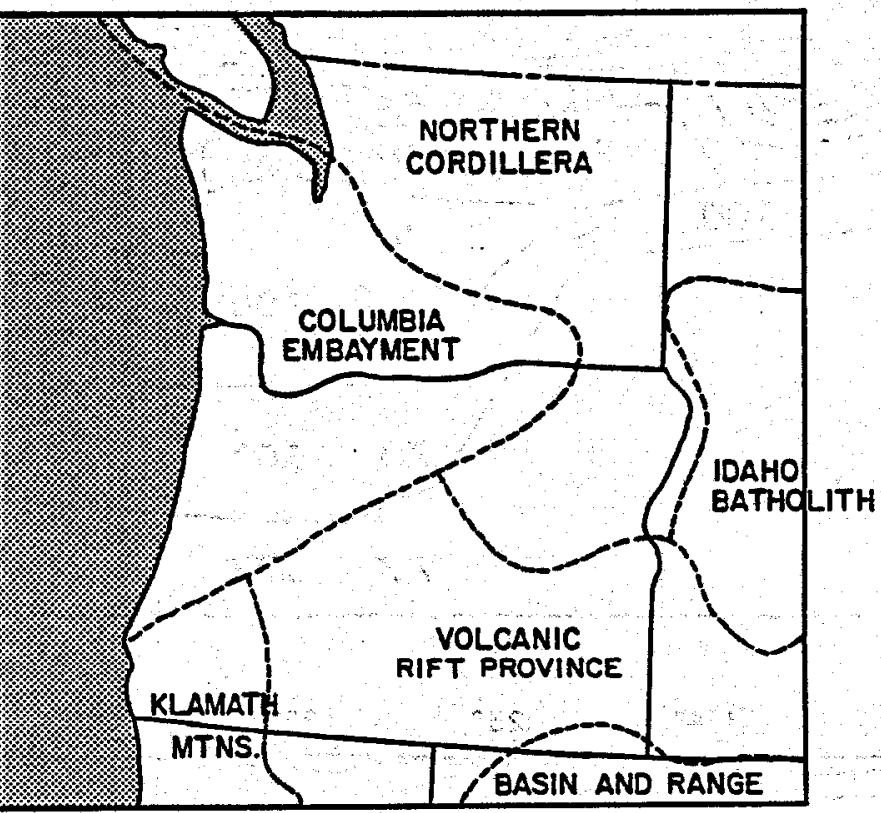

Figure 16. Map showing the location of the Columbia embayment of Carey (1958). Figure modified from Hamilton and Myers (1966). 


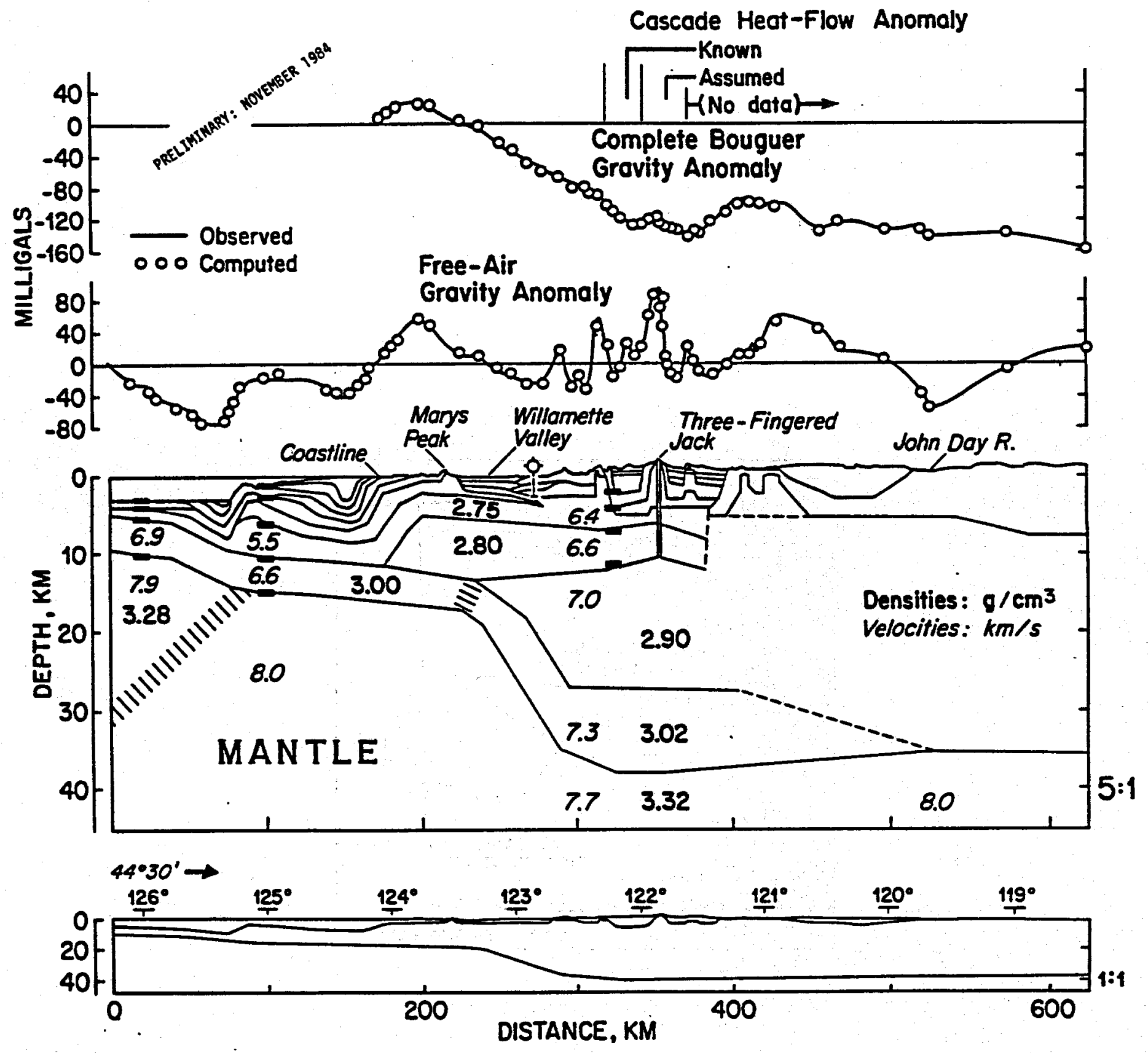

Figure 17. Theoretical east-west cross section across the Oregon Cascade Range showing densities of crustal layers based on gravity, seismic, and drill-hole data. The cross section trends roughly eastwest at a latitude of $44^{\circ} 30^{\prime} \mathrm{N}$. through Three Fingered Jack, an extinct volcano $5 \mathrm{~km}$ north of Santiam Pass. Figure from unpublished work of R.W. Couch and co-workers at Oregon State University, Corvallis, Oregon, 1985. 


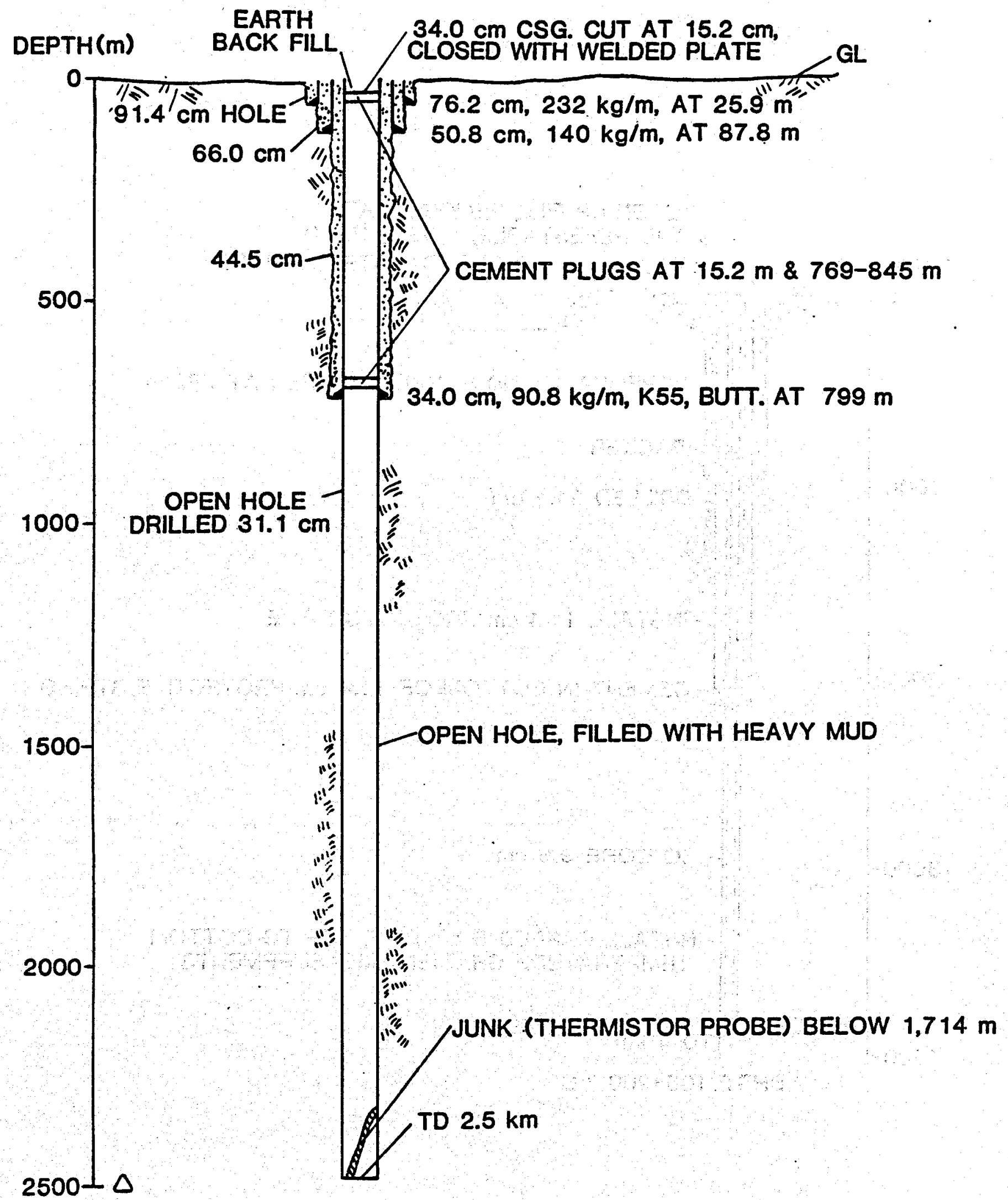

Figure 18. Present status of Sunedco Well No. 58-28. 


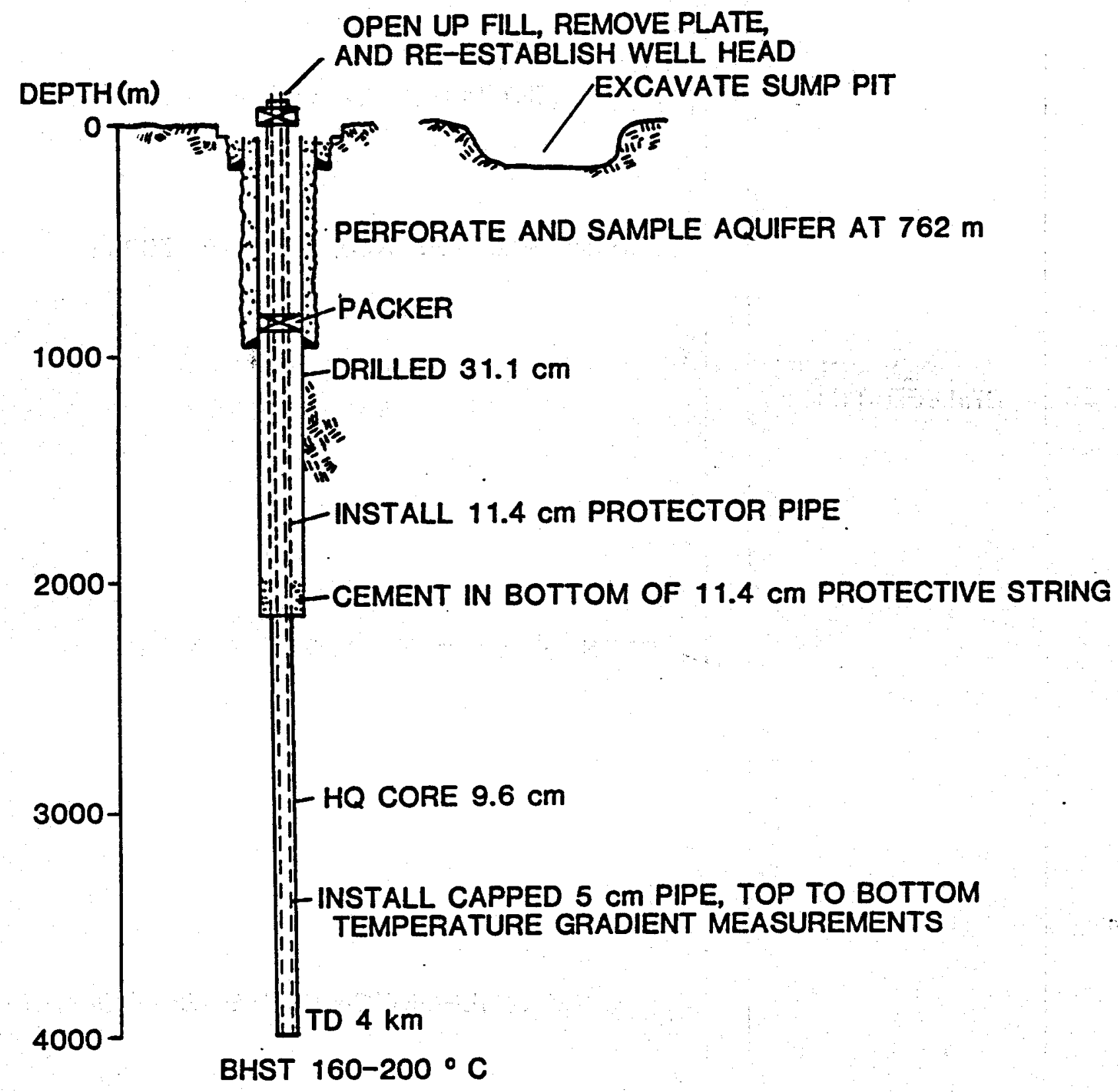

Figure 19. Drill-hole design for deepening Sunedco Well No. 5828 to $4.0 \mathrm{~km}$. 

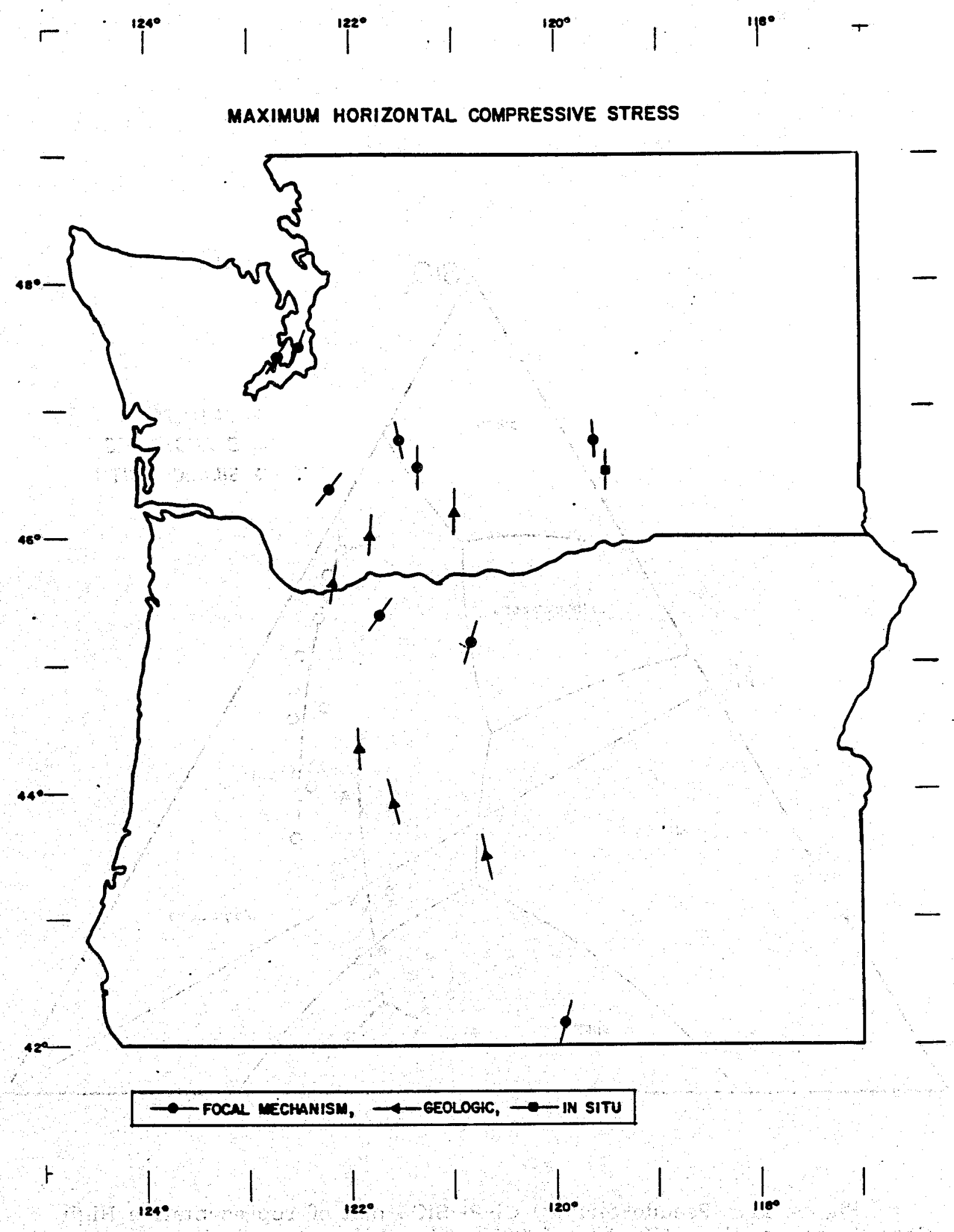

Figure 20. State-of-stress data for the northwestern United States. Symbols indicate types of methods used to determine stress direction. Figure from Zoback and Zoback (in preparation), with additional data from Haimson and $\mathrm{Kim}$ (1982) and $\mathrm{Kim}$ and others (1986). 


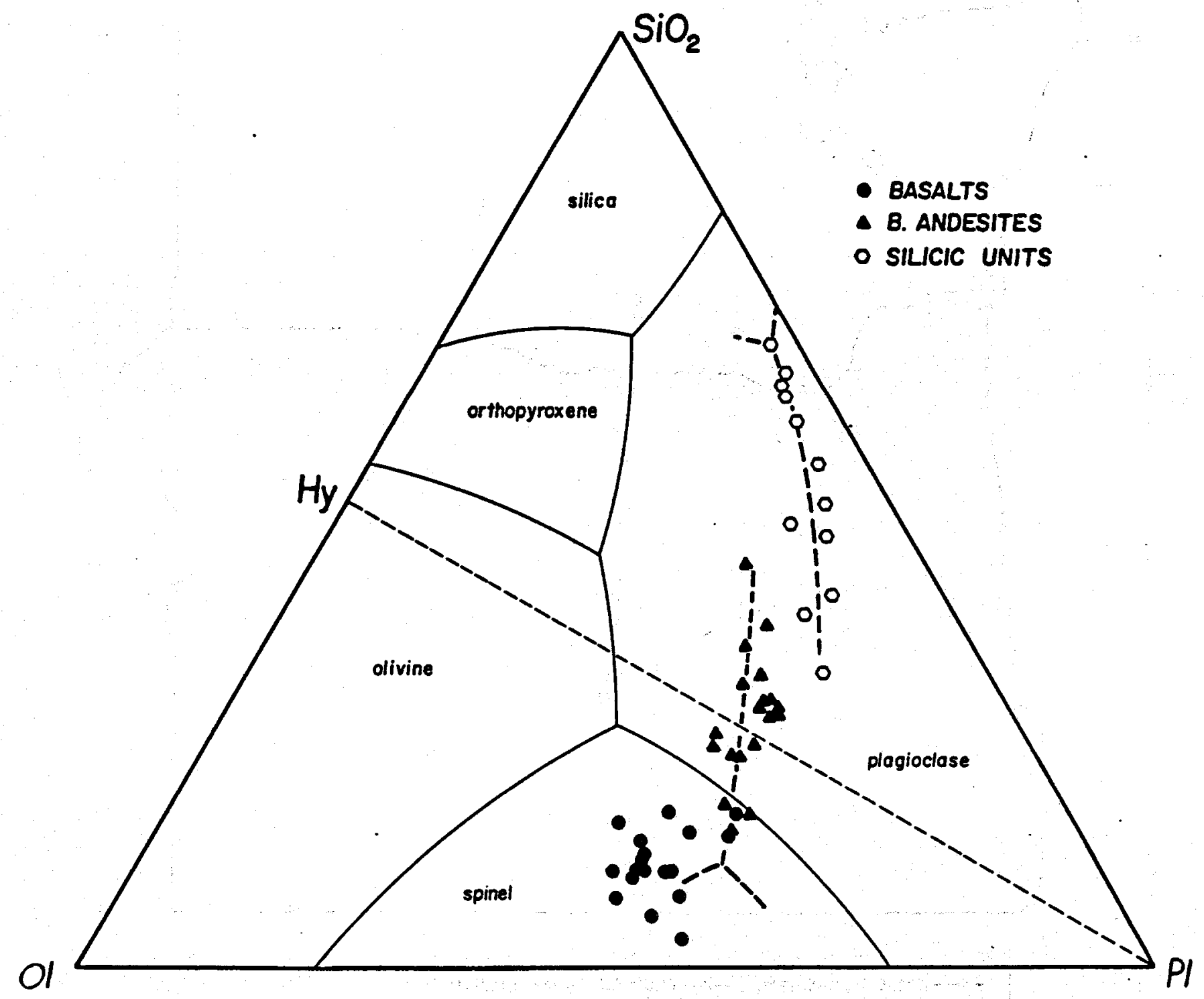

Figure 21. Pseudo-ternary $\mathrm{Ol}-\mathrm{Pl}-\mathrm{SiO}_{2}$ plot of representative High Cascade compositions (Hughes, 1982). The shift in trends is caused by the transition of basaltic andesite compositions, which have primitive mineralogies, to dacites and rhyodacites, which exhibit mineralogies appropriate to upper crustal realms. The silicic magmas require either extensive fractional crystallization of basaltic andesite magma or the remelting of earlier added crustal components. 


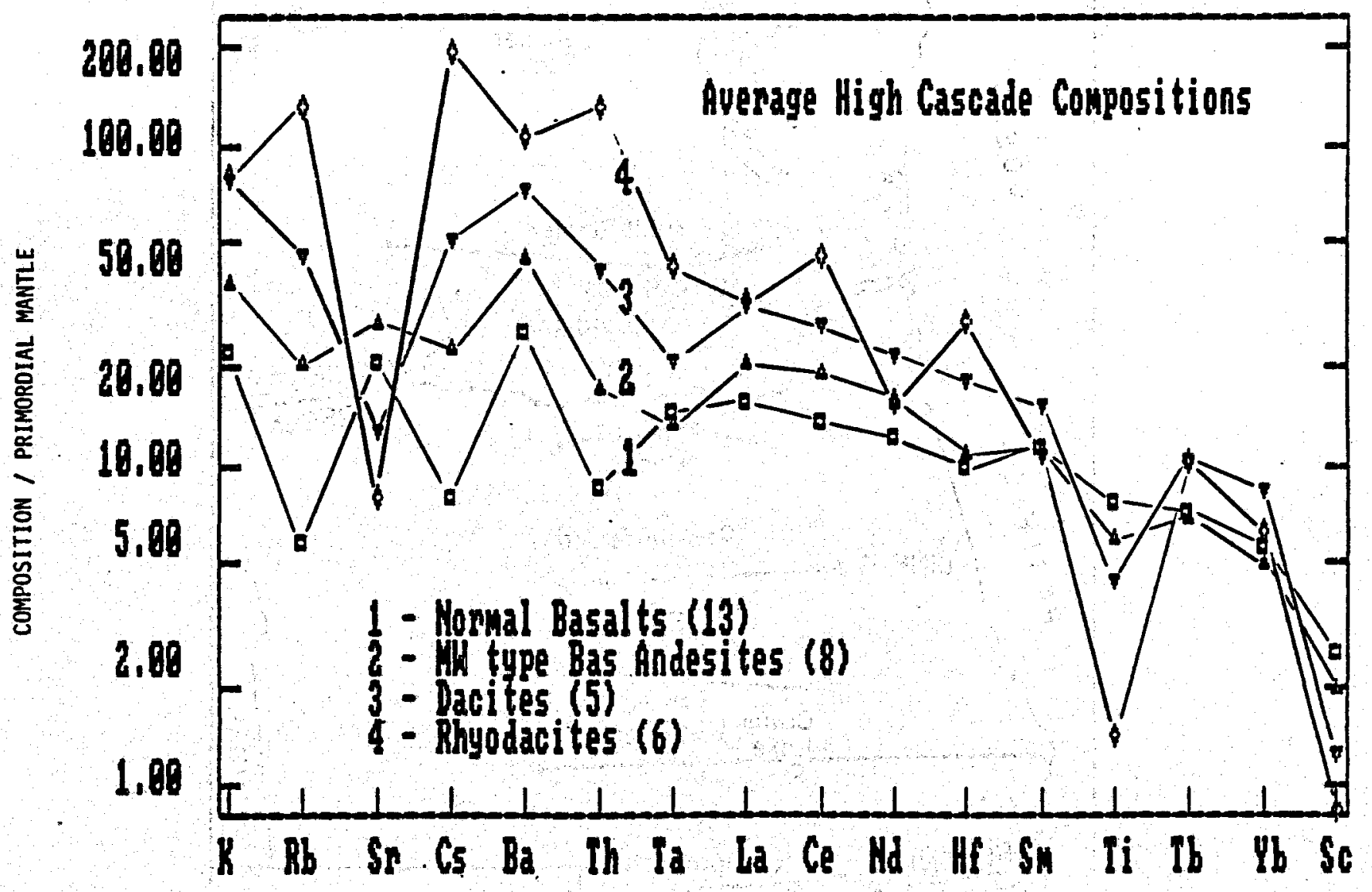

Figure 22. Representative High Cascade incompatible element and Sc compositions normalized to primordial mantle values (Wood and others, 1979, 1981). Numbers in parentheses indicate numbers of analyzed samples. Depletions in $\mathrm{Sr}, \mathrm{Ti}$, and $\mathrm{Sc}$ attest to the extreme crustal history required for evolution of silicic units. The relatively higher values of mobile elements $K, R b, C s$, and $B a$ compared to $T h$, $\mathrm{Ta}, \mathrm{REE}$, and Hf result from the influence of water-rich fluids during magma genesis, whereas the lower enrichments for less-mobile elements result from upper mantle source enrichment. 


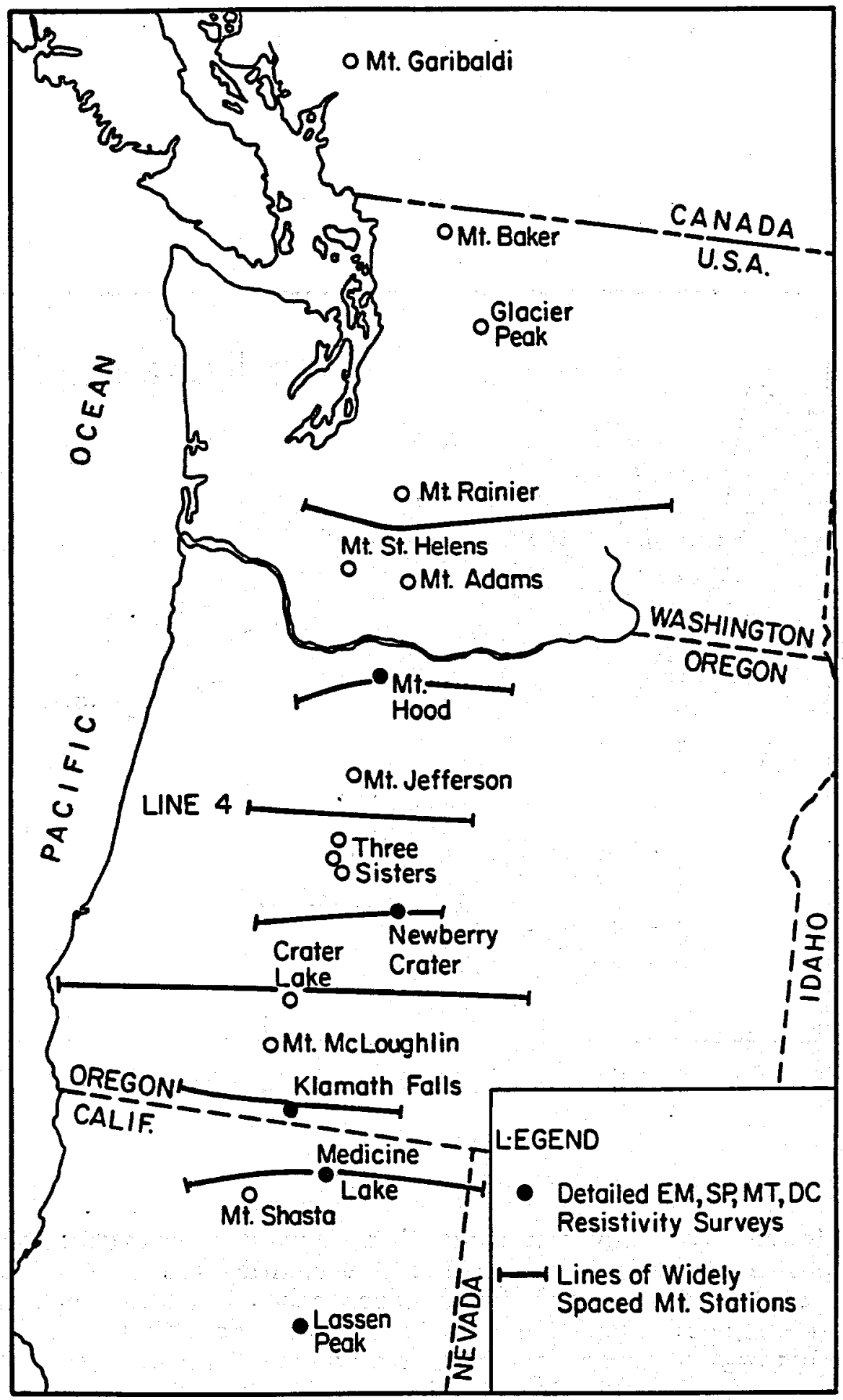

Figure 23. Location map for magnetotelluric (MT) lines of Stanley $(1982,1984)$. Interpretation of MT line 4 is shown on Figure 24. 
W

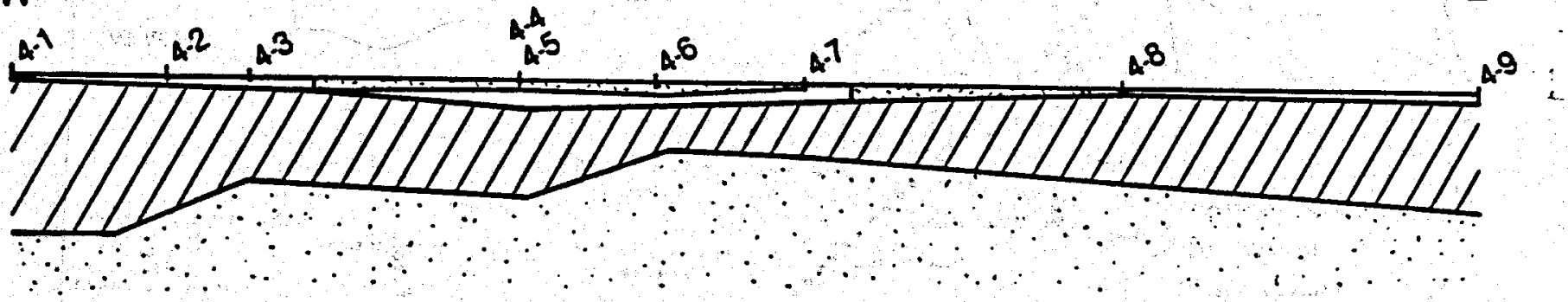

Lower Crustal

Conductor $(<10 \Omega \cdot m)$

2-50 $\Omega \cdot m$

DT] 30-1000 $\Omega \cdot m$

50-1000 $\mathrm{\Omega} \cdot \mathrm{m}$

\begin{tabular}{|c|c|c|c|c|c|c|c|c|c|}
\hline $\begin{array}{l}0 \\
u\end{array}$ & 4 & 1 & 15 & 20 & 25 & $\begin{array}{r}30 \\
1\end{array}$ & 35 & $\begin{array}{r}40 \\
1 \\
\end{array}$ & 45 miles \\
\hline & 5 & 10 & 20 & 30 & 40 & & 50 & $60 \mathrm{~km}$ & \\
\hline
\end{tabular}

Figure 24. Preliminary interpretation of magnetotelluric (MT) line 4 of Figure 23. Taken from Stanley (1982). 


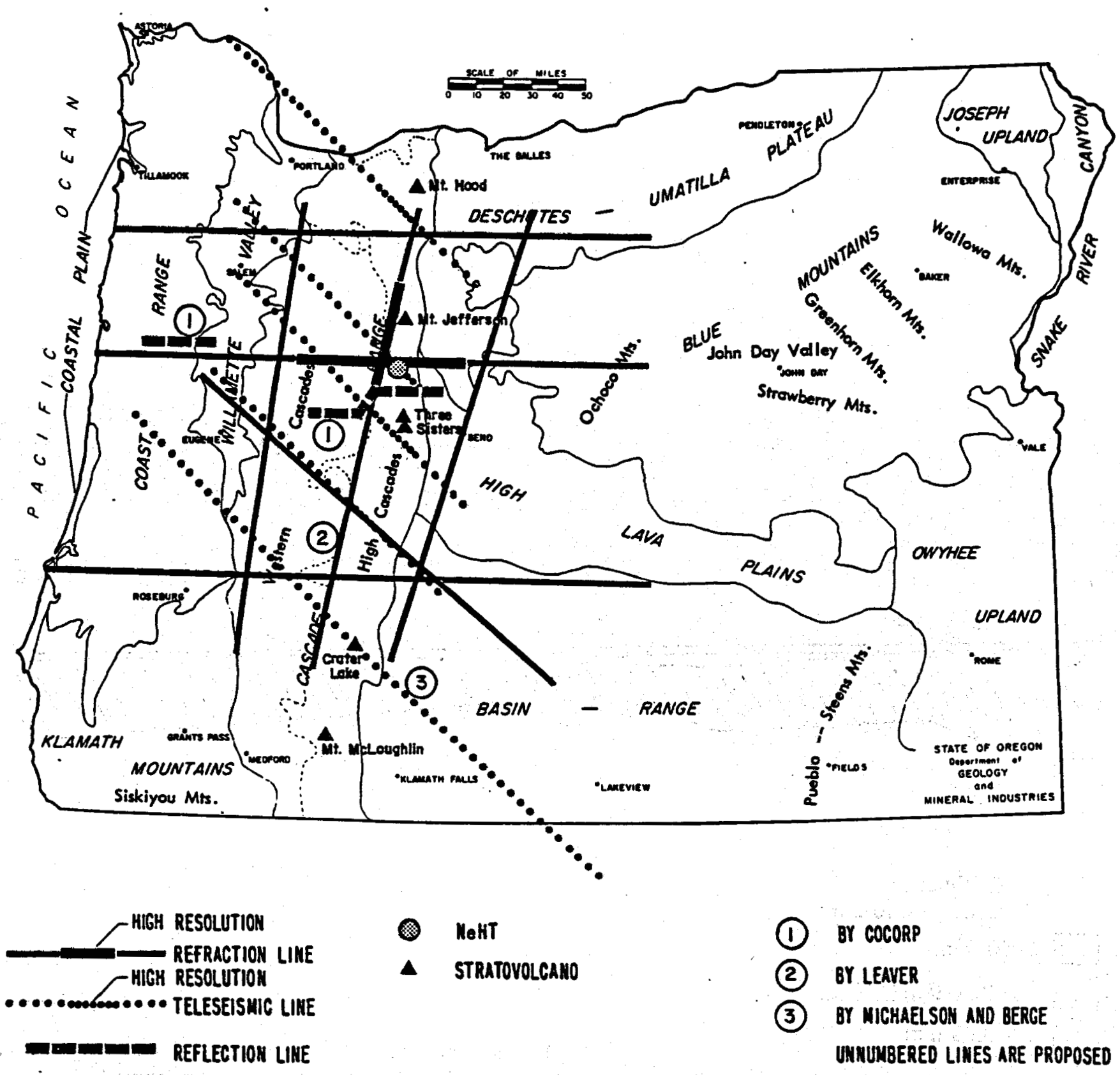

Figure 25. Map showing previous seismic lines and new seismic experiments proposed for Tasks 9 and 10 . Circled number 1 refers to the location of the COCORP line (1986); circled number 2 refers to the location of previous experiments by Leaver and others (1984); circled number 3 refers to the location of previous experiments by Michaelson and Berge (written communication, 1985). Unnumbered lines indicate proposed work. Dotted lines indicate the locations of teleseismic experiments (Task 10); solid lines are proposed seismic refraction lines for regional-scale targets (Task 10); the stippled area is the site of the proposed high-resolution refraction (NeHT) experiment. 


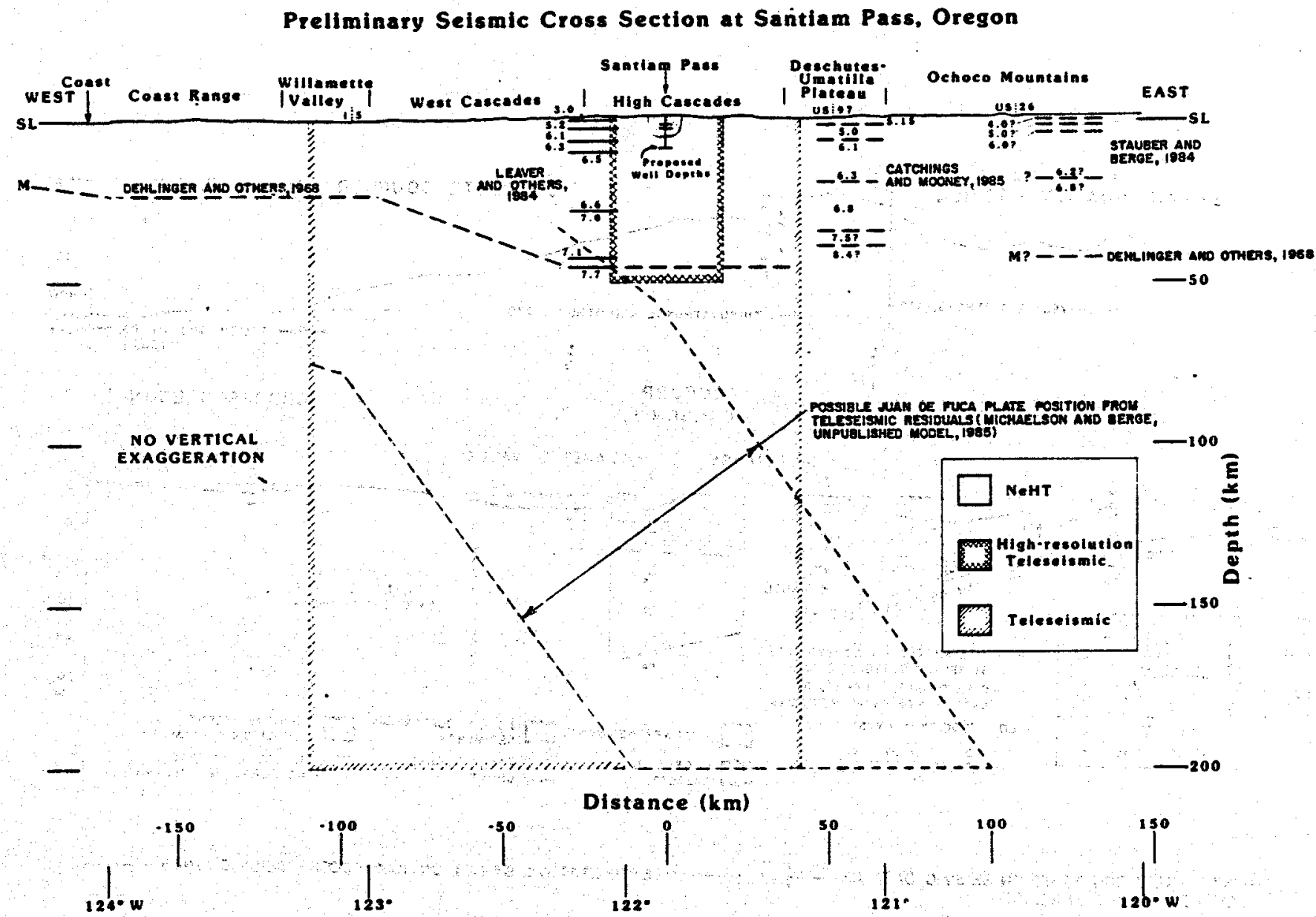

Figure 26. Preliminary east-west cross section through Santiam Pass, based on available seismic data. Figure, including topography, is true scale. The location of the subducted oceanic slab was inferred from the teleseismic line of Michaelson and Berge (Figure 25; written communication, 1985) projected into this section. The section shows an area of high density in the upper mantle hypothesized to be the subducted oceanic slab. Dashed lines show the maximum limits for the upper and lower boundaries of the slab within the (rather loose) constraints of the data. The lines do not therefore represent an inferred thickness for the slab. SL = sea level; $M=$ Mohorovicic discontinuity. 


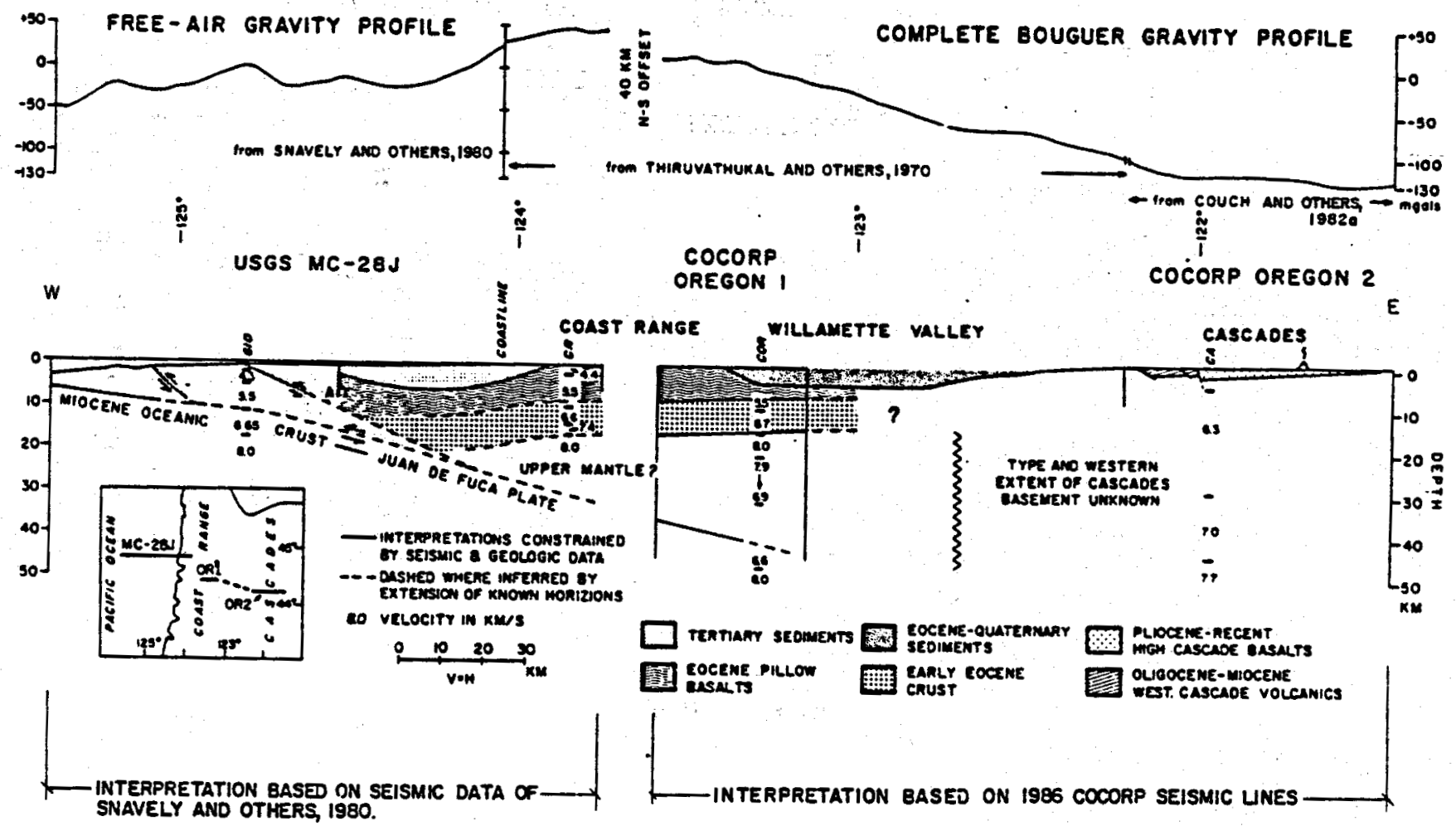

Figure 27. Regional transect of western Oregon, continental margin-volcanic arc. COCORP profiles are combined with the USGS continental margin transect MC-28J (Snavely and others, 1980). Dashed lines represent an extrapolation between seismic reflection data sets. Inferred horizons were further constrained by velocity profiles by shor and others (1968) (G10), Berg and others (1966) (CR), Langston (1977) (COR), and Leaver (1982) (CA). Profiles G10 and CA were reversed refraction profiles, whereas profile $C R$ was unreversed. Profile COR was derived from teleseismic P-wave conversions. The offshore gravity data are free air, and onshore data are Bouguer. Figure taken from Keach (1986). 


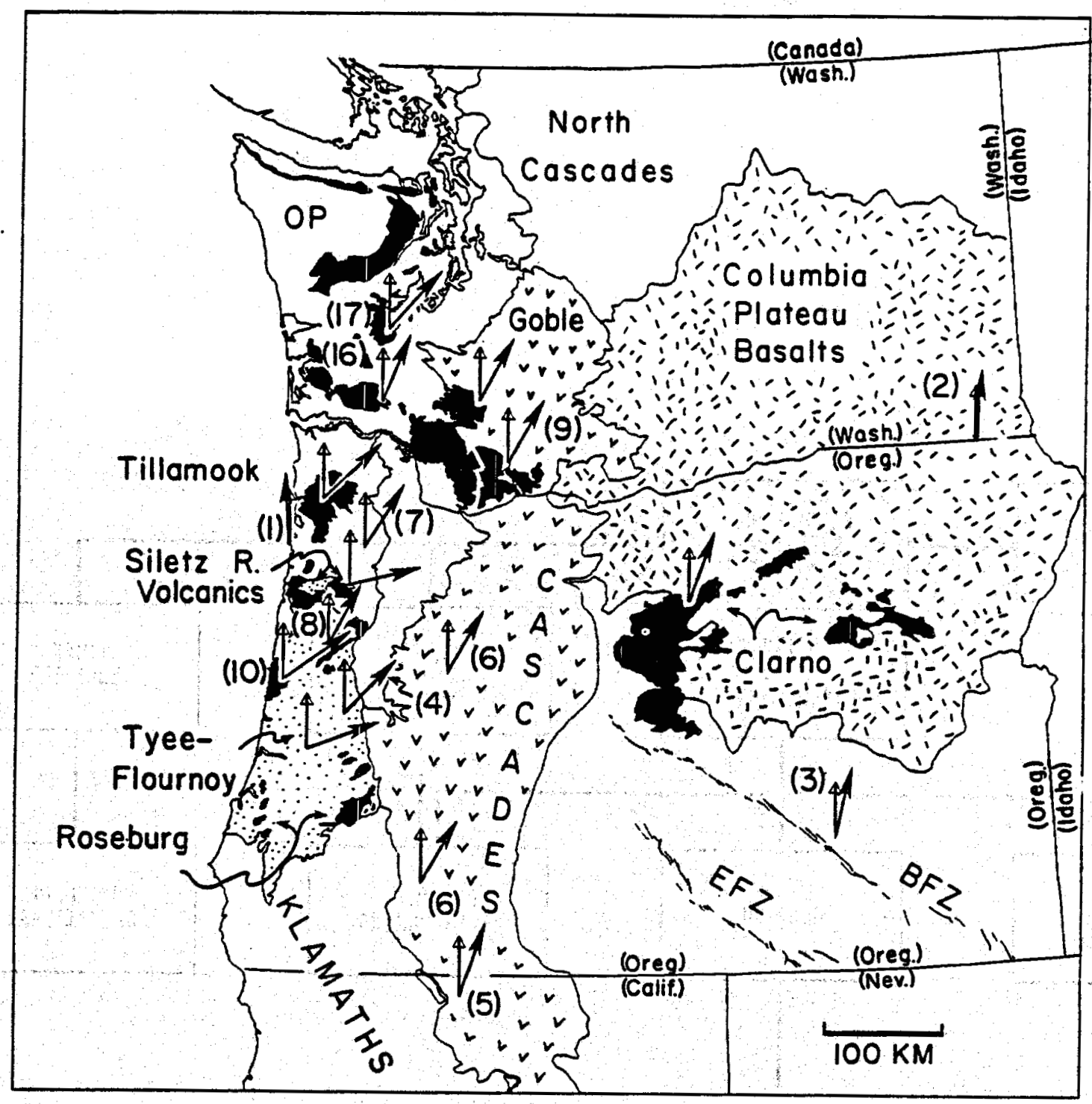

Figure 28. Generalized geotectonic map of Oregon and Washington. Arrows indicate the mean paleomagnetic directions found for the respective geologic units. The open arrow marks the expected declination, and the solid arrrow indicates the observed declination. The arrows have been adjusted so that the expected declinations point due north. An easterly directed solid arrow therefore indicates a $90^{\circ}$ clockwise rotation. Numbers in parentheses indicate numbers of measurements made. Goble = Goble Volcanics; Tillamook = Tillamook Volcanics; Tyee = Tyee Formation; Flournoy = Flournoy Formation of Baldwin (1974); Roseburg = Roseburg Formation of Baldwin (1974); Clarno = Clarno Formation; OP = Olympic Peninsula; BFZ = Brothers fault zone; EFZ = Eugene-Denio fault zone. Figure is from Magill and Cox (1980). 


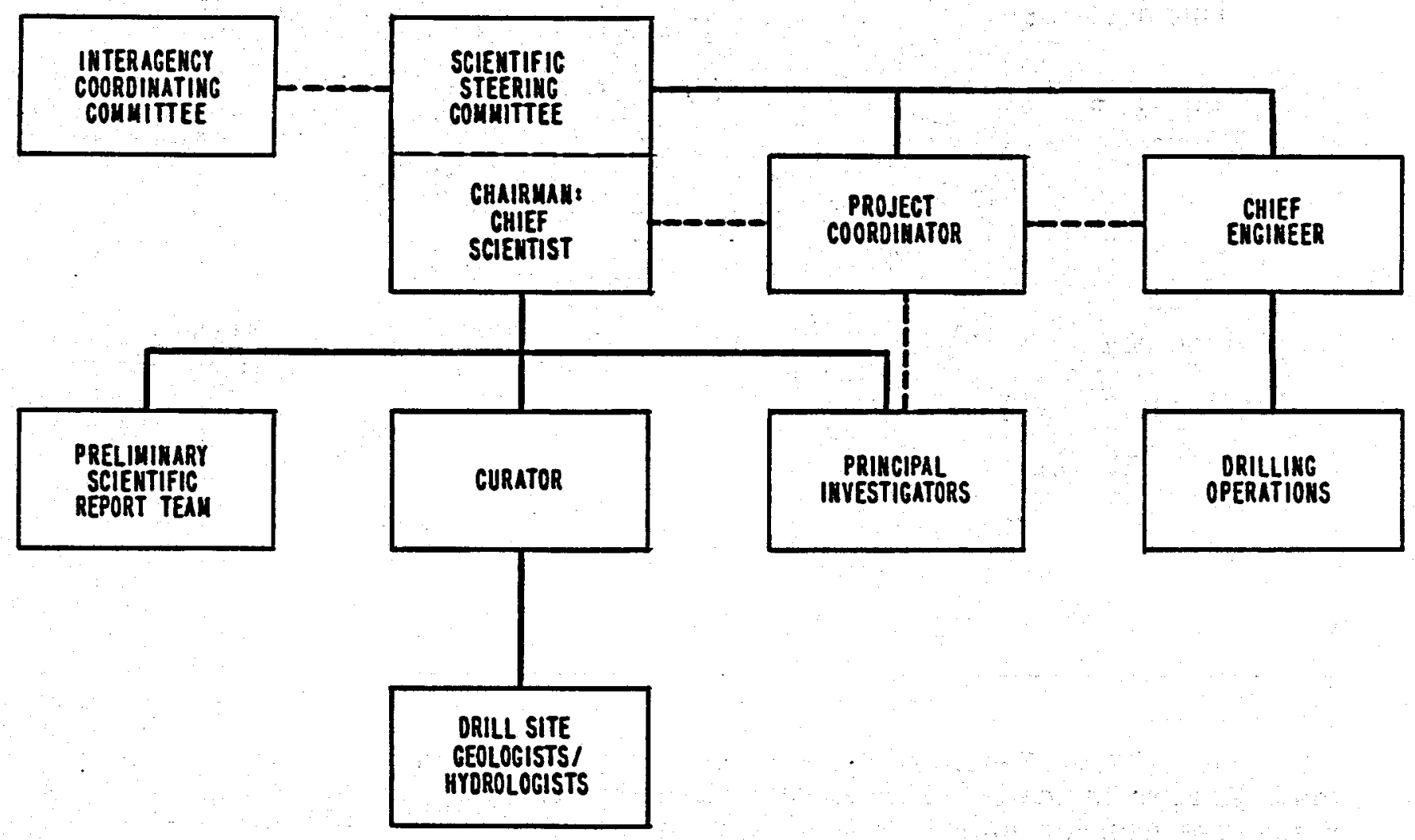

Figure 29. Management structure. Solid lines indicate direct supervision; dotted lines indicate coordination and advice. 


\section{TABLES}


Table 1. Qualitative summary of the quality of the data base, access, and geothermal-resource potential at possible sites for research drilling in the Cascades ( 0 =poor; 1 =moderately poor; $2=$ moderate; $3=$ moderately good; 4=good; 5=very good). Soil geochemical surveys in the public domain are available only for Newberry and Medicine Lake volcanoes. Data from wells drilled to depths in excess of $600 \mathrm{~m}$ are available only for the Mount Hood area, the Breitenbush area, the Lassen Peak area, the areas on the east flank of Mount Mazama adjacent to Crater Lake, and Newberry volcano.

\begin{tabular}{|c|c|c|c|c|c|}
\hline $\begin{array}{l}\text { Gec } \\
\text { cove }\end{array}$ & $\begin{array}{l}\text { ogic } \\
\text { age }\end{array}$ & $\begin{array}{c}\text { Drilling } \\
\text { (heat flow) }\end{array}$ & $\begin{array}{l}\text { Geophysics } \\
\text { (non-heat flow) }\end{array}$ & Access & $\begin{array}{l}\text { Resource } \\
\text { potential }\end{array}$ \\
\hline \multicolumn{6}{|c|}{ W A S I I G T O N } \\
\hline Mount Baker & 3 & 0 & 3 & 3 & 4 \\
\hline Mount Rainier & 3 & 0 & 2 & 1 & 4 \\
\hline Glacier Peak & 2 & 0 & 2 & 1 & 4 \\
\hline Mount Adams & 5 & $\mathbf{0}$ & 4 & 1 & $\overline{4}$ \\
\hline Mount St. Helens & 5 & 0 & 4 & 1 & 4 \\
\hline $\begin{array}{l}\text { North \& central } \\
\text { Washington }\end{array}$ & & & & & \\
\hline between volcanoes & 2 & $\mathbf{0}$ & 2 & 2 & $\mathbf{0}$ \\
\hline $\begin{array}{l}\text { boutween volcanoes } \\
\text { between }\end{array}$ & 2 & 2 & 3 & 4 & 2 \\
\hline \multicolumn{6}{|c|}{ O R E G $\mathbf{O}$} \\
\hline Mount Hood & 4 & 2 & 3 & 1 & 4 \\
\hline $\begin{array}{l}\text { Adjacent to } \\
\text { Mount Hood }\end{array}$ & 3 & 4 & 3 & 3 & 2 \\
\hline $\begin{array}{l}\text { Mount Jefferson } \\
\text { area }\end{array}$ & 4 & 0 & 3 & 0 & 4 \\
\hline Breitenbush area & 5 & 5 & 3 & 5 & 4 \\
\hline Santiam Pass area & 5 & 2 & 3 & 4 & 4 \\
\hline North Sister area & 5 & $\mathbf{0}$ & 3 & $\mathbf{0}$ & 4 \\
\hline Middle Sister area & 5 & 0 & 3 & $\mathbf{0}$ & 4 \\
\hline McKenzie Pass & 5 & 1 & 3 & 1 & 4 \\
\hline South Sister & 5 & 0 & 3 & $\mathbf{0}$ & 5 \\
\hline Century Drive area & 5 & 0 & 3 & 2 & 5 \\
\hline Newberry volcano & 5 & 4 & 5 & 3 & 5 \\
\hline Willamette Pass area & 4 & 2 & 3 & 4 & 3 \\
\hline Crater Lake & 5 & 1 & 3 & 1 & 5 \\
\hline Adjacent to & & & & & \\
\hline Crater Lake & 3 & 3 & 3 & 4 & 4 \\
\hline $\begin{array}{l}\text { Oregon passes south } \\
\text { of Crater Lake }\end{array}$ & 3 & $\mathbf{0}$ & 3 & 4 & 3 \\
\hline \multicolumn{6}{|c|}{ C A L I F O R N I A } \\
\hline Mount Shasta & 5 & 0 & 5 & 1 & 4 \\
\hline $\begin{array}{l}\text { Adjacent to } \\
\text { Mount Shasta }\end{array}$ & 5 & 3 & 5 & 4 & 3 \\
\hline Medicine Lake & 5 & 3 & 5 & $\begin{array}{l}\mathbf{z} \\
\mathbf{5}\end{array}$ & 5 \\
\hline Lassen Peak & 5 & 3 & 4 & 1 & 4 \\
\hline $\begin{array}{l}\text { Between California } \\
\text { stratocones }\end{array}$ & 3 & 1 & 3 & 4 & 3 \\
\hline Stralocones & 3 & 1 & 3 & & 3 \\
\hline
\end{tabular}


Table 2. Ranking of sites based on total scores from Table 1. Parentheses indicate site has poor or moderately poor accessibility. Brackets indicate site has poor resource potential.

\begin{tabular}{ll}
\hline Score & \multicolumn{1}{c}{ Site } \\
\hline 22 & Breitenbush Hot Springs area, Medicine Lake volcano \\
20 & Newberry volcano \\
19 & Areas adjacent to Mount Shasta \\
18 & Santiam Pass area \\
17 & Areas adjacent to Crater Lake, (Lassen Peak) \\
16 & Willamette Pass area \\
15 & Areas adjacent to Mount Hood, Century Drive area, (Crater \\
14 & Lake), (Mount Shasta) \\
& (Mount Adams), (Mount St, Helens), (Mount Hood), (McKenzie \\
13 & Pass), areas between northern California stratocones south of \\
12 & Mount Shasta \\
11 & Lake, southern Washington Cascades between major volcanoes \\
10 & (North Sister area), (Middle Sister area) \\
9 & (Mount Jefferson area) \\
6 & (Gount Rainier) \\
\hline
\end{tabular}


Table 3. Thermal conductivity measurements from Sunedco Well No. 58 (T. 9 S., R. T E., 28Cd).*

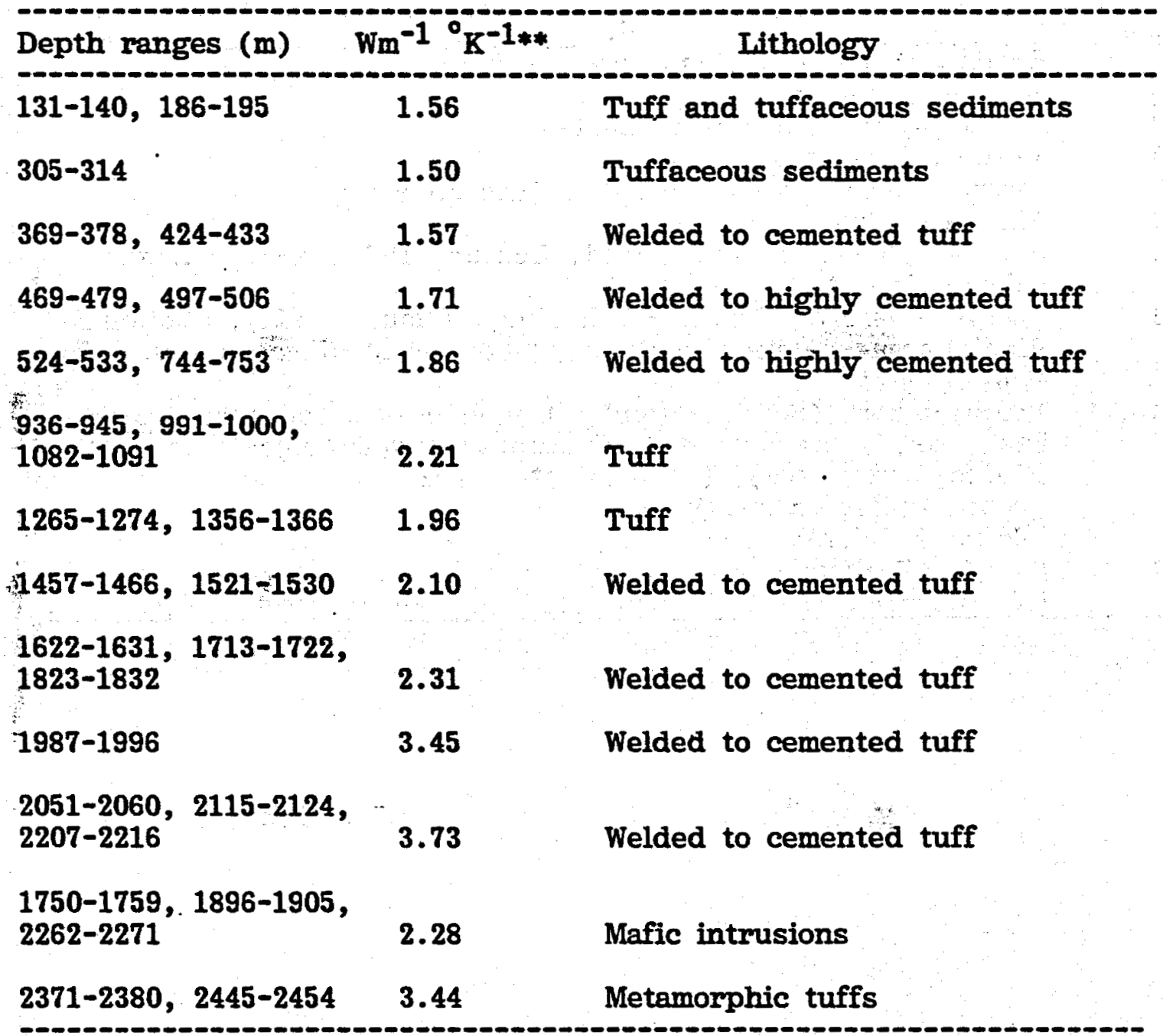

*. Unpublished data of David D. Blackwell, Southern Methodist University, May 18, 1986.

** Bulk value, not corrected for porosity. 

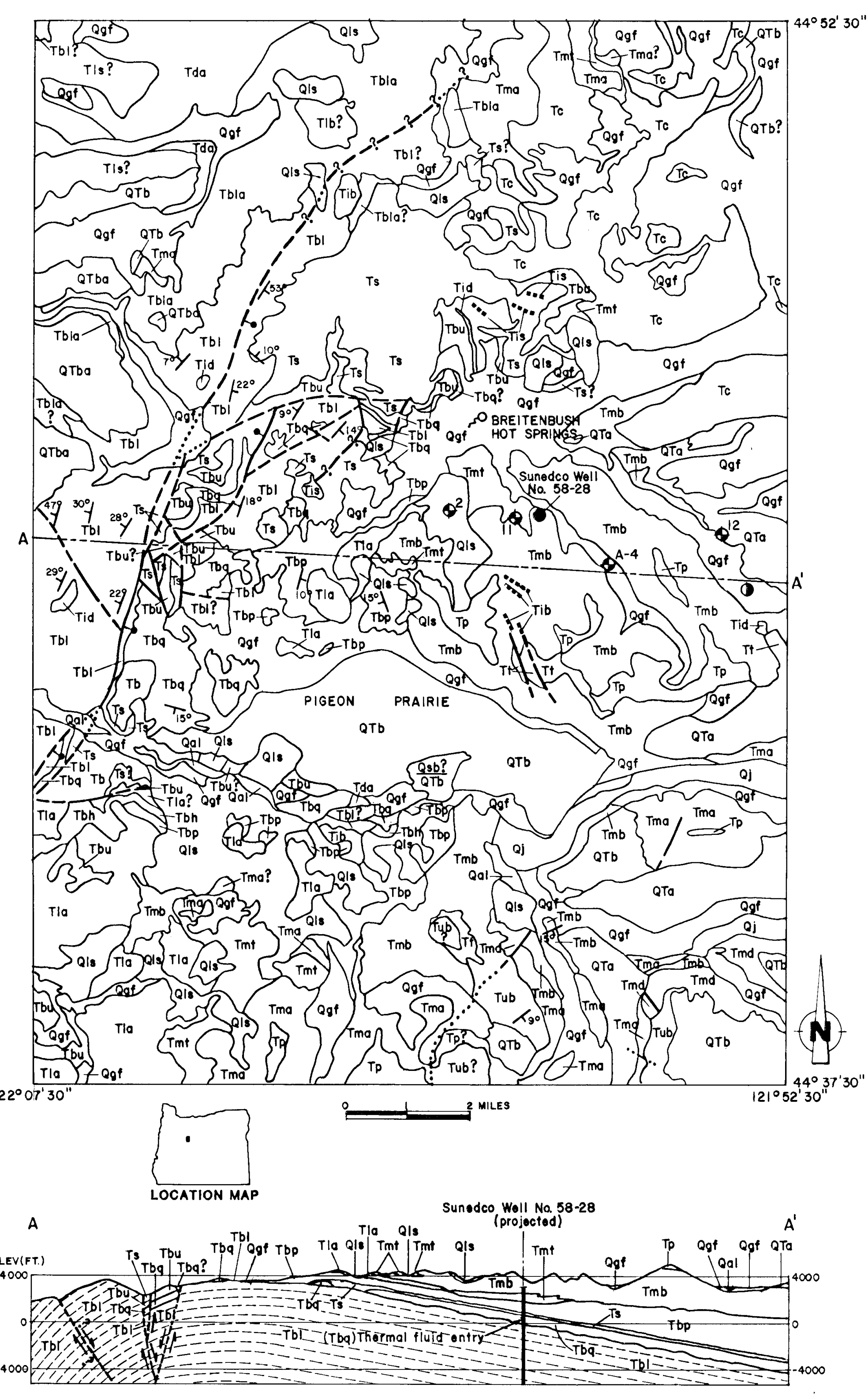

SYMBOLS

Contact

Fault--Dashed where inferred; dotted where concealed below

Dike

$\perp^{15^{\circ}} \quad$ Strike and dip

"11 Temperature-gradient hole with hole number

- Proposed drill site of Task 3

- Geothermal test well

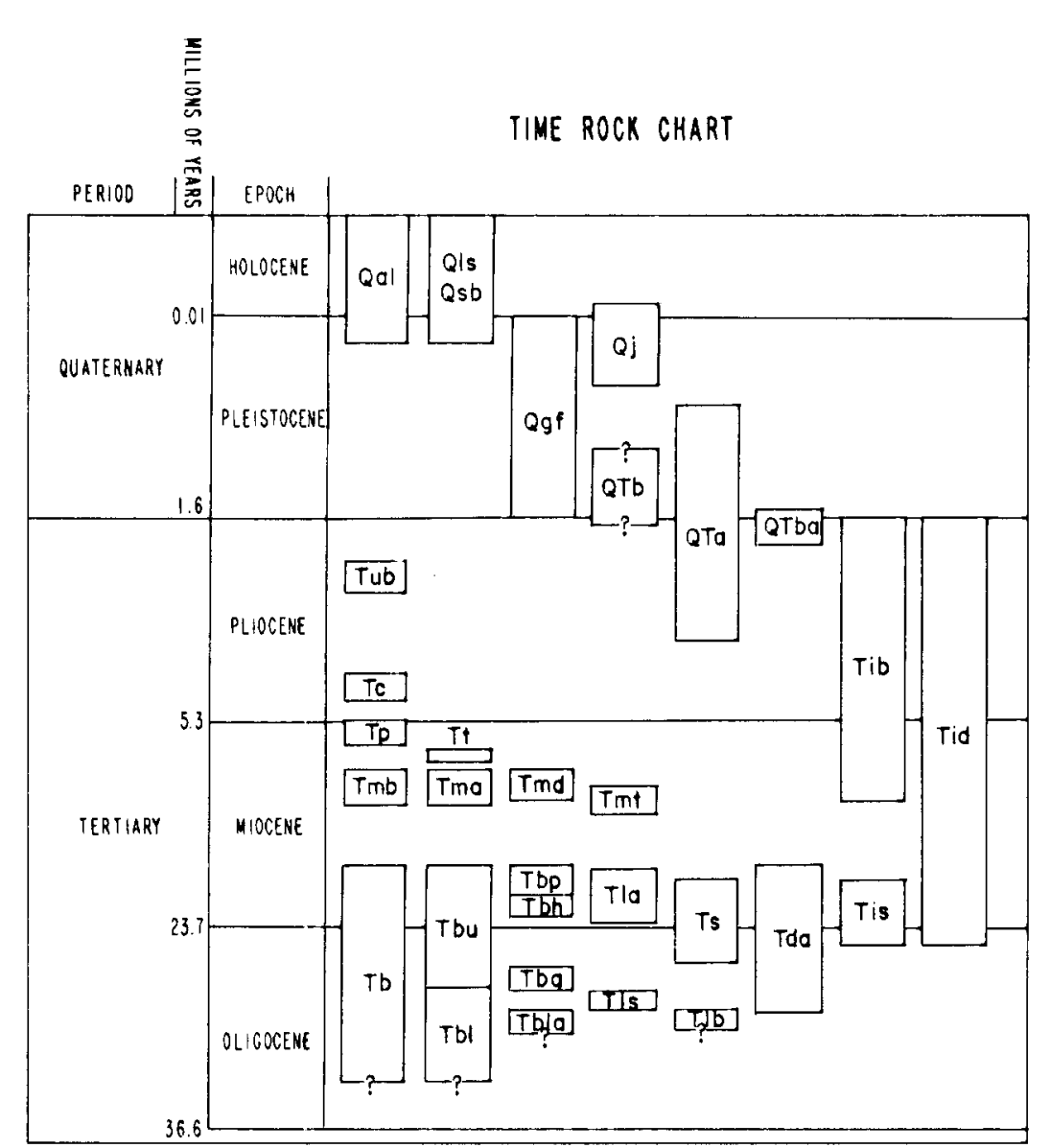

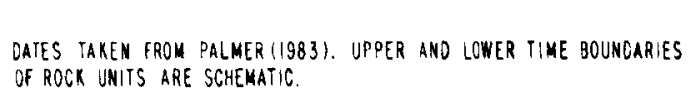

\section{EXPLANATION}

SURFICIAL UNITS

Alluvium (upper Pleistocene and Holocene)

Landslide deposits (upper Pleistocene and Holocene)

Slide block (upper Pleistocene and Holocene)

Glacial-fluvial deposits (Quaternary)

VOLCANIC UNITS

Upper Pliocene and Quaternary volcanic and volcaniclastic rocks

Block-and-ash flows of Mount Jefferson (upper Pleistocene Occurs only in the Whitewater and Pamelia Creek Valleys. Originated from Mount Jefferson

Olivine basalt and basaltic andesite of Pigeon Prairie (upper

Two-pyroxene andesite and pyroxene-rich basaltic andesite and benches on the sides of modern stream valleys

Lavas of Battle Ax Mountain (upper Pliocene and lowe Peistocene)--Chiefly basaltic andesite. Flows were erupted from the Battle
(White, 1980b)

Basalt and basaltic andesite of Mount Bruno (upper Pliolava flows

Upper Miocene and lower Pliocene volcanic and volcaniclastic rocks

Tavas of Collawash Mountain (lower Pliocene)---Thin flows of basalt and basaltic andesite that filled and overtopped a
deep $(>370 \mathrm{~m})$ north-northeast-trending paleocanyon

Lavas of Triangulation Peak (upper Miocene)--Basalt and eastern margin of the Western Cascades

uff of Outerson Mountain (upper Miocene)---Nonwelded dacitic and andesitic ash-flow tuff, locally interbedded with
volcaniclastic sediments and andesitic or dacitic debris flows

iddle and upper Miocene volcanic and volcaniclastic rocks

asalt and basaltic andesite (middle and upper Miocene)-

Two-pyroxene andesite and dacite lavas (middle and upper
Miocene)

Dacite and rhyodacite lava (middle and upper Miocene)--
Banded, nearly aphyric vitrophyric dacite and rhyodacite pyroxene andesite interbeds

OPEN-F'ILE REPORT O-86-3

INVESTIGATION OF THE THERMAL REGIME AND GEOLOGIC HISTORY

FOR SCIENTIFIC DRILLING IN THE CASCADES By G.R. Priest and others

FIGURE 11 Geologic map of the Breitenbush River area, Linn and Marion Counties,
Oregon

Ash-flow and air-fall tuff (middle and upper Miocene)-Lithic-rich welded to nonwelded gray ash flows interbedded for most of the large landslides in the tuff.

Oligocene and lower Miocene volcanic and volcaniclastic rocks

Breitenbush Tuff, undifferentiated (Oligocene and lower comiclastic tuff with a large component of mudflow and laharic deposits. Most of the rocks show some degree of alteration. Where possible, unit $\mathbf{T b}$ is divided into the

Upper part of the Breitenbush Tuff, undifferentiated (uli Unit Tbu consists of quartz-bearing (Tbq), hornblendebearing (Thh), and welded pyroxene-bearing (Tbp)
ash-flow tuff, interbedded nonwelded ash-flow tuff, and flows

Welded pyroxene-bearing ash-flow tuff (lower Miocene)--Includes all welded pyroxene-bearing, horn ash-flow sequence (unit Tbq)

Hornblende-bearing nonwelded ash-flow tuff (lower erized by sparse small hornblende crystals

Quartz-bearing ash-flow tuff (upper Oligocene)-Q units. Characterized by deeply embayed, 1- to 2

Lower part of the Breitenbush Tuff (Tbl) and inter-

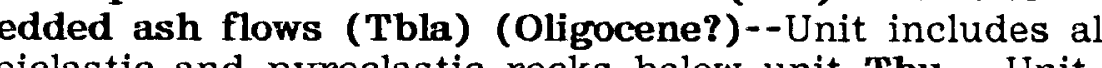
Tbl consists of dominantly lithic-rich tuffs with dant lapilli- and coarse-ash-size lithic frarments in a fine ash matrix. All glass is altered, giving glass-rich units a distinctive green to blue-green colo

Lower andesite sequence (lower Miocene)--Two-pyroxene andesite lavas in
part of unit Ts

Lavas and volcaniclastic rocks of Scorpion Mountain (upper chiefly dark-gray iron-rich basaltic andesite and andesite
lite

Lower basaltic andesites (Oligocene ?)--Heavily altered plagioclase-pyroxene(?)-phyric dark-gray lavas interbedded

Lavas of Sardine Mountain (Olipcene)--Aphyric and plagiobasaltic andesite and andesite lavas (Walker and others, 1985)
(ase-pyroxene-phyric basaltic

\section{INTRUSIVES}

Basalt and basaltic andesite dikes, plugs, and sills (middle

Tholeiitic basalt and tholeiitic andesite dikes, plugs, and (upper Oligocene to lower Miocene)

Dacite and rhyodacite dikes, plugs, and sills (upper Oligo-

Fine-grained diorite, quartz diorite, granodiorite, and 